Portland State University

PDXScholar

Spring 6-2-2014

\title{
The Antimalarial Activity of PL74: A Pyridine-Based Drug Candidate
}

Cheryl Anne Hodson Shirley

Portland State University

Follow this and additional works at: https://pdxscholar.library.pdx.edu/open_access_etds

Part of the Medicinal and Pharmaceutical Chemistry Commons

Let us know how access to this document benefits you.

\section{Recommended Citation}

Hodson Shirley, Cheryl Anne, "The Antimalarial Activity of PL74: A Pyridine-Based Drug Candidate" (2014). Dissertations and Theses. Paper 1821.

https://doi.org/10.15760/etd.1820

This Dissertation is brought to you for free and open access. It has been accepted for inclusion in Dissertations and Theses by an authorized administrator of PDXScholar. Please contact us if we can make this document more accessible: pdxscholar@pdx.edu. 
The Antimalarial Activity of PL74:

A Pyridine-Based Drug Candidate

$$
\text { by }
$$

Cheryl Anne Hodson Shirley

\title{
A dissertation submitted in partial fulfillment of the
} requirements for the degree of

\author{
Doctor of Philosophy \\ in \\ Chemistry
}

\begin{abstract}
Dissertation Committee:
David H. Peyton, Chair

A. Steven Benight

Gwen Shusterman

Carl C. Wamser

Sherry L. Cady
\end{abstract}

Portland State University

2014 
(C) 2014 Cheryl Anne Hodson Shirley 


\begin{abstract}
In spite of great effort aimed at eradication, the malaria epidemic still claims over 600,000 lives each year, and $50 \%$ of the world is at risk of contracting the disease. The most deadly form of malaria is caused by Plasmodium falciparum, which is spread from human to human via the female Anopheles mosquito. P. falciparum's lifecycle, which includes both sexual and asexual reproduction, facilitates rapid evolution in response to drug pressure, resulting in the emergence of resistant strains against every antimalarial medication that has been deployed. There is a great need for new antimalarial drugs.

Chloroquine (CQ), an aminoquinoline drug deployed in the 1940s, was an inexpensive, effective and safe drug but now has been rendered ineffective throughout much of the tropical regions due to the emergence of CQ-resistant strains of $P$. falciparum. A new class of hybrid drugs, called Reversed-CQs, has been developed by linking a molecule with a CQ-like moiety to a molecule with a reversal agent (RA) moiety; an RA is a chemosensitizer that can reverse CQ-resistance. The prototype Reversed-CQ, PL01, was shown to be effective in vitro against sensitive and resistant $P$. falciparum cell cultures, with $\mathrm{IC}_{50}$ values of 2.9 and $5.3 \mathrm{nM}$, respectively, in comparison to $\mathrm{IC}_{50}$ values for $\mathrm{CQ}$ which were 6.9 and $102 \mathrm{nM}$, respectively.

In the course of the Reversed-CQ research, PL74 was synthesized with a pyridine ring replacing the quinoline ring. It was expected that PL74 would display reversal agent activity but would not display antimalarial activity. However PL74 showed antimalarial
\end{abstract}


activity with $\mathrm{IC}_{50}$ values of 185 and $169 \mathrm{nM}$ in vitro against CQ-sensitive and CQresistant strains, respectively. In the investigation of PL74 it has been found that this molecule has a pyridinium salt structure, novel to the Reversed-CQ compounds, and through a structure-activity relationship (SAR) study, it was shown to have activity that may indicate a mode of action different from the Reversed-CQ compounds. A study of the literature revealed that pyridinium salt compounds, with some similarity to PL74, were found to operate as choline analogs inhibiting the biosynthesis of phosphatidylcholine as their main antimalarial mode of action. 
To Brayden and Aurora, my future scientists 


\section{Acknowledgements}

I would like to thank my advisor, Dr. David Peyton, for all his help, support, and endurance through the years of this project. I would also like to thank the Peyton group members, both past and present, for their friendship and encouragement; it has been a great pleasure to work with such a fine and varied group of scientists. Special thanks must go to Dr. Steven Burgess for his valuable help in this work and to Dr. Jane Kelly and her group for carrying out all the malaria testing for this project. I would also like to thank Dr. A. Steven Benight, Dr. Sherry Cady, Dr. Gwen Shusterman, and Dr. Carl Wamser for serving on my committee.

I would like to thank my friends and family who over the years have become a great squad of cheerleaders, oscillating between, "Get a real job," and "Don't give up." You have been such a great source of support and encouragement in my life. Thank you to my husband, Mark Shirley, for his constant help through the completion of my research and the writing of this dissertation. 


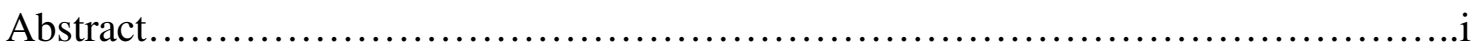

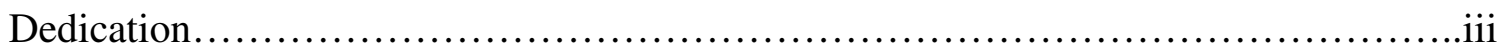

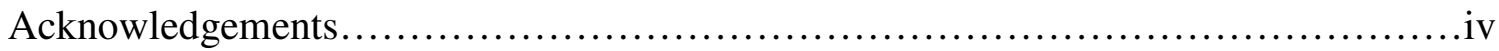

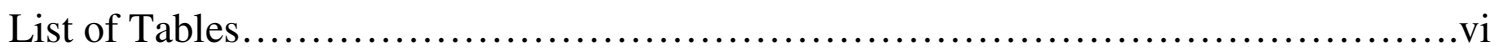

List of Figures.............................................................

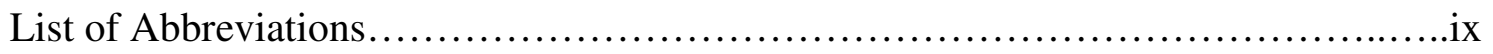

Chapter 1: Introduction...................................................

Chapter 2: The Structure of PL74 ..........................................28

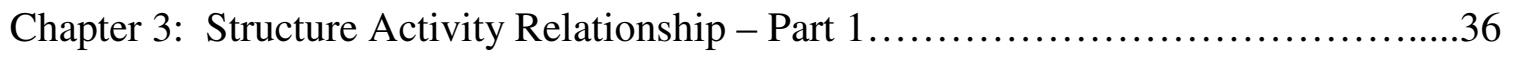

Chapter 4: Structure Activity Relationship - Part 2............................46

Chapter 5: Literature Case Studies..........................................51

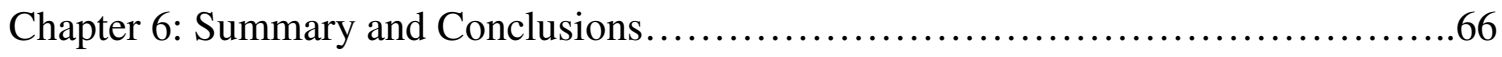

Chapter 7: Experimental Methods.........................................69

References.............................................................. 88 


\section{List of Tables}

\section{Chapter 1}

Table 1.1: In vitro Drug Susceptibility, Binding, and $\beta$-Hematin Inhibition Assay Results

Chapter 3

Table 3.1: The Hammett Substituent Constants $(\sigma)$ Based on Ionization of Benzoic

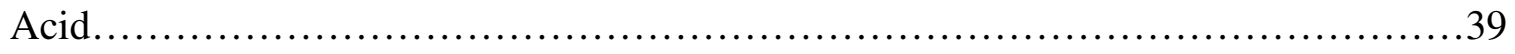

Table 3.2: IC $_{50}$ Values of Analogs with Pyridine Ring Substituents.................40

Table 3.3: $\mathrm{IC}_{50}$ Values for PL330, PL342, PL240, and PL165......................42

Table 3.4: $\mathrm{IC}_{50}$ Values for PL238, PL236, and PL232.........................43

Chapter 4

Table 4.1: IC $_{50}$ Values of Analogs with Amine Linkage...........................48

\section{Chapter 5}

Table 5.1: The Antimalarial Activity of Mono- and Bis-Quaternary Ammonium Compounds. 


\section{List of Figures}

\section{Chapter 1}

Figure 1.1: The Inverse Relationship of Malaria Burden and Wealth Distribution........2

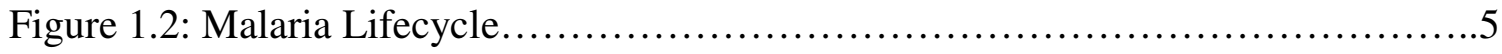

Figure 1.3: Structure of Quinine..............................................

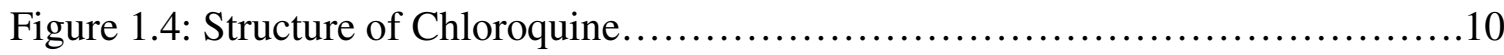

Figure 1.5: Structure of Artemisinin..........................................11

Figure 1.6: Structure of Artemisinin-Based Combination Therapies (ACTs)............12

Figure 1.7: Prophylactic Drugs for Travelers..................................16

Figure 1.8: Structure of Hemozoin......................................... 18

Figure 1.9: Chloroquine Accumulation..........................................19

Figure 1.10: Pharmacophore of Reversal Agents...............................20

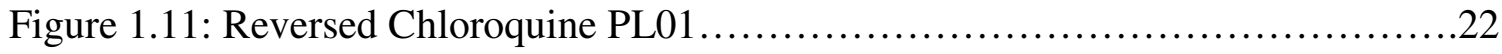

Figure 1.12: Reversed CQ Molecules..........................................23

Figure 1.13: Amine-Linkage Structure for PL74 Proposed by Steven Burgess..........24

Figure 1.14: Structures of CQ and Selected PL Compounds........................26

Chapter 2

Figure 2.1: Proposed Structures for PL74 ..................................... 28

Figure 2.2: The Proton NMR Spectra of PL74 ................................. 30

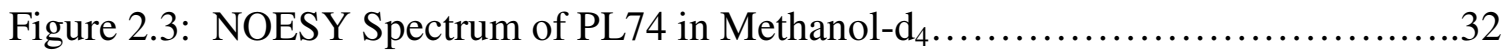

Figure 2.4: The Proton NMR Spectra of PL343 ..................................33

Figure 2.5: The NOESY Spectrum of PL343 in DMSO- $\mathrm{d}_{6} \ldots \ldots \ldots \ldots \ldots \ldots \ldots \ldots \ldots \ldots \ldots \ldots$ 
Chapter 3

Figure 3.1: Synthesis Pathway for PL74 .................................... 37

Figure 3.2: Alternate Pathway for the Synthesis of PL74 Analogs.....................37

Figure 3.3: Analogs with Pyridine Ring Substituents.............................40

Figure 3.4: PL74 Analogs................................................42

Figure 3.5: PL74 Analogs with RA Modifications..............................43

Figure 3.6: Reversed-CQ Compounds with RA Modifications.......................44

Chapter 4

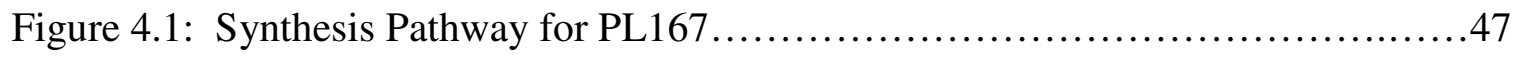

Figure 4.2: Amine Linkage Analogs........................................48

Chapter 5

Figure 5.1: Biosynthetic Pathways of Phospholipids.............................53

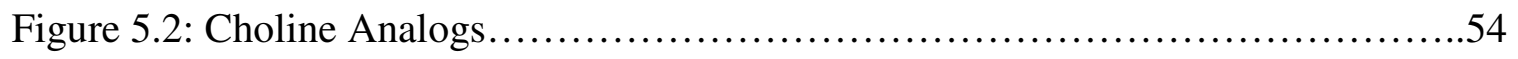

Figure 5.3: Mono- and Bis-Quaternary Ammonium Compounds....................56

Figure 5.4: Structure and Activity of Bis-Quaternary Compounds..................62 


$\begin{array}{ll}\text { ACT } & \text { Artemisinin-containing combination therapy } \\ \text { CDP-Cho } & \text { Cytidine diphosphate choline } \\ \text { CDP-Etn } & \text { Cytidine diphosphate ethanolamine } \\ \text { Cho } & \text { Choline } \\ \text { ChoK } & \text { Choline kinase } \\ \text { CS } & \text { Cytosome } \\ \text { CQ } & \text { Chloroquine } \\ \text { DV } & \text { Digestive vacuole } \\ \text { DMSO } & \text { Dimethylsulfoxide } \\ \text { E } & \text { Erythrocyte } \\ \text { eChoT } & \text { Erythrocyte choline transporter } \\ \text { Etn } & \text { Ethanolamine } \\ \text { GDP } & \text { Gross domestic product } \\ \text { HOMO } & \text { Highest occupied molecular orbital } \\ \text { IPT } & \text { Intermittent Preventative Therapy } \\ \text { ITN } & \text { Insecticide-treated bed nets } \\ \text { LUMO } & \text { Lowest unoccupied molecular orbital } \\ \text { NMR } & \text { Nuclear magnetic resonance } \\ \text { NOESY } & \text { Nuclear Overhauser Effect Spectroscopy } \\ \text { NPP } & \text { New Permeation Pathway } \\ \text { OCT } & \text { Organic-cation transporter } \\ \text { PCho } & \text { Phosphocholine } \\ \text { P-Etn } & \text { Phosphoethanolamine } \\ \text { PfCCT } & \text { CTP-phosphocholine cytidylyltransferase } \\ \text { PfCCT } & \text { CTP-phosphocholine cytidylyltransferase } \\ \text { PfCK } & \text { Choline kinase } \\ & \end{array}$




$\begin{array}{ll}\text { PfPMT } & \text { Phosphoethanolamine methyltransferase } \\ \text { PLMT } & \text { Phospholipid methyltransferace } \\ \text { PtdCho } & \text { Phosphatidylcholine } \\ \text { PtdEtn } & \text { Phosphatidylethanolamine } \\ \text { PV } & \text { Parasitophorous vacuole } \\ \text { QAC } & \text { Quaternary ammonium compounds } \\ \text { QSAR } & \text { Quantitative structure-activity relationship } \\ \text { RA } & \text { Reversal Agent } \\ \text { RBC } & \text { Red blood cell } \\ \text { SAR } & \text { Structure-activity relationship } \\ \text { SD } & \text { Serine decarboxylase } \\ \text { SER } & \text { Serine } \\ \text { WHO } & \text { World Health Organization }\end{array}$




\section{Chapter 1}

\section{Introduction}

Malaria is a worldwide problem causing approximately 200 million cases of illness, resulting in over 600,000 deaths per year. ${ }^{1}$ The majority of this disease burden is borne by the sub-Saharan Africa population, and the majority of the global malaria mortalities are among the children of this region. Nearly $50 \%$ of the world's population is currently at risk of contracting malaria. ${ }^{1}$ These statistics show a marked improvement in the mortality rate from the estimated one million deaths per year from 2000 to 2005 . $^{1}$ However, an analysis of the mortality rates by Christopher Murray and his team at the Institute for Health Metrics and Evaluation, University of Washington, found that the death toll due to malaria has been about twice the estimates reported by the World Health Organization (WHO) for the years of 1980-2008; thus the 2013 WHO statistics may be an understatement of the situation. ${ }^{2}$

Malaria has a catastrophic effect on the economics of the endemic regions, severely hindering social stability and development. ${ }^{3}$ Malaria and extreme poverty form a vicious cycle: Malaria causes extreme poverty by causing an unreliable workforce and deterring investments in the region; extreme poverty makes it impossible to fight effectively against malaria because of the high costs of public education, vector control, and treatment. In this way malaria is a history shaper, so it is not coincidental that the 
map of malaria disease burden is the approximate inverse of the map of the distribution of wealth (Figure 1.1).
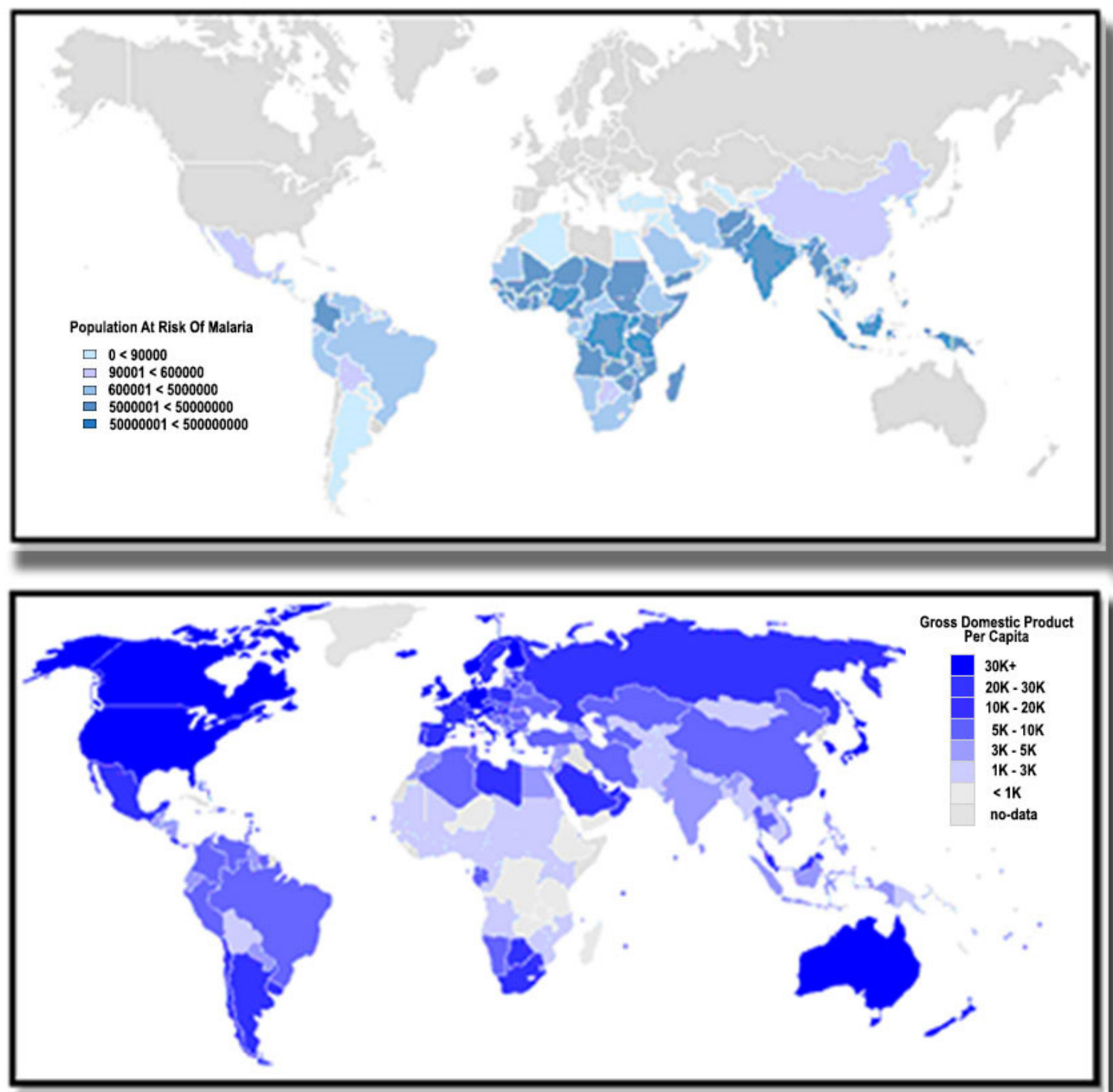

Figure 1.1: The Inverse Relationship of Malaria Burden to Wealth Distribution Map of Malaria Risk (Top).

The Global Malaria Mapper plotted March, 2014, http://www.worldmalariareport.org. Map of Gross Domestic Product Per Capita (Bottom). GDP data from 2005, http://commons.wikimedia.org 
The most alarming part of the malaria situation is that the drugs and insecticides that have been useful in the past against malaria are losing their effectiveness due to the development of resistance in both the malaria parasite and the Anopheles mosquito, which serves as the vector of disease transmission. There is a need for a constant supply of new tools and thoughtfulness in their use to bring this epidemic under control and perhaps to the eventual eradication of malaria.

\section{Background}

Plasmodium protozoa are the causative parasitic organisms of malaria. ${ }^{4}$ There are over 120 different species of Plasmodia, but only five types of malarial parasites $(P$. falciparum, $P$. vivax, $P$. malariae, $P$. ovale, and $P$. knowlesi) are commonly found in humans. ${ }^{4,5} P$. falciparum, the most virulent of the five, is the most studied form of malaria, and the target of this research.

The onset of malaria is generally characterized by flu-like symptoms: fever, shaking chills, headache, sweats, fatigue, nausea, and vomiting. ${ }^{6}$ The signature symptom of a malaria infection is that the febrile symptoms occur in a cyclic pattern. However, most adults in endemic regions remain asymptomatic during malaria infections. ${ }^{7}$ Untreated or improperly treated $P$. falciparum malaria may lead to kidney failure, mental confusion, coma, pulmonary edema, and death. ${ }^{6}$

$P$. falciparum is spread from human host to human host exclusively via the female Anopheles mosquito. ${ }^{8,9}$ The Anopheles mosquitoes are nocturnal insects that breed in standing water, then emerge as fully developed adults within days, ${ }^{9}$ and mate within one 
to two days after emergence. ${ }^{10}$ The female will lay 50 to 200 eggs within two to three days in tropical climates. ${ }^{10}$ The female requires blood meals during the egg maturation process, in which it may ingest the malaria parasite from an infected human or transmit the parasite.

The lifecycle of P. falciparum (Figure 1.2) requires both a female Anopheles mosquito host and human host, and includes both sexual and asexual reproduction. When an infected female Anopheles mosquito bites a human, $P$. falciparum sporozoites are released from the mosquito's salivary glands into the bloodstream of its victim. ${ }^{8}$ Within a few minutes the sporozoites enter the liver and invade the hepatocytes. The parasites undergo asexual multiplication in the liver cells, increasing to tens of thousands over 9 to 16 days, then burst from the liver cells and invade the erythrocytes. The sporozoites undergo further asexual multiplication in the erythrocytes - resulting in 12-16 merozoites from each sporozoite, eventually rupturing the cells and invading other erythrocytes. This erythrocytic stage cycles every 48 hours for $P$. falciparum, $P$. vivax and $P$. ovale; every 72 hours for P. malariae; and every 24 hours for $P$. knowlesi. $^{7,11}$ In response to this periodic rupturing, the host's immune system causes the cyclic fevers and chills which are the signature clinical manifestations of malaria infections. Some of the merozoites differentiate into male and female gametocytes but remain in an immature form while in the human host. However, if these gametocytes are taken up as a female Anopheles mosquito takes a blood meal and enter the gut of the mosquito, the male gametocyte is able to mature and fertilize the female gametocyte, creating an oocyte which may be the beginning of a new strain of $P$. falciparum. Within the oocyte, 


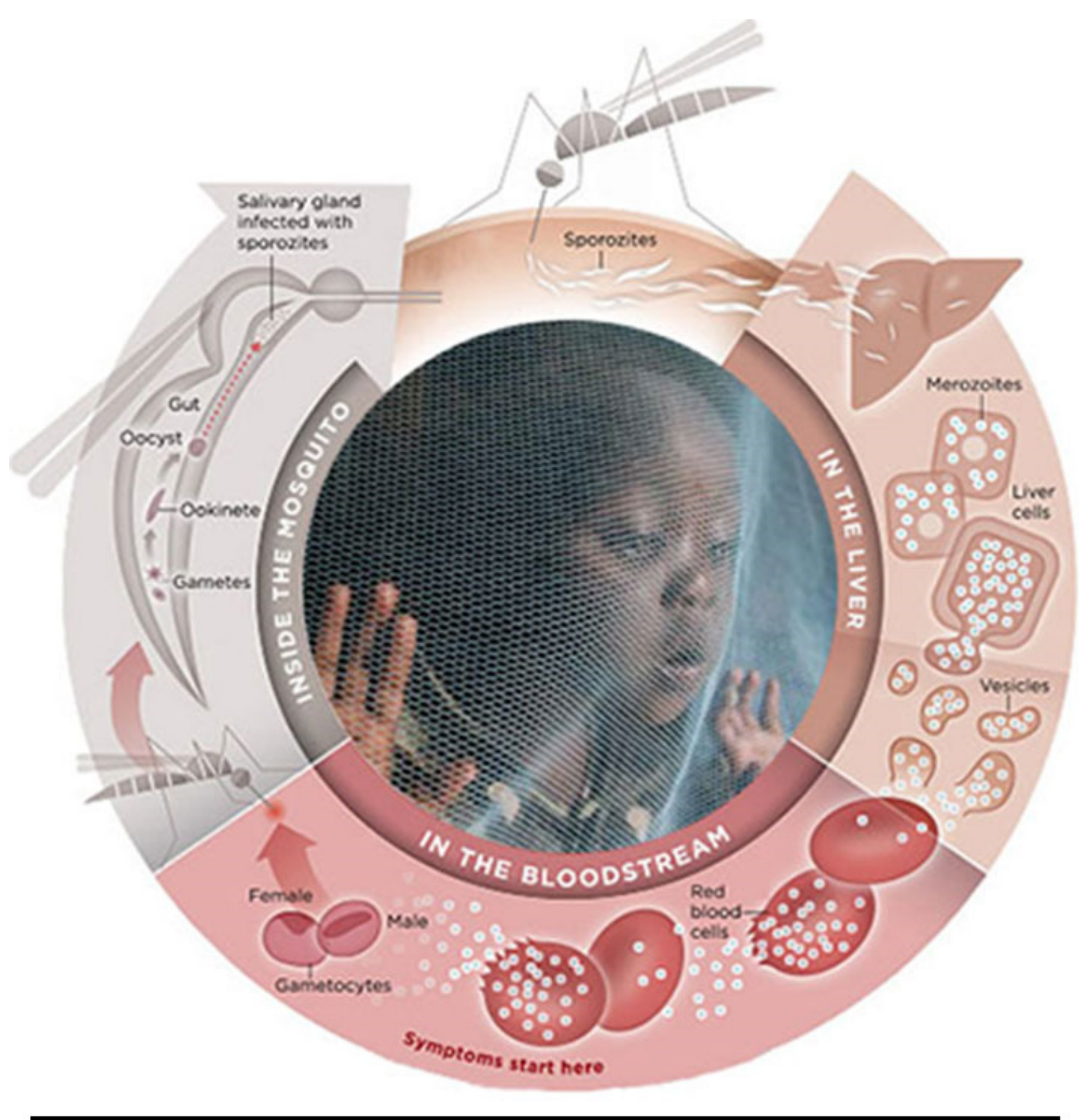

Figure 1.2: Malaria Lifecycle

Repurposed graphic combining figure from Malaria Vaccine Initiative (www.malariavaccine.org) and picture by Mr. Stephen Morrison (European Press Agency)

sporozoites are formed by asexual reproduction. The oocyte will eventually burst open

and release the sporozoites. These sporozoites migrate to the salivary glands of the mosquito and are released into human hosts during blood meals. Parasite development in the mosquito, from the time of ingestion to transmission, is 10 to 21 days. ${ }^{9}$ 
When the human host takes an antimalarial drug during the life cycle of the parasite, the hope is to kill all the parasites and thereby end the malaria sickness. However, if the drug is not potent enough, or if it is not taken over a long enough time, a few parasites may survive, some of which might happen to have a variation in their genome that gives them an enhanced ability to survive and continue to replicate, allowing the emergence of new strains. When the genomes of those survivors are crossed with the genomes of other survivors during sexual reproduction, new parasites with adaptations that can withstand the antimalarial action of a drug may emerge. When sufficient and widespread resistance has emerged against a specific drug, then that drug is deemed no longer useful in that area.

\section{Strategies for Control}

In developing a strategy to control and eventually eradicate malaria, three areas of response emerge: vector controls, vaccines, and antimalarial drugs. ${ }^{1}$ No one method of the control is adequate, but efforts in all three areas are reducing the number of deaths due to malaria.

Vector Controls: There are over 40 species of Anopheles mosquitos that have the abundance, longevity, capacity and preference for human blood to make them a significant threat. ${ }^{12}$ Among these species there are diverse habitat and feeding requirements, making it difficult to find just one single answer to control the mosquito populations. Several approaches are in use to reduce the mosquito populations including eliminating or treating standing water to lessen the available breeding grounds for larva. 
Such treatments include the introduction of larva-eating fish or treating the waters with Bacillus thuringiensis isrealensis and Bacillus sphaericus, bacterial pathogens selective for mosquito larva. ${ }^{12}$ Insecticides are employed to reduce the adult population of mosquitoes, however, the mosquitos are developing resistance to the insecticides so that they are becoming less potent over time. ${ }^{12}$

An obvious way to interrupt the malaria transmission cycle is to keep mosquitoes from biting humans. A way to accomplish this goal is by protecting humans with insecticide treated bed nets (ITNs), especially during the nighttime when the Anopheles mosquitoes are most active. When surveying populations at risk, it was self-reported that $55 \%$ of households own at least one ITN, 33\% own an adequate number to protect all the members of the household, and $86 \%$ of ITN owners diligently use them. ${ }^{1}$ The WHO estimates, admittedly crudely, that there are over 300 million ITNs currently in service, but at least 450 million are needed for adequate coverage. ${ }^{1}$ The useful life expectancy of an ITN is three years; one third of the ITNs retiring each year makes it difficult to build to the needed level of availability. ${ }^{1}$ The use of ITNs has been shown to reduce mortality rates for children (under the age of 5) by approximately 16\%, in a 2002 study in western Kenya. ${ }^{13}$ Even with such a remarkable achievement, vector controls alone are not adequate to control, eliminate, or eradicate malaria.

Vaccines: A vaccine against malaria would be a very useful tool to combat malaria in endemic areas. Vaccines ideally educate the immune system to provide longterm immunity against disease. Although several successful vaccines have been produced against viruses such as smallpox and measles, the antimalarial vaccines that are 
now in human trials are the first vaccines that have been produced with a degree of success against any parasite. As discussed next, the success is modest.

A vaccine against a parasite is more challenging than an antiviral vaccine because the parasite potentially presents thousands of antigens to the human immune system, changes forms throughout its life stages in the human host, evolves to render the immune responses ineffective (as do viruses), and spends much of its lifecycle inside host cells. ${ }^{14}$ On the other hand, there are indicators that a malaria vaccine may be feasible: the occurrence of natural immunities developed in response to severe disease, the finding that irradiated sporozoites introduced into humans provided some protection from subsequent challenges, and the finding that immunity can be passively transferred by injecting antibodies from a host that has acquired immunity. ${ }^{14,15}$

A notable accomplishment of the vaccine research to date is the Glaxo Smith Kline RTS,S/AS01, a vaccine candidate that acts against liver stage malaria. In Phase III clinical trials, RTS,S/AS01 has shown to reduce the incidence of clinical disease by $55 \%$ for the year following vaccination. ${ }^{1,16}$

The PfSPZ vaccine comprised of non-replicating, whole P. falciparum sporozoites being developed by Sanaria has recently completed a Phase I clinical trial; the early findings show that the vaccine was well tolerated by the study participants, and that 12 out of 15 were protected from a challenge infection administered three weeks later. ${ }^{15}$ Although these results look promising, the cost and time investment to produce whole organism vaccines makes this a less desirable vaccine for widespread use. ${ }^{17}$ 
Pfs25-EPA is a transmission-blocking vaccine that acts against antigens expressed on the surface of the gametocyte, the sexual form of the parasite that remains in the blood stream. ${ }^{18,19}$ When the gametocyte is taken up by the mosquito it is unable to reproduce. The drawback of this approach is that it carries no direct protective benefit for the vaccinated person and requires widespread employment before any benefit would be realized.

There are several other vaccine candidates that are being pursued that are much earlier in the development process; they are estimated to be five to ten years away from clinical trials. ${ }^{1}$ Among these candidates are blood stage infection and transmission blocking vaccines, all showing promise of usefulness. ${ }^{1}$ However, even after decades of research and development, we still do not have a vaccine that is ready for widespread use. Our inability to eradicate the mosquito vector quickly, or to develop a wide-spectrum, long-lasting vaccine quickly leaves us with the alternative of fighting pandemic active infections with chemotherapeutic drugs.

Antimalarial Drugs: Quinine (Figure 1.3), an extract from Cinchona bark, has

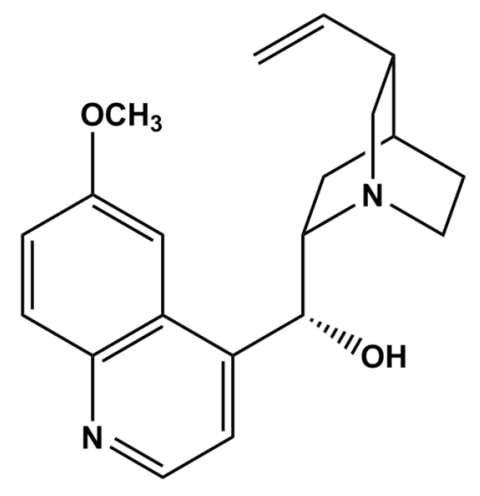

Figure 1.3: Structure of Quinine served as a leading antimalarial for hundreds of years. $^{20}$ It was used in the unextracted form since the 1600s, and was isolated and named in 1817 by French researches Pierre Pelletier and Joseph Caventou. In 1964, Robert Woodward and coworkers achieved the first total synthesis of quinine. ${ }^{21,22}$ Quinine was very effective for 
the treatment of malaria caused by $P$. falciparum, and it remained the frontline drug until the 1940s when chloroquine (CQ) took over. Although quinine is effective, it has many unpleasant, but usually temporary, side effects. It causes sweatiness, tinnitus, vision problems, hearing impairment, confusion, headaches, rashes, abdominal pain, photosensitivity, vertigo, dysphoria, nausea, vomiting, and diarrhea. ${ }^{20}$

In 1946, CQ (Figure 1.4) was introduced as an antimalarial. CQ was synthesized and studied as an antimalarial beginning in 1934 by Hans Andersag at Bayer I.F. Farbenindustrie A.G. Laboratories in Eberfeld, Germany. ${ }^{23}$ However, CQ was abandoned in favor of Atabrine, another drug candidate, because of its slight toxicity in birds, and so CQ was overlooked until 1946 when it was recognized for its safe and

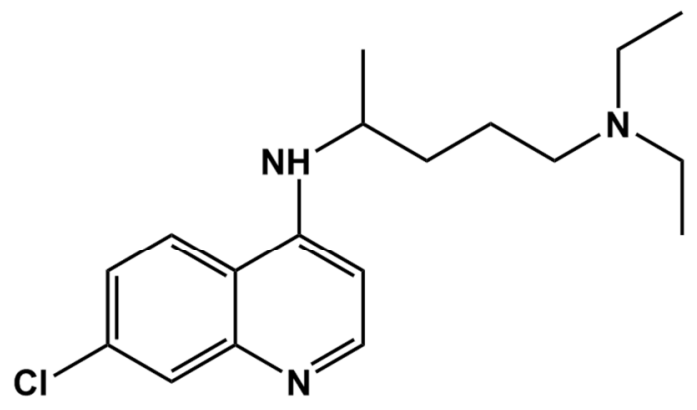
effective antimalarial properties by British and US scientists. CQ Figure 1.4: Structure of Chloroquine (CQ) quickly became the main drug used for malaria treatment and prevention because it was effective in a few doses, had mild side effects, was safe even for infants and pregnant women, and was very inexpensive. It was hoped that this drug, along with mosquito control, would be the means to eradicate the disease worldwide. However, by the 1950s CQ-resistant strains of malaria emerged in South America and Southeast Asia, then quickly spread throughout the world except for Africa. In the 1980s CQ-resistant strains began to emerge in Africa. Although still used in Africa, CQ has been rendered nearly 
ineffective in much of the world, and its continued use will certainly promote the evolution of CQ-resistant strains of $P$. falciparum malaria. Discussion of the CQ mode of action and mechanism of resistance is deferred to a later section of this chapter.

Artemisinin (Figure 1.5), the current lead antimalarial, is a sesquinterpene lactone with a peroxide bridge. Artemisinin is isolated from the plant, Artemisia annua, and has been known in traditional Chinese medicine for thousands of years. The earliest mention of its use dates back to 168 B.C., but the first mention of its use as an antimalarial was by Wenbing Tiaohian in $1798 .{ }^{24}$ It was forgotten, then rediscovered in 1972 by Tu Youyou, who was evaluating traditional Chinese medicines for treating malaria. ${ }^{24}$ The practical use of artemisinin as an antimalarial agent is impaired by its insolubility in both water and oil, poor efficacy by oral administration, and the rate of recrudescence in treated patients. To

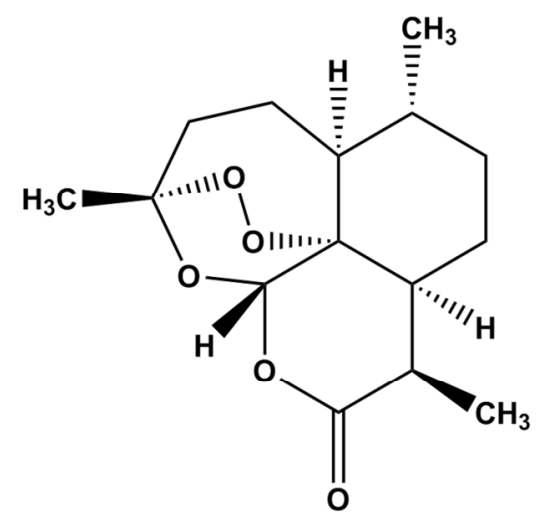
improve solubility and bioavailability, semi-

Figure 1.5: Structure of Artemisinin synthetic analogs were devised. Three that are currently in use are artemether, artesunate, and dihydroartemisinin (Figure 1.6). The artemisinins are very potent antimalarials that are effective against both sexual and asexual forms of the parasite; in addition, they are very fast acting drugs, killing the malaria parasite within minutes and clearing the blood of $98 \%$ of infection with a single dose. However, artemisinins have very short half-lives 


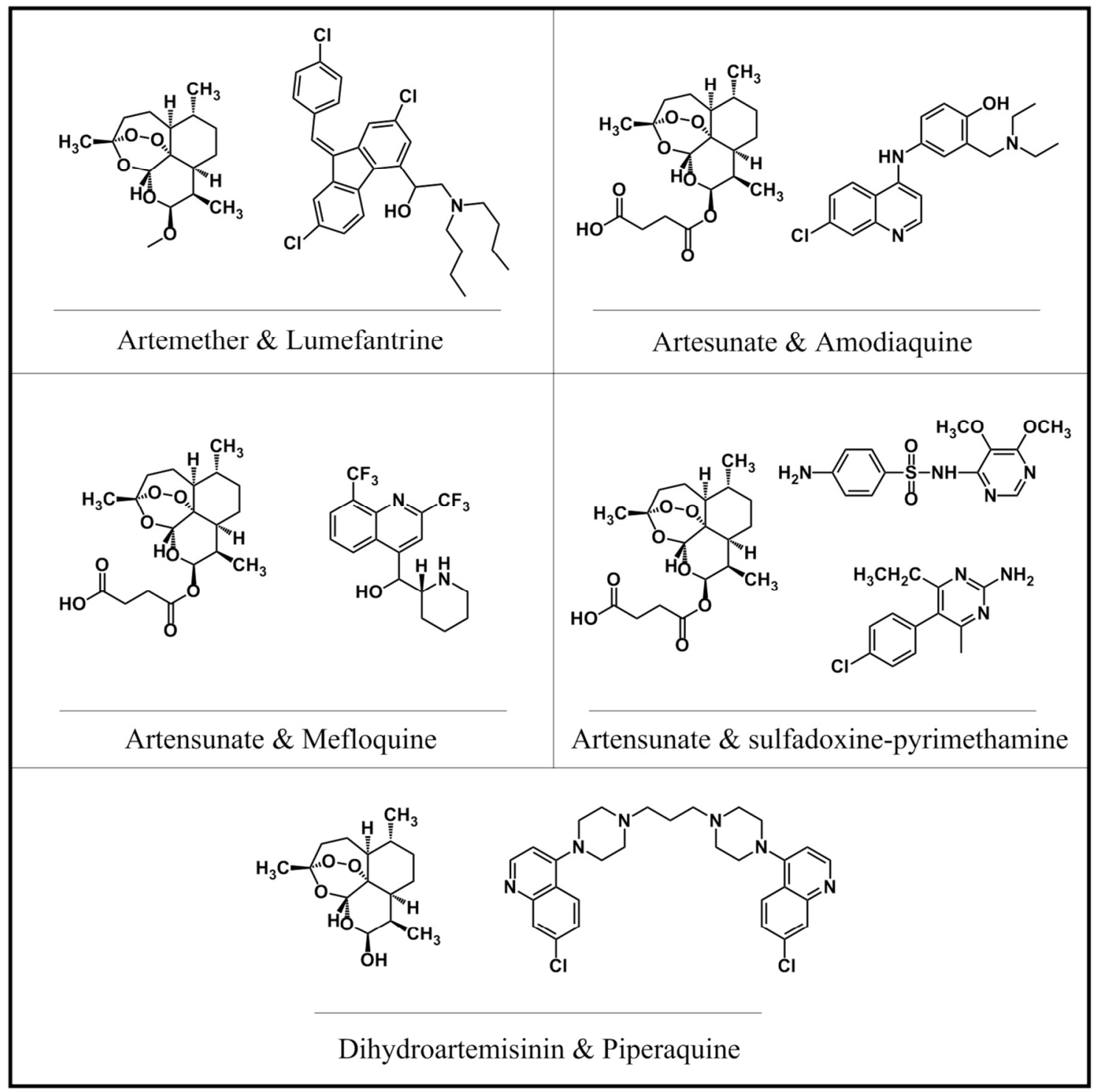

Figure 1.6: Structures of Artemisinin-Based Combination Therapies (ACTs)

in the body, which makes it difficult to dose for continuity of coverage over a span of the parasite's lifecycle. $^{25}$

The mode of action for the artemisinins is still under investigation. It is known that the peroxide bridge is essential to the activity of the artemisinins: when one peroxide 
oxygen is replaced by a carbon, the resulting analog is inactive. ${ }^{26}$ The mode of action of the artemisinins is via a free radical mechanism, shown by the fact that free radical scavengers have an antagonistic effect on the antimalarial activity of these drugs. ${ }^{27,28}$ Free iron and/or heme-bound iron activate the homolytic cleavage of the endoperoxy bridge of the artemisinins to form a radical. The need for an iron-rich environment for activation may be the reason that this drug acts selectively against the parasite. The free radical may act as an oxy radical or rearrange to a carbon centered radical. ${ }^{29}$ Several possible actions of the radical have been suggested, including acting as a strong reducing agent, alkylating heme, and/or alkylating proteins. ${ }^{30}$

Because of the increasing problem of resistance against antimalarial therapies, the WHO recommended in 2005 that all countries experiencing $P$. falciparum drug resistance use drugs in combination therapies, preferably artemisinin-based combination therapies (ACTs). ${ }^{31}$ The rationale for ACTs is that it combines drugs with different modes of action against the same parasite life stage, making it statistically improbable that mutant strains would develop resistance mechanisms at both sites of action, thereby killing more (or all) of the parasites of an infection, and thereby protecting against the development of resistance to either of the drugs.

In the design of an ideal combination therapy there are several pharmacodynamic and pharmacokinetic factors to consider. It is important that these drugs be synergistic (or at least non-antagonistic), and have different modes of action against the same life stage, providing a parasite killing efficacy of nearly $100 \%$ per cycle. ${ }^{32}$ It is important that the drugs are a good pharmacokinetic match so that they both keep constant pressure on 
the parasite during the whole course of treatment in order to protect both drugs against the development of resistance. The combination needs to be delivered in a simple regimen to facilitate patient compliance, and ideally be able to maintain a therapeutic level for 3 cycles, which is 6 days for $P$. falciparum malaria. It is also preferred that the partner drugs have moderate half-lives so the time the drugs reside in the patient at subtherapeutic levels is minimized, reducing the opportunity for resistance to develop.

The ACTs that are currently in use are artemether/lumefantrine, artesunate/amodiaquine, artensunate/mefloquine, artensunate/sulfadoxinepyrimethamine, and dihydroartemisinin/piperaquine (Figure 1.6). Lumetantrine, amodiaquine, mefloquine and piperaquine are active against the erythrocytic stages. The modes of action for these drugs are not fully elucidated, but all are suspected to inhibit hemozoin formation, much like CQ, discussed below. ${ }^{33}$ The sulfadoxine-pyrimethamin have a well- defined mode of action: inhibiting the enzymes involved in parasitic folic acid synthesis. ${ }^{34}$ These partner drugs all have half-lives longer than the artemisinins. ${ }^{33}$ In spite of the precaution of a policy of combination therapy, $P$. falciparum strains that are resistant to the artemisinins have emerged both in the Cambodia-Thailand border and at the Northern Thailand-Myanmar border. ${ }^{35}$ Artemisinin resistance is so far defined by the slow clearing of the parasites and is specifically related to the ring-stage parasite. ${ }^{35}$ These first signs of resistance are quite alarming in the absence of another lead drug to replace the artemisinins as the next cornerstone of malaria chemotherapy. In addition, resistance has emerged to each of the partner drugs currently used in combination with the artemisinins. 
In addition to the curative therapies, intermittent preventive therapy (IPT) is used to protect the populations that are most at risk from malaria. These populations are pregnant women, infants, and children, in high transmission areas. The risk of severe $P$. falciparum malaria is increased for pregnant women and associated with a mortality rate of nearly $50 \% .^{7}$ At the time of giving birth, there is evidence of malaria in $25 \%$ of the women. $^{36}$ The incidence of babies with low birth weight is twice that of births for noninfected mothers and the incidence for infant mortality is markedly increased for low birth weight babies. ${ }^{36}$ Seventy percent of the annual death toll for malaria is comprised of children that are under the age of 5 years old in high transmission areas. ${ }^{1}$

The combination of sulfadoxine-pyrimethamine has been the IPT of choice since the mid-1990s. ${ }^{37}$ Several IPT studies from since the mid-1990s to 2008 have shown decrease in both the incidence of malaria and the mortality rate for stable and seasonal high transmission areas. ${ }^{36-41}$ However, studies over the last 10-12 years, in Malawi, Tanzania, Uganda and Mozambique all show the lessening or loss of benefit from IPT with sufladoxine-pyrimethamine because of the growing resistance against the drugs. ${ }^{37,40}$ Another need for prophylactic drugs is among travelers who will be going into high transmission areas. It is estimated that currently there are over a billion international border crossings per year. ${ }^{42}$ It is important to protect travelers for their sake, but with such a high volume of travelers it also important to keep malaria from spreading to new areas. 
A wider range of drugs is available to travelers than can be used in the endemic countries based both on the cost and the pharmacokinetics of the drug. Prophylactic drugs currently in use are shown in Figure 1.7.43,44 Travelers have the advantage of being able to both build to and wane from therapeutic levels while they are not under the threat of malaria infection; malaria infections that occur when drugs are at a sub-therapeutic level breed resistance to the drug. The causal malaria prophylactic drugs act against the

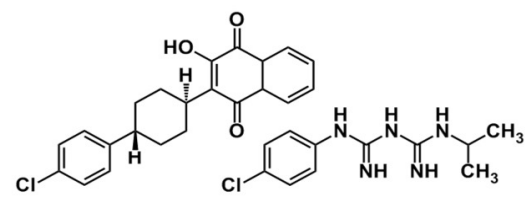

Atovaquone/Proguanil (Malarone)

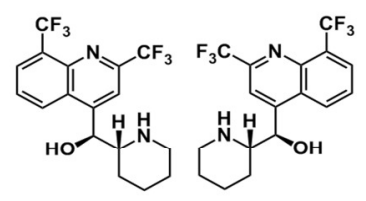

Mefloquine (Lariam)

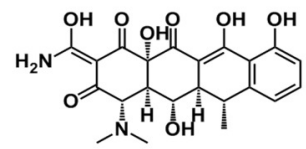

Doxycycline (Vibramycin, Doryx)

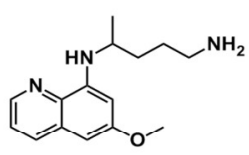

Primaquine

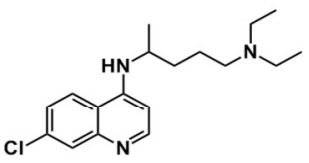

Chloroquine (Aralen)

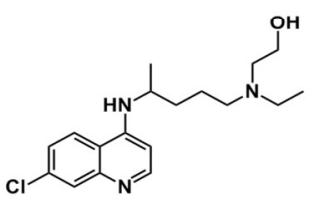

Hydroxychloroquine (Plaquenil)

liver-stage of the

parasites lifecycle and

the suppressive drugs

act against the blood

stage of the parasite. ${ }^{45}$

The drug choice and

regimen are customized

to each traveler based

on the details of their

itinerary and the

Figure 1.7: Prophylactic Drugs for Travelers

availability of

immediate medical

support during their trip. The drugs are continued for one to three weeks after exiting the endemic regions to facilitate total clearance of the parasite. Even with a customized regimen and good compliance, prophylactic drugs are only 75 - 95\% effective for no incidence of malaria infection. $^{44}$ 


\section{A Closer Look at Chloroquine Mode of Action, and Resistance to Chloroquine}

During the blood stage of malaria, $P$. falciparum imports and digests $60-80 \%$ of the hemoglobin from the cytoplasm of the host's red blood cell. ${ }^{46}$ The four embedded heme groups in hemoglobin are freed and cannot be degraded by the parasite. The accumulation of free heme in the digestive vacuole (DV) would be fatally toxic to the parasite. $^{47}$ To avoid the toxic effects, the free heme is crystallized into insoluble, densely packed hemozoin, as shown in Figure 1.8.

The mechanism for hemozoin formation is not fully understood. Studies of the in vitro formation of $\beta$-hematin, a compound that is spectrometrically and crystallographically the same as hemozoin and thus presumed to be identical to hemozoin, ${ }^{47}$ have shown the following: Nucleation of $\beta$-hematin occurs spontaneously at physiological temperature and acidic $\mathrm{pH}$ of the $\mathrm{DV}$ but at a rate too slow to be effective as the detoxification pathway. ${ }^{48}$ It has been found that both histidine rich protein and lipids promote the nucleation of $\beta$-hematin. ${ }^{48}$ Once nucleation has occurred, the $\beta$ hematin formation process is autocatalytic. ${ }^{47}$

Recently it was discovered that lipid nanospheres are present in the $\mathrm{DV}^{49}$ and they are the site of hemozoin formation. ${ }^{50,51}$ Further studies have shown that a two-phase system, such as octanol-water or pentanol-water, promotes hemozoin formation over the rates seen in water alone, and over the rates seen in octanol or pentanol alone. ${ }^{47}$ This suggests that the interface of the two-phase system catalyzes the formation of hemozoin. 


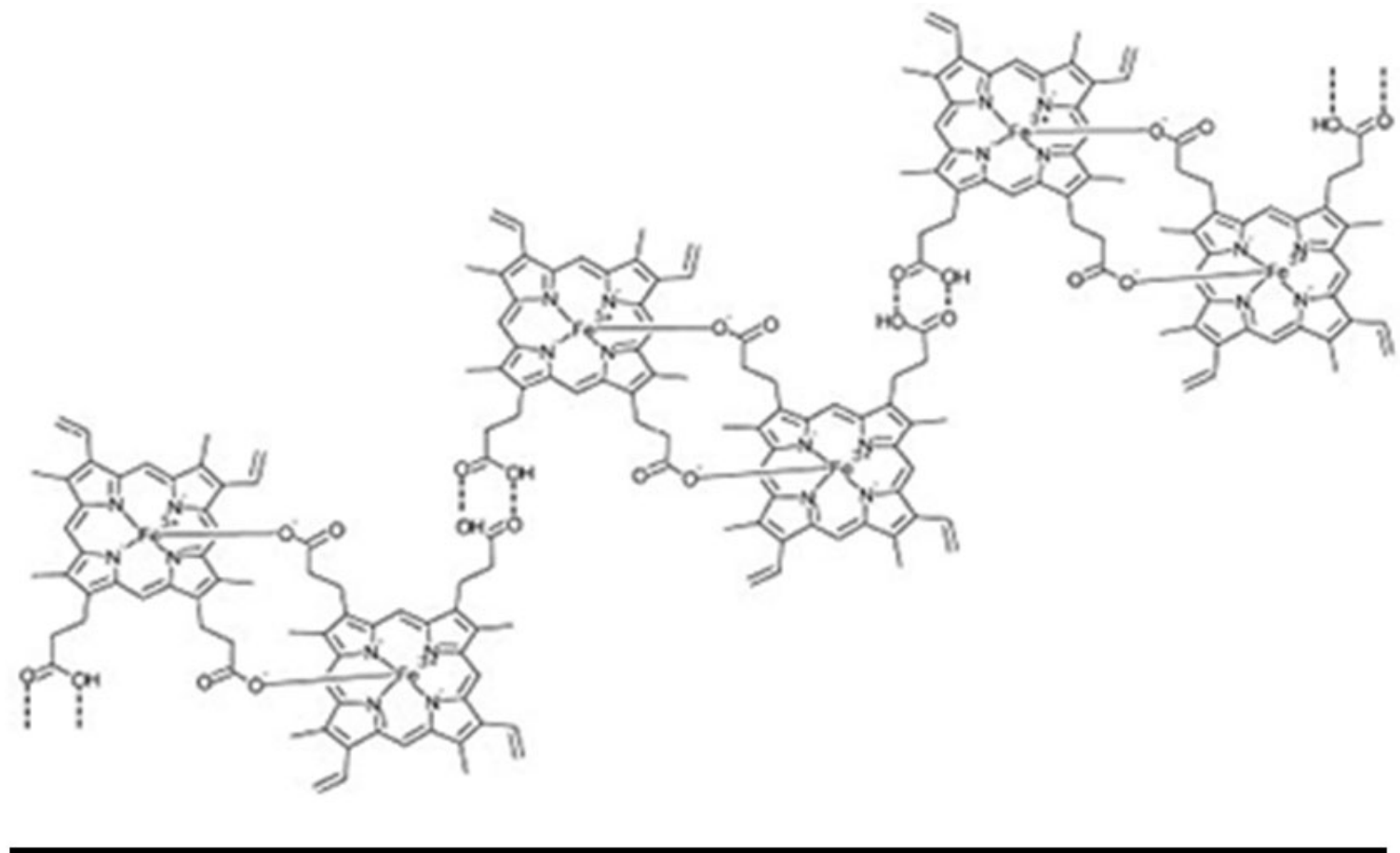

Figure 1.8: Structure of Hemozoin

Molecular and Biochemical Parasitology 2008, 157, 128

The currently-accepted mode of action of CQ is the inhibition of hemozoin formation, thus subjecting the parasite to the toxic effects of the free heme. ${ }^{52} \mathrm{CQ}$ has two protonatable nitrogens; the quinolyl nitrogen has a $\mathrm{pK}_{\mathrm{a}}$ of 9.8 and the tertiary sidechain nitrogen has a $\mathrm{pK}_{\mathrm{a}}$ of $8.6 .{ }^{53} \mathrm{CQ}$ in the uncharged state is membrane-permeable and diffuses into the parasite's DV (Figure 1.9). ${ }^{52}$ In the acidic DV the CQ becomes doubly charged and complexes with the free heme. ${ }^{54}$ Both the high proton concentration and the free heme shift the equilibrium toward CQ in the DV. ${ }^{54} \mathrm{CQ}$ accumulates in the DV to approximately 6000 times more than the concentration in uninfected red blood cells. ${ }^{55}$ 


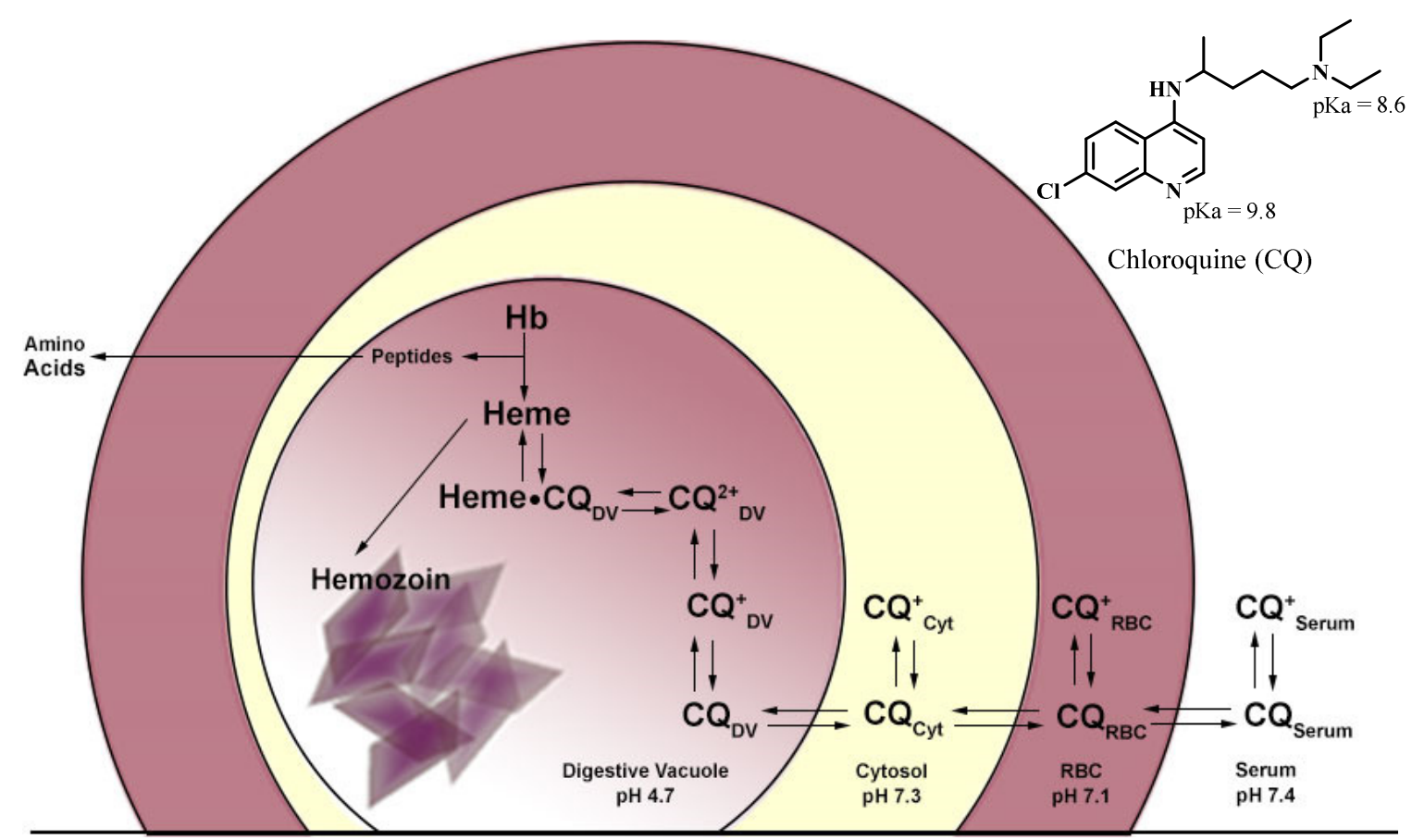

Figure 1.9: Chloroquine Accumulation

Graphic inspired by Hladky, S. B. Chloroquine Accumulation, http://www.phar.cam.ac.uk, 2006. $\mathrm{pK}_{\mathrm{a}}$ values from Journal of Medicinal Chemistry, 2008 June 26; 51(12): 3466.

Through cell fractionation methods measuring the iron and hemozoin concentrations, it has been shown that there is a dose-dependent inhibition of hemozoin formation by $\mathrm{CQ}$, which results in the buildup of free heme in the malaria cell and tightly correlates to the parasite death. ${ }^{56}$ Also, tunneling electron microscope images show the disruption of hemozoin crystallization by $\mathrm{CQ}{ }^{56}$ Thus, $\mathrm{CQ}$ complexing with heme inhibits the biocrystallization of hemozoin, which results in the parasite's death.

In CQ-resistant strains of $P$. falciparum, it has been shown that CQ accumulation is four to ten times less in the DV of the parasites than for CQ-sensitive strains. ${ }^{57}$ From comparisons between CQ-resistant and CQ-sensitive strains, it was determined that the primary determinants of CQ-resistance are mutations in the $p f c r t$ gene. ${ }^{58}$ The $p f c r t$ gene gives rise to the PfCRT (Plasmodium falciparum CQ resistance transporter) protein, and 
has been shown to transport CQ out of the digestive vacuole. ${ }^{59}$ The PfCRT protein has been shown to be located in the DV membrane, and is predicted to have 10 transmembrane domains. ${ }^{60}$

\section{Reversal Agents}

A reversal agent (RA) is a drug that reverses the effect of resistance against another drug. ${ }^{61}$ Because of similarities seen in the resistance of $P$. falciparum and neoplastic cells, the possibility of reversing the resistance was pursued. ${ }^{59}$ Verapamil, a calcium channel blocker, had been useful in reversing drug resistance in neoplastic cell cultures by inhibiting the active efflux of anticancer drugs. When Verapamil was coadministered with $\mathrm{CQ}$, the $\mathrm{IC}_{50}$ of $\mathrm{CQ}$ against $\mathrm{CQ}$-resistant strains was reduced to nearly the $\mathrm{IC}_{50}$ of the CQ-sensitive strain. ${ }^{59}$

Several reversal agents

have been found for $P$.

falciparum, and from these

known reversal agents, a

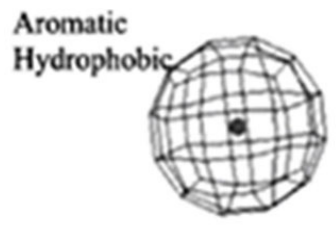

Aromatic Hydrophobic geometric distribution map of their common chemical features was determined through modeling studies (Figure 1.10). ${ }^{62}$ This three-dimensional map, or Journal of Chemical Information and Modelling 2002, 42, pharmacophore, based on the (5), 1214 
specific set of reversal agents was comprised of two aromatic hydrophobic sites and a hydrogen bond acceptor site (generally a nitrogen atom located on a side chain two to three bonds removed from the aromatic sites). ${ }^{62}$ This pharmacophore can be applied as a predictor of reversal agent potency for analogous molecules.

Although the demonstration that reversal agents can restore the effectiveness of CQ was encouraging, using reversal agents as part of a treatment regimen has a major drawback. The known antimalarial reversal agents are usually drugs designed for nonantimalarial purposes. For example, there are several examples of reversal agents that are antihistamines, anti-depressants, anti-hypertensives, or anti-psychotics. Because these drugs were designed to affect other targets, they require a relatively large dose to accumulate enough in the DV to reverse CQ-resistance. In order to make use of an RA to restore the activity of $\mathrm{CQ}$, it is necessary to find a way to target the RA to the site of action in malaria infections.

\section{Reversed-Chloroquines}

A solution was proposed to link the reversal agent covalently to a CQ-like moiety, forming a hybrid molecule, in this case a 'Reversed-CQ', that has a dual mode of action (Figure 1.11). ${ }^{63}$ The concept was that the CQ-like moiety can act as an antimalarial, while the reversal agent-like moiety can circumvent the mechanism of resistance; the covalent linkage between these two moieties ensures that they are both present in the DV at the same time. It was hoped that a much smaller dose would be needed against CQresistant strains than when they are administered separately, minimizing the toxic effects 


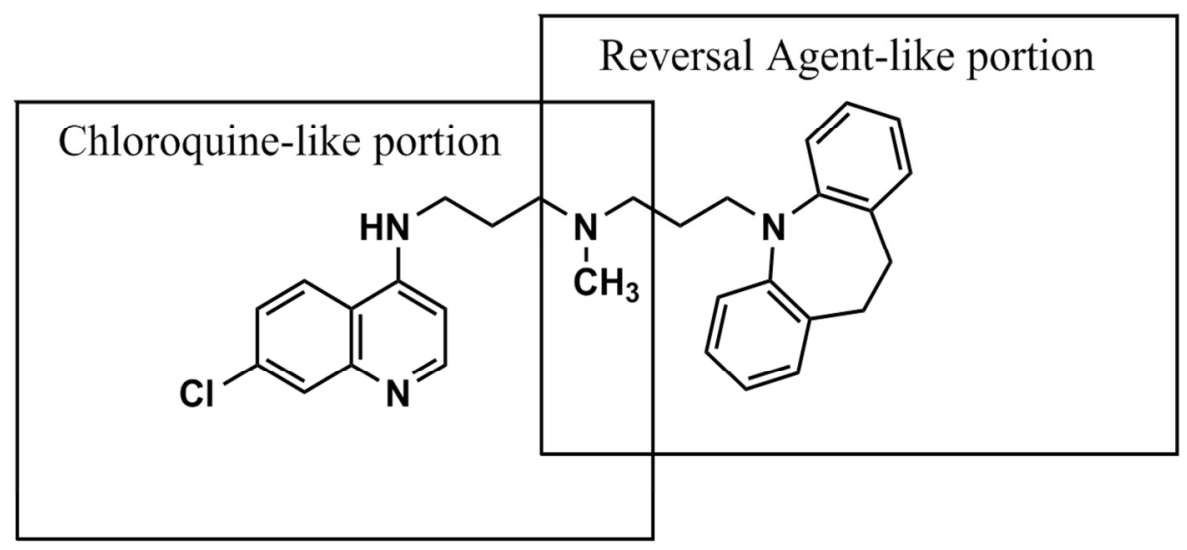

Figure 1.11: Reversed Chloroquine PL01

to the host. ${ }^{63}$

To test the Reversed-CQ-concept, PL01 was synthesized by Steven Burgess. ${ }^{63}$ PL01 is constructed to include an imipramine-like moiety (the RA) and a CQ-like moiety. Imipramine is a known reversal agent and fits the Bhattacharjee pharmacophore. ${ }^{62,64}$ The CQ methyl at the side chain $\mathrm{C}_{1}$ chiral center has been shown to be non-essential for antimalarial activity, ${ }^{65}$ and thus has not been included in the CQ-like moiety, leading to an achiral molecule.

The antimalarial effectiveness of PL01 was evaluated by in vitro drug susceptibility assays against $P$. falciparum parasites. The assays were conducted using D6 (a CQ-sensitive strain) and Dd2 (a CQ-resistant strain) P. falciparum cell cultures. PL01 gave an $\mathrm{IC}_{50}$ that was slightly lower than for CQ against the CQ-sensitive strain, and nearly a 20-fold increase in activity for the CQ against the CQ-resistant strain, making this value nearly that of the $\mathrm{IC}_{50}$ against the $\mathrm{CQ}$-sensitive strain. This indicates that PL01 is active against the CQ resistance mechanism present in the Dd2 CQ-resistant strain. The reduced $\mathrm{IC}_{50}$ against $\mathrm{CQ}$-sensitive strain relative to that of $\mathrm{CQ}$ may suggest 
low-level resistance in the D6 CQ-sensitive strain, or may be a reflection of a fitness level difference between the strains. ${ }^{66}$

The antimalarial effectiveness of PL01 was also evaluated in an in vivo study in mice. This study demonstrated that $64 \mathrm{mg} / \mathrm{kg} /$ day for 4 days suppressed over $99 \%$ of the P. chabaudi (a rodent malaria commonly used as a model organism). ${ }^{67}$ Poor bioavailability of PL01 was expected because of the drug's lipophilic nature as estimated by $\operatorname{cog} \mathrm{P}$ (the calculated $\log$ of the partition coefficient between n-octanol and water). The clogP of PL01 is 8.9, which is much higher than the $5.1 \operatorname{cog} \mathrm{P}$ of CQ. ${ }^{63}$ Lipinski's Rule of Fives, a set of rules to estimate the solubility and permeability of investigational compounds, indicates that a $\log \mathrm{P}$ of less than five is favored for a compound to be orally active. ${ }^{68}$ However, the mouse result demonstrates that PL01 has some oral bioavailability, and also has in vivo antimalarial activity.

The binding constant of PL01 to the heme was evaluated by UV-vis titration. ${ }^{63}$ It was found that the Reversed-CQ-heme 2 binding constant at $\mathrm{pH} 5.7$ was about the same as for $\mathrm{CQ}$-heme 2 at the same $\mathrm{pH}$, confirming that the modifications to the CQ-like moiety and the addition of reversal agentlike moiety do not interfere with the binding of heme.

PL02 (Figure 1.12) was designed on the same concept of linking a CQ-like molecule to an RA-like molecule.

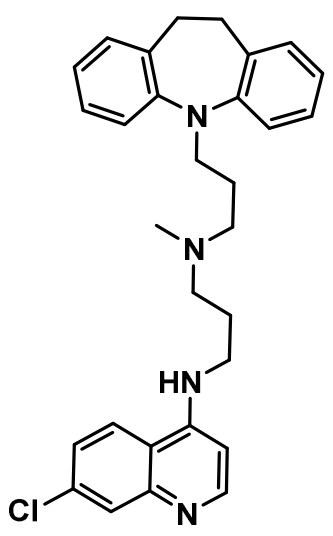

PL01

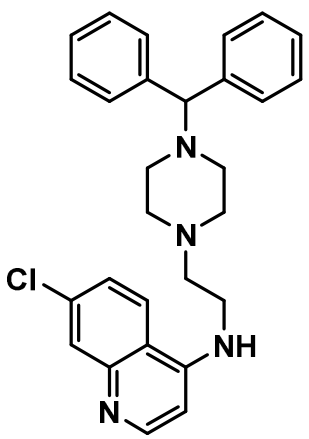

PL02

Figure 1.12: Reversed CQ Molecules Synthesized by Steven Burgess 
However instead of using a known reversal agent, diphenylmethylpiperazine was chosen such that it possesses the essentials of the RA pharmacophore as defined by the Bhattacharjee study ${ }^{62}$ but without its "tricyclic antidepressant" structure. In in vitro drug susceptibility assays against $P$. falciparum, $\mathrm{PL} 02$ gave a low $\mathrm{IC}_{50}$ against both CQsensitive D6 and CQ-resistant Dd2. In fact, the P. falciparum $\mathrm{IC}_{50}$ values were slightly lowered (improved) over the results for PL01. Heme binding studies revealed nearly the same association constant as for PL01.

\section{PL74: A Molecule of Interest}

PL74 (Figure 1.13 for amine-linkage target structure) was originally synthesized by Steven Burgess to be a PL02 analog without antimalarial activity, in order to test the RA activity. ${ }^{69}$ In a structure activity relationship (SAR) study of aminoquinolines, Egan concluded that the quinoline ring forms a complex with heme largely based on $\pi-\pi$ interaction. ${ }^{54}$ Egan also concluded that the 7-chloro substituent on the quinoline ring is the minimum critical feature for $\beta$-hematin inhibition. ${ }^{54}$ In the

change from PL02 to PL74 both the chlorine and half of the quinoline were removed. It was postulated that this modification should abolish $\beta$-hematin inhibition and diminish the $\pi-\pi$

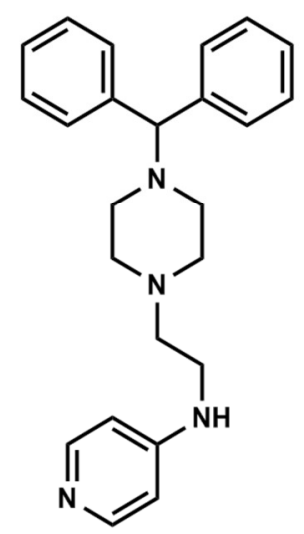

Figure 1.13: Amine-Linkage Structure for PL74 Proposed by Steven Burgess 
interaction with heme.

However, in vitro drug susceptibility assays were performed for PL74 against two cell cultures: D6 (a CQ-sensitive culture) and Dd2 (a CQ- resistant culture). It was found that the compound had an $\mathrm{IC}_{50}$ for $\mathrm{D} 6$ (CQ-sensitive) of $185 \mathrm{nM}$ and an $\mathrm{IC}_{50}$ for Dd2 (CQ-resistant) of $169 \mathrm{nM} .^{69}$ These results are modest in comparison with the prototype Reversed-CQ but far better than anticipated (Figure 1.14, Table 1.1).

Optical spectroscopic studies were carried out to determine equilibrium binding and $\beta$-hematin inhibition. ${ }^{70}$ For equilibrium binding, addition of the CQ and the PL compound showed a clear perturbation of the heme dimer absorption spectrum upon binding. The 2:1 Affinity Model, in which the heme dimer bonds to one drug molecule (previously reported by Jane Kelly), can be used to determine the association constant $\left(\mathrm{K}_{\mathrm{a}}\right)$ from the dose-response curve. ${ }^{71}$ The Ka for PL74 was determined to be 5,000, a five-fold reduction from the $\mathrm{K}_{\mathrm{a}}$ of $\mathrm{CQ}$. Again, the value of $\mathrm{K}_{\mathrm{a}}$ is small in comparison to CQ, PL01, and PL02--but still indicates that PL74 can associate with the heme dimer.

For the $\beta$-hematin inhibition assay a solution of heme, Tween 20 , and sodium acetate buffer ( $\mathrm{pH} 4.8$ ) was used to mimic the digestive vacuole environment. ${ }^{70}$ After 24 hours incubation of this solution, there was a complete loss of absorbance in the Soret range, indicating the absence of measurable quantities of free heme. On repeat with the addition of active PL compounds, the Soret band absorbance was preserved, indicating the presence of free heme, thus indicating the inhibition of $\beta$-hematin formation. The inflection point of the sigmoidal dose-response curves indicates the $\mathrm{IC}_{50}$ of $\beta$-hematin formation. The $\mathrm{IC}_{50}$ for PL74 was found to be $290 \mu \mathrm{M}$, a value more than $10 \mathrm{x}$ the $\mathrm{IC}_{50}$ 
for CQ, but still far greater than expected. See Table 1.1 for comparison of the $\beta$-hematin inhibition $\mathrm{IC}_{50}$ values for CQ, PL01, PL02, and PL74.

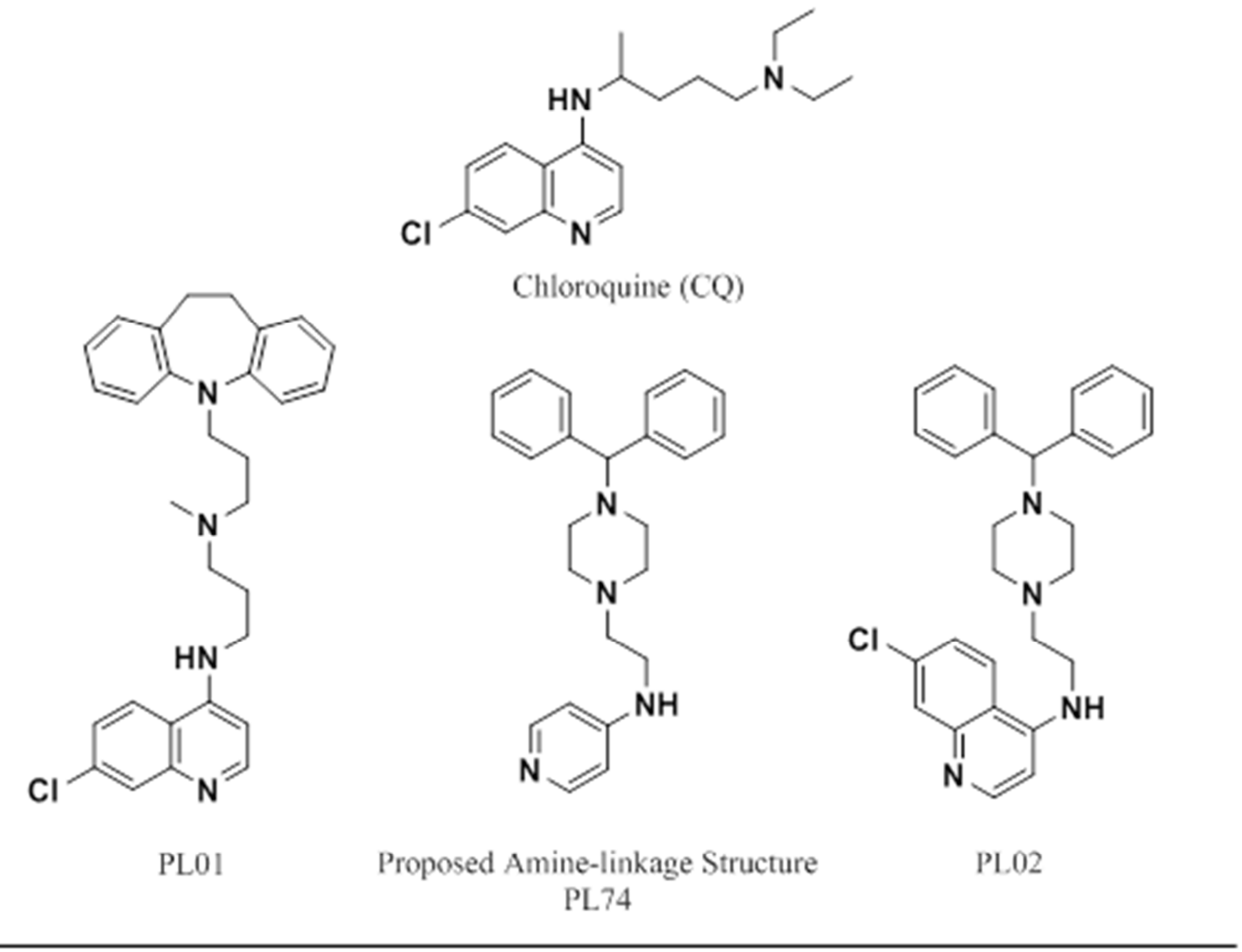

Figure 1.14: Structures of CQ and Selected PL Compounds

Table 1.1: In vitro Drug Susceptibility, Binding, and $\beta$-Hematin Inhibition Assay
Results $\quad$\begin{tabular}{ccc} 
UV Titration Studies \\
\hline
\end{tabular}


The unexpected activity of PL74 was intriguing and warranted further investigation. This dissertation is a record of the investigation. Through these studies it was found that PL74 does in fact have some unique features and possibly a mode of antimalarial action different from the Reversed-CQ molecules. As shown in the following chapters, both the structure of the molecule and its proposed mechanism of action needed revision. 


\section{Chapter 2}

\section{The Structure of PL74}

PL74 and its proposed amine-linkage structure (Figure 2.1) were a paradox in some ways. Not only did PL74 have stronger antimalarial activity than expected from the proposed amine-linkage structure, but its solubility and reactivity were also perplexing. PL74 was not soluble in water above pH 5.5. Attempts at syntheses via routes similar to those used for the RCQs were rarely successful. These observations led me to propose a re-evaluation of the structure and propose an alternative pyridinium salt structure (Figure 2.1).

The proton NMR peak assignments of the 1D spectrum acquired in methanol- $\mathrm{d}_{4}$ originally made for the amine-linkage structure of PL74 are shown in Figure 2.2, Spectrum A. These assignments were made based on consideration of analogous peak assignments for the RCQ molecules. The amine-linkage structure is consistent with the chemical shifts, integral values, and signal splitting seen in the spectrum. However, a careful examination of the proton NMR spectra in both methanol- $\mathrm{d}_{4}$ and DMSO- $\mathrm{d}_{6}$ gives

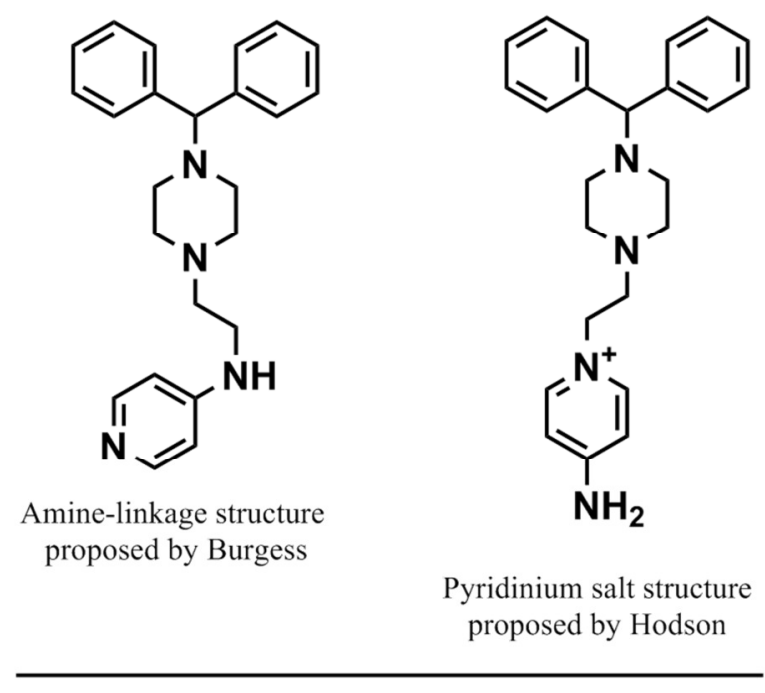

Figure 2.1: Proposed Structures for PL74 
an indication that PL74 might be a pyridinium salt; the NOESY spectrum in methanol- $\mathrm{d}_{4}$ gives the conclusive evidence. For further assurance of the pyridinium structural determination, the PL74 spectra were evaluated in contrast to the analog PL343 spectra; PL343 is not a pyridinium salt but has an amine linkage. My interpretation of the 1D and 2D ${ }^{1} \mathrm{H}$ NMR spectra of PL74 is as follows.

In the ${ }^{1} \mathrm{H}$ NMR spectrum acquired in methanol-d $\mathrm{d}_{4}$ (Figure 2.2, Spectrum A), five peaks appear in the aromatic region. The AA'BB' spin system of the pyridine ring protons give rise to signals at 8.03 and $6.79 \mathrm{ppm}$. Due to the electronegativity of the nitrogen, the two protons closest to the aromatic nitrogen are the most deshielded of the aromatic protons, and so give rise to the peak at $8.03 \mathrm{ppm}$. The shielding from the electron density donated by the amine substituent shifts the second doublet upfield to $6.79 \mathrm{ppm}$. The 10 phenyl protons give rise to three signals at $7.41,7.25$, and $7.16 \mathrm{ppm}$, which integrate to $4 \mathrm{H}, 4 \mathrm{H}$, and $2 \mathrm{H}$, respectively, relative to the $2 \mathrm{H}$ integration of the pyridine doublet at $8.03 \mathrm{ppm}$. There are also five peaks that appear in the aliphatic region in this spectrum. The methine proton signal is a singlet at $4.20 \mathrm{ppm}$ and has a relative integral value of $1 \mathrm{H}$. The ethyl linker chain gives rise to two triplets at $4.15 \mathrm{ppm}$ and $2.74 \mathrm{ppm}$, both with relative integration of $2 \mathrm{H}$. The eight piperazine ring protons are averaged by the chair-flipping of the ring and result in broad signals at 2.53 and 2.38 ppm. The methylene next to the piperazine nitrogen has a micro-environment most like the piperazine and so is assigned to the upfield triplet peak at $2.74 \mathrm{ppm}$. The amine protons are not seen in methanol- $\mathrm{d}_{6}$ because they are exchanged with deuterium from the solvent. The one indication in this spectrum that PL74 is, in fact, the pyridinium salt is 

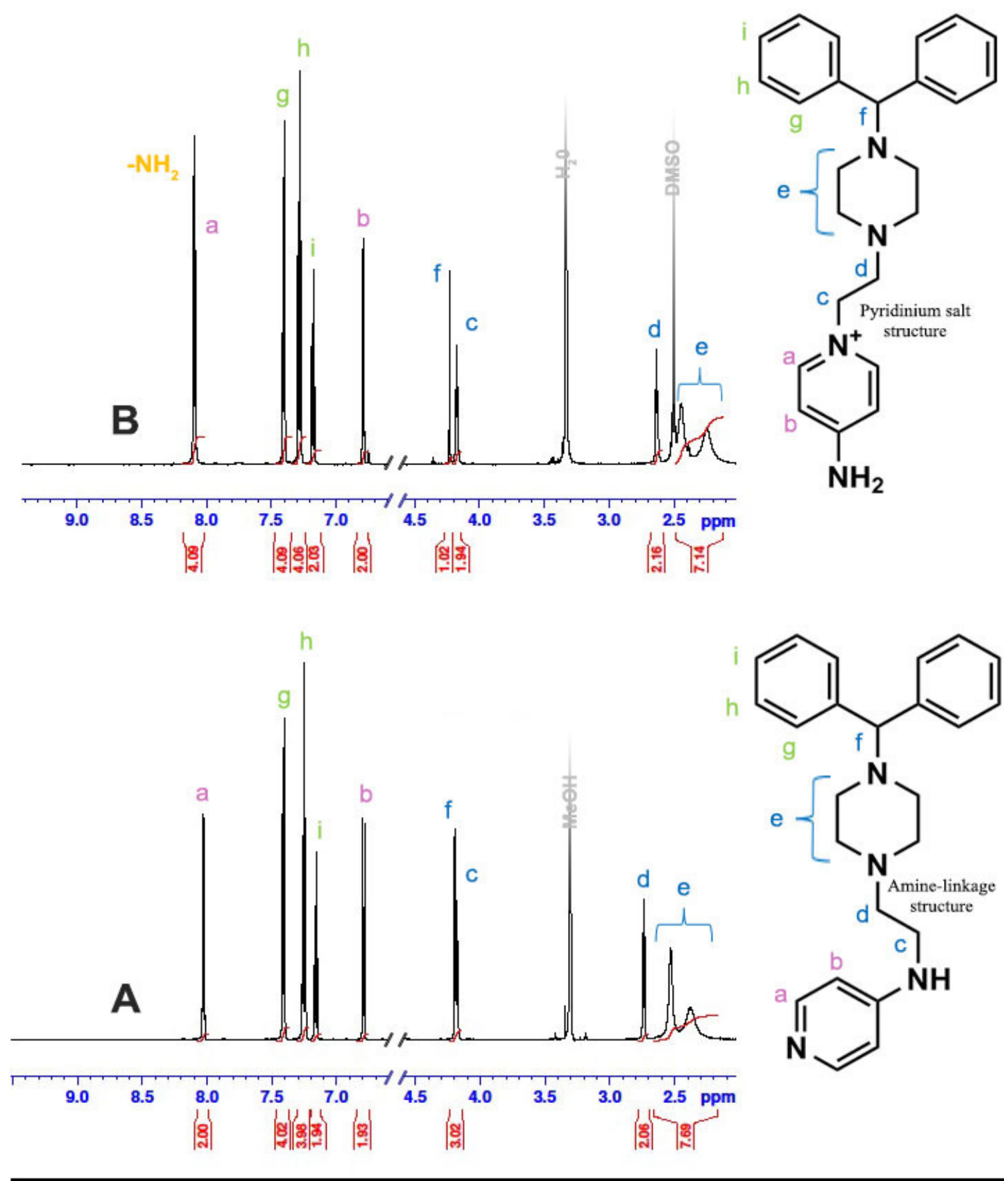

Figure 2.2: Proton NMR Spectra of PL74

Spectrum A: 1-d spectrum in methanol- $\mathrm{d}_{4}$; Spectrum B: 1-d spectrum in DMSO- $\mathrm{d}_{6}$ 
the methylene peak's chemical shift, downfield to $4.15 \mathrm{ppm}$, suggesting that the protons are strongly deshielded; the position next to the aromatic quaternary nitrogen would be expected to lead to a strong deshielding effect, while the amine of the amine-linkage structure would not.

There are two indications of the pyridinium salt structure seen in the DMSO-d ${ }_{6}^{1} \mathrm{H}$ proton spectrum (Figure 2.2: Spectrum B). The amine protons, which would not exchange with the solvent, give rise to a signal at $8.10 \mathrm{ppm}$. This amine peak overlaps with the downfield pyridinium peak, but the two peaks together have the relative integration of $4 \mathrm{H}$; the $2 \mathrm{H}$ increase to the integral value indicates that the amine is a primary amine, as in the pyridinium salt structure, instead of the secondary amine, as in the amine-linkage structure. In addition, when the amine proton signal appears in the spectrum, its nuclear spin will cause additional splitting on the vicinal protons; in the proposed structure, a splitting of the triplet to a doublet of triplets from this additional coupling would be seen. The absence of the additional splitting on the peak at $4.15 \mathrm{ppm}$ (peak c in Figure 2.2B) is a strong indication against the initially proposed structure.

A nuclear Overhauser effect spectroscopy (NOESY) experiment measures the transfer of energy through space between protons that are within about $5 \AA$ of each other; the closer the protons are in space the stronger the effect will be. In the 2D NOESY spectrum (Figure 2.3) a cross peak, indicating energy transfer, correlates the methylene peak at $4.15 \mathrm{ppm}$ to the pyridine peak at $8.03 \mathrm{ppm}$ (indicated by the purple arrow in Figure 2.3). There is no cross peak from the methylene peak at $4.15 \mathrm{ppm}$ to the pyridine peak at $6.79 \mathrm{ppm}$, indicating that these peaks are further apart (region marked by purple 


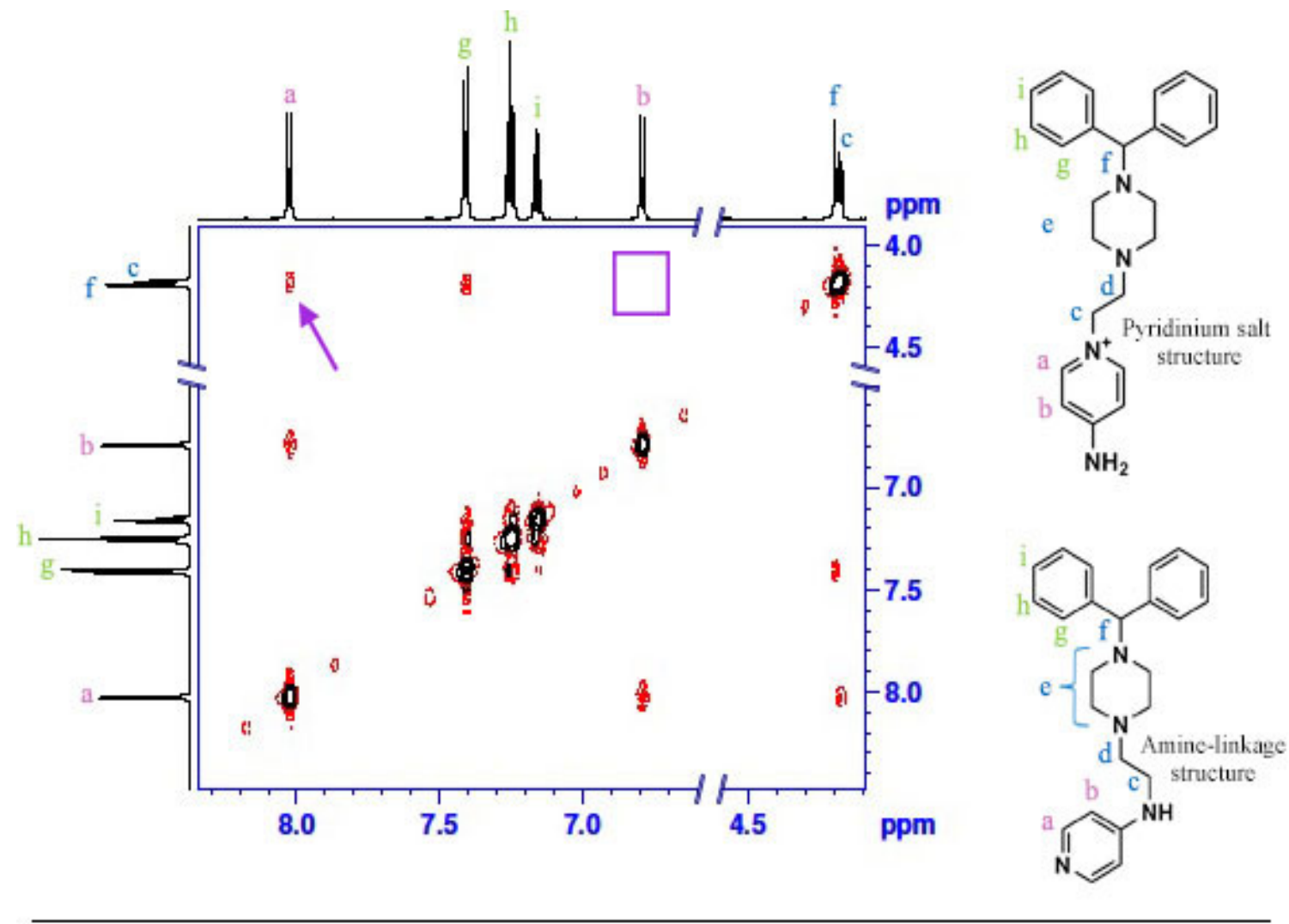

Figure 2.3: NOESY Spectrum of PL74 in Methanol- $\mathrm{d}_{4}$

(Purple arrow indicates cross peak between aromatic peak a and methylene peak c. Purple box around region where a cross peak between peak $\mathrm{b}$ and methylene peak $\mathrm{c}$ would occur.)

box in Figure 2.3). This clearly indicates that the pyridinium structure is the molecule actually synthesized by Burgess.

In the spectra of PL343 (Figures 2.4 and 2.5), the five expected observations are seen for a molecule with an amine linkage between the 4-aminopyridine and the headgroup. In the ${ }^{1} \mathrm{H}$-spectrum recorded in methanol- $\mathrm{d}_{4}$, Figure $2.4 \mathrm{~A}$, the triplet arising from the methylene near the amine is shifted further upfield to $3.51 \mathrm{ppm}$, midway between the piperazine protons at $2.50-2.62 \mathrm{ppm}$ and the methine protons at $4.27 \mathrm{ppm}$. In the ${ }^{1} \mathrm{H}$-spectrum in DMSO-d ${ }_{6}$ (Figure 2.4: Spectrum B), the amine proton peak at 8.51 

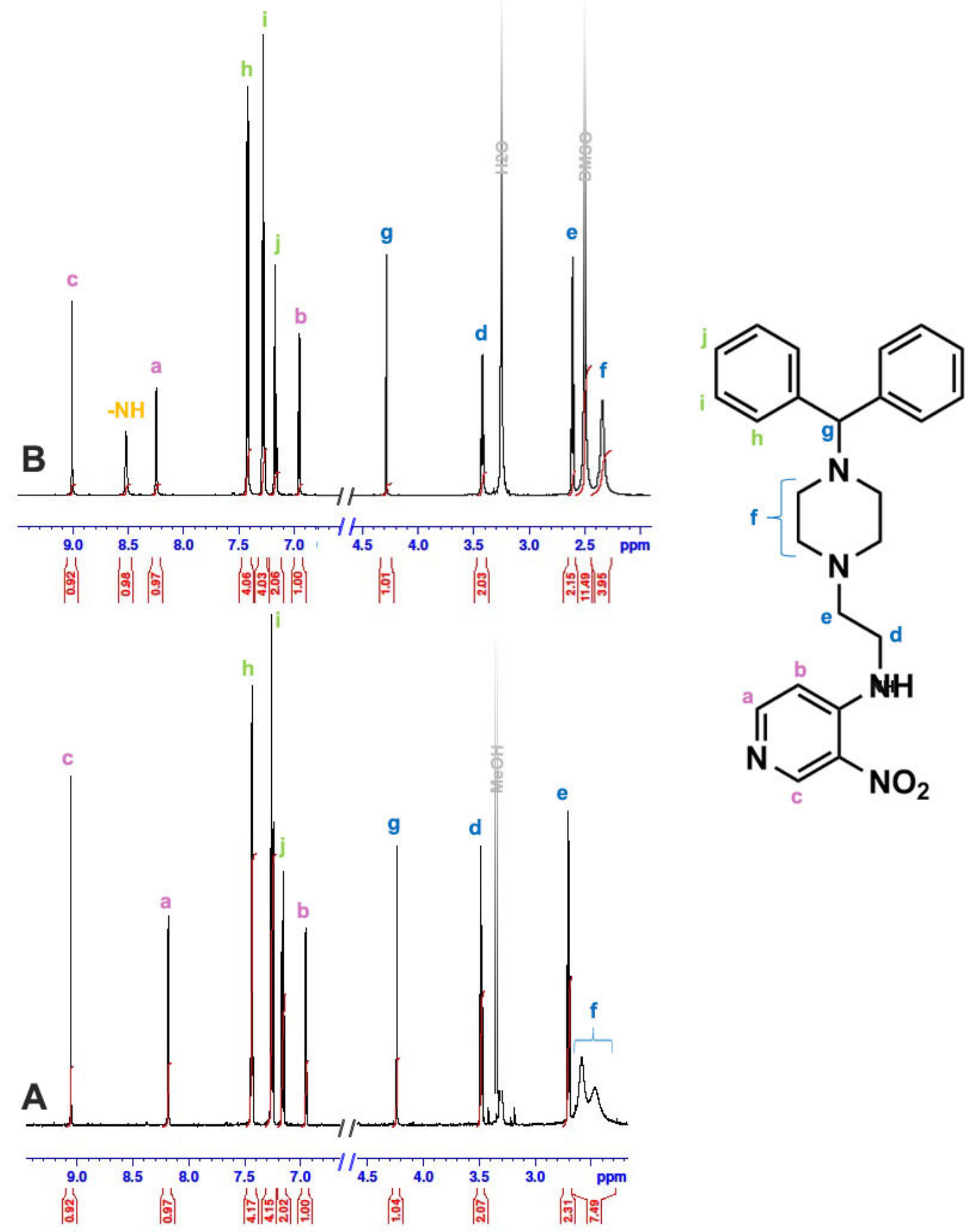

Figure 2.4: Proton NMR Spectra of PL343

Spectrum A: 1-d NMR spectrum in methanol- $\mathrm{d}_{4}$; Spectrum B: 1-d NMR spectrum in DMSO-d $\mathrm{d}_{6}$ 
ppm has a relative integration of only $1 \mathrm{H}$. In the DMSO- $\mathrm{d}_{6}{ }^{1} \mathrm{H}$-spectrum, there is additional splitting from the coupling between the amine proton peak at $8.51 \mathrm{ppm}$ and the adjacent methylene peak at $3.42 \mathrm{ppm}$.

Finally, in the NOESY spectrum acquired in DMSO- $\mathrm{d}_{6}$ (Figure 2.5) there are through-space correlations from the methylene at $3.51 \mathrm{ppm}$ (peak d) to the amine peak at $8.51 \mathrm{ppm}$ and from the methylene peak at $3.51 \mathrm{ppm}$ (peak d) to the pyridine peak at 6.98 ppm (peak b). These five features clearly indicate that PL343 is an analog with an amine-linkage and, when contrasted with the PL74 spectral features, these observations confirm that PL74 does not have the previously reported amine-linkage.
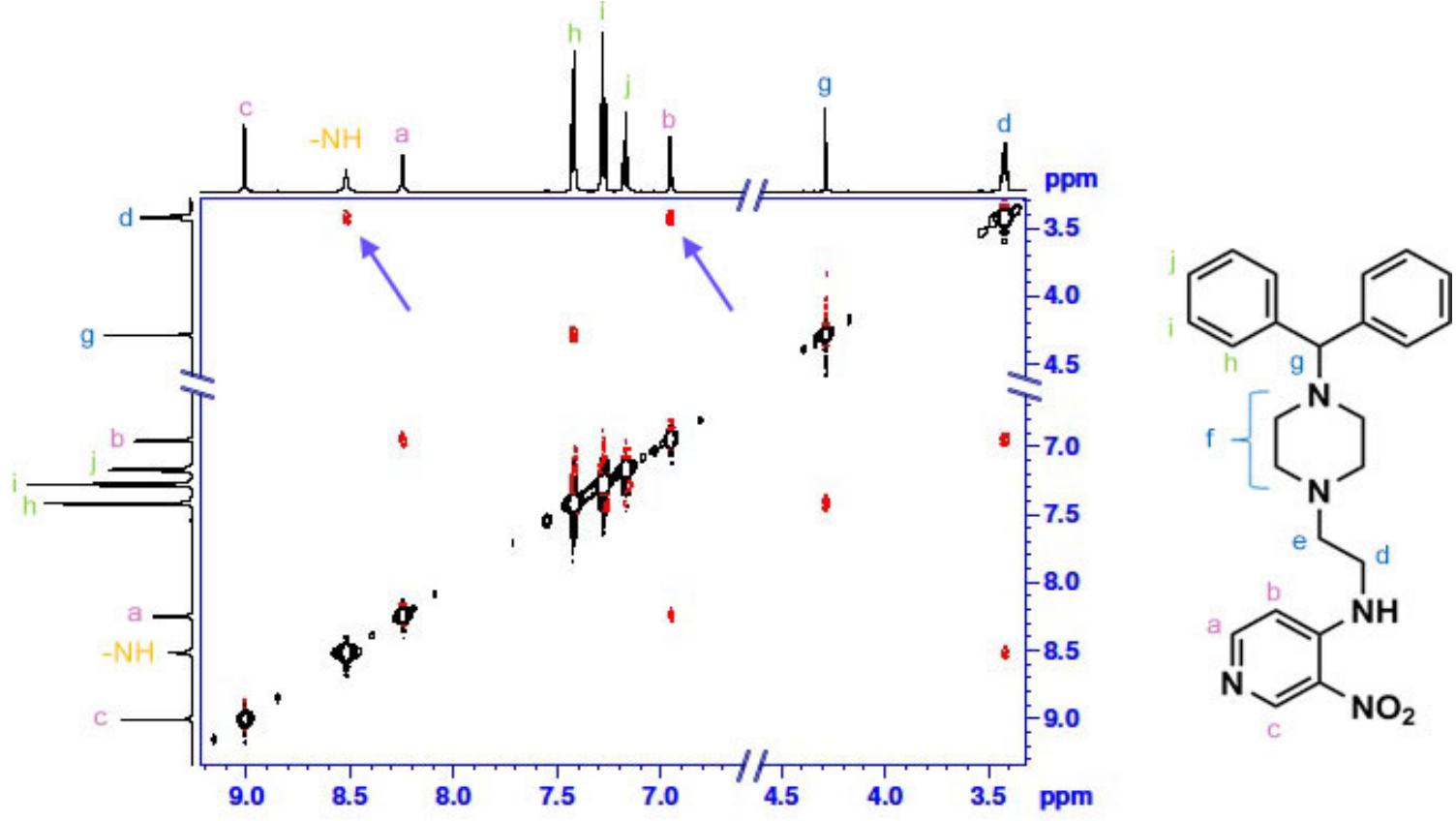

Figure 2.5: NOESY Spectrum of PL343 in DMSO- $\mathrm{d}_{6}$

(Right arrow indicates cross peak from amine proton peak to methylene peak $\mathrm{d}$. Left arrow indicates cross peak from aromatic peak $b$ to methylene peak d.) 
Based on the evidence just presented, the molecule named PL74 has been determined to have a pyridinium salt structure. The "yet-to-be-synthesized" aminelinkage structure will be named PL388 from here forward.

Once the structure of PL74 was determined to be a pyridinium salt, the spectra for each analog I had synthesized were examined to determine which was a pyridinium salt. It was found that every analog that was synthesized using a 4-aminopyridine starting material resulted in a pyridinium salt; while each analog synthesized not using a 4aminopyridine had the expected amine linkage. 


\section{Chapter 3}

\section{Structure Activity Relationship: Part 1}

An SAR study was initiated for the purpose of optimizing in vitro antimalarial activity and to gain insights into the mechanism of action of PL74. The quaternary ammonium moiety is a unique feature among the compounds that have been made in the Peyton laboratory to date. (See Figure 1.12 for examples of Peyton Lab Compounds) The presence of a quaternary ammonium cation and its impact in the conjugated aminopyridine system is therefore of special interest. Analogs with modifications to the pyridine ring and the ethyl linker chain attached to the cationic center were prepared for study and tested for in vitro antimalarial activity. In addition, analogs were prepared and tested to investigate the role of RA-like moiety of this compound.

The general synthesis pathway (Figure 3.1) used for the pyridinium compounds

was the route reported by Steven Burgess. ${ }^{69}$ In this synthesis, chlorodiphenylmethane is combined with 1-(2-hydroxyethyl)piperazine to give PL72. The alcohol is treated with thionyl chloride, then treated with the appropriate 4-aminopyridine in ethanol to yield the PL74 analog. This synthesis was found to be a simple and reliable method. However, attempts to increase the yield of the final step by the addition of base gave the opposite result; several bases were tried, and each attempt resulted in drastically diminished yield. It was found that no base, including using only 1 eq of the amine (as opposed to the 4 eq used by Burgess), led to improved yields for the addition of 4-aminopyridine. 


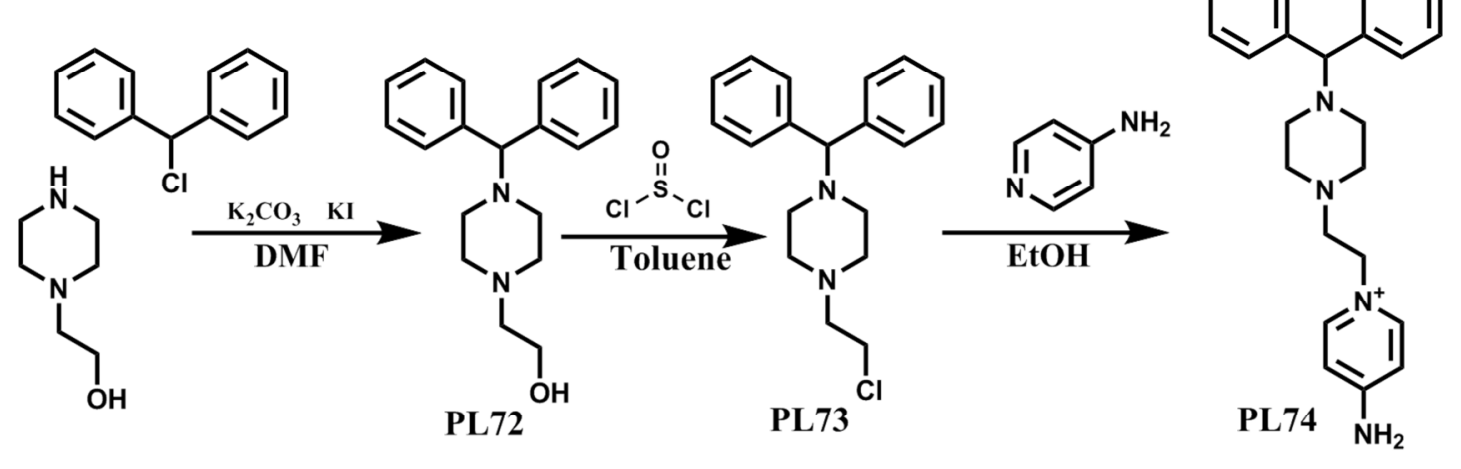

Figure 3.1: Synthesis Pathway for PL74 and Its Analogs

Another synthetic pathway was explored, as shown in Figure 3.2. In this synthesis, the appropriate amine was treated with chloroacetyl chloride, resulting in an acyl pyridinium. The isolated acyl pyridinium was then treated with diphenylmethylpiperazine, followed by reduction with $\mathrm{LiAlH}_{4}$. The acyl pyridinium was very easy to isolate but the yields were $20 \%$, at best. The reduction in the final step was very difficult and resulted in yields below 5\%. Several of the analogs were made by this route but it is not the recommended pathway because of the low yields.

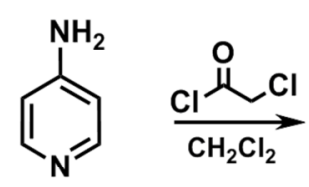<smiles></smiles><smiles>c1ccc(C(c2ccccc2)(c2ccccc2)N2CCNC2)cc1</smiles><smiles></smiles><smiles>Nc1cc[n+](CCN2CCN(C(c3ccccc3)c3ccccc3)CC2)cc1</smiles>

Figure 3.2: Alternative Synthesis Pathway for PL74 Analogs 
The in vitro antimalarial activities of the purified products were measured through drug susceptibility assays against $P$. falciparum parasites in red blood cell culture. ${ }^{63}$ The results shown are measurements carried out in triplicate, and are interpreted as active or inactive; compounds with an $\mathrm{IC}_{50}>2500 \mathrm{nM}$ are considered inactive. Repeat measurements (in triplicate) were made only for PL74. The $\mathrm{IC}_{50}$ reported by Burgess was $\mathrm{IC}_{50}$ of $185 \mathrm{nM}$ against the CQ-sensitive $P$. falciparum $\mathrm{D} 6$ strain and $169 \mathrm{nM}$ against the CQ-resistant $P$. falciparum $\mathrm{Dd} 2$ strain. On a repeat test, PL74 had higher $\mathrm{IC}_{50}$ values of $385 \mathrm{nM}$ against D6 (CQ-sensitive strain) and $245 \mathrm{nM}$ against Dd2 (CQ-resistant strain). This illustrates that there is some variability in the testing; thus smaller fluctuations in $\mathrm{IC}_{50}(<3$ fold $)$ are only considered to be significant if a discernable trend across several compounds was found and not considered significant if the fluctuation involved only a single compound. Also, the higher, more recent results are the ones that will be used for comparison since the $\mathrm{IC}_{50}$ measurements were made at or near the time of testing for the other analogs.

A set of four compounds, PL324, PL325, PL327, and PL328, were made that include substituents on the pyridine ring (Figure 3.3). The methyl and bromine substituents were chosen because they are similar in size (van der Waal volumes of 22.7 $\AA^{3}$ and $23.9 \AA^{3}$, respectively) and have the opposite electronic effects, methyl donating and bromine withdrawing electron density. Analog PL327 was synthesized with a bromine substituent at the ring position alpha to the quaternary ammonium nitrogen but was converted to the methoxy during workup with $100 \%$ conversion. 
The Hammett sigma constant $(\sigma)$ indicates the electronic effect of a substituent on the acid dissociation of benzoic acid; these values can be used as an estimate in other aromatic systems. Negative sigma values indicate that the substituent is donating electrons into the system, and positive values indicate the withdrawal of electrons from the system. The Hammett constant is dependent on the position on the ring, relative to the carboxy moiety. In the meta-position, the substituent effect is inductive; in the para-position, there is both an inductive and resonance effect. The resonance effect can be estimated by the difference of the para- and meta-values.

Literature $\sigma_{\text {meta }}, \sigma_{\text {para }}$ and the difference for the bromo, methyl, and methoxy substituents are given in Table 3.1 .

The substituent effect in the orthoTable 3.1 The Hammett Substituent Constants $(\sigma)$ Based on Ionization of Benzoic Acid ${ }^{72}$

position is more complicated in that it includes a steric effect in addition to the inductive and resonance effects, and $\sigma_{\text {ortho }}$ is

\begin{tabular}{lccc}
\hline Substituent & $\sigma_{\text {meta }}$ & $\sigma_{\text {para }}$ & $\sigma_{\text {para }}-\sigma_{\text {meta }}$ \\
\hline Bromo & 0.391 & 0.232 & -0.159 \\
\hline Methyl & -0.069 & -0.107 & -0.038 \\
\hline Methoxy & 0.115 & -0.268 & -0.383 \\
\hline Amino & -0.016 & -0.66 & -0.64 \\
\hline Methylamino & --- & -0.84 & --- \\
\hline
\end{tabular}
generally not used. The closer the substituent is to the reaction center, the more enhanced the effect will be; when the reaction center is in the ring, the substituent effect is enhanced. The Hammett Equation cannot be rigorously applied to determine specific effects in the complex pyridinium system. (It is also not accurate to apply the nomenclature positions ortho, meta and para for the relationship to the quaternary ammonium cation in the ring, however to simplify this discussion and stay in step with the Hammett constants, ortho-to-the-cation and meta-to-the-cation will be used.) It can be said that at the position meta-to-the-cation, the methyl will be electron donating and 
the bromo will be electron withdrawing. Also, it can be said that at the position ortho-tothe-cation it is not clear if the methyl and methoxy groups are electron donating or withdrawing because of the steric contribution, but their effect may have a strong impact on the reaction center because of their close proximity to the cation.

The analogs, PL324, PL325, PL327, and PL328, all show in vitro antimalarial activity for both the CQ-sensitive and CQ-resistant strains; the $\mathrm{IC}_{50}$ values are shown in Table 3.2. From these results it can be seen that substituents on the ring are generally tolerated. With the addition of electron-donating methyl substituents on PL324 and PL325 and the electron-withdrawing bromo substituent on PL328, there was little change<smiles>Cc1cc(N)cc[n+]1CCN1CCN(C(c2ccccc2)c2ccccc2)CC1</smiles>

PL324<smiles>Cc1c[n+](CCN2CCN(C(c3ccccc3)c3ccccc3)CC2)ccc1N</smiles>

PL325<smiles>COc1cc(N)cc[n+]1CCN1CCN(C(c2ccccc2)c2ccccc2)CC1</smiles>

PL327<smiles>Nc1cc[n+](CCN2CCN(C(c3ccccc3)c3ccccc3)CC2)cc1Br</smiles>

PL328

Figure 3.3: Analogs with Pyridine Ring Substituents

from the antimalarial activity of PL74.

With the addition of a methoxy group on

PL327, there is a significant drop in antimalarial activity .

The general tolerance for the

\begin{tabular}{lcc}
\hline $\begin{array}{l}\text { Table 3.2: } \mathrm{IC}_{50} \text { Values of Analogs with Pyridine } \\
\text { Ring Substituents (PL74 } \mathrm{IC}_{50} \text { included for } \\
\text { comparison) }\end{array}$ \\
\hline & $\begin{array}{c}\mathrm{IC}_{50} \text { (nM) D6 } \\
(\mathrm{CQ}-\text { Sensitive) }\end{array}$ & $\begin{array}{l}\mathrm{IC}_{50} \text { (nM) Dd2 } \\
\text { (CQ-Resistant) }\end{array}$ \\
\hline PL74 & 385 & 245 \\
\hline PL324 & 344 & 229 \\
\hline PL325 & 539 & 378 \\
\hline PL327 & 1529 & 836 \\
\hline PL328 & 433 & 300 \\
\hline
\end{tabular}


addition of substituents to the pyridine ring suggests that at the site of action there is space to accommodate the substituents as the compound performs its mechanism of antimalarial action. This advantageous characteristic allows for future SAR investigations and possibly increasing the functionality of this compound.

The methoxy substituent was not tolerated in the position ortho-to-the-cation, while the methyl was tolerated. The electron contribution of the methoxy is unclear but it certainly has a much larger capacity for electron donation through resonance than the methyl substituent. If the steric constraints at this location allow for resonance, then it may be that methoxy has a strong electron-donating effect and the resulting decreased cationic charge is disfavored. However, if the steric constraints hinder resonance, then the electron-withdrawing inductive effect of the oxygen in close proximity may be the result of increased cationic charge being disfavored.

Analogs PL342, PL330, PL165 and PL240 show further examples of analogs that may perturb the electronic nature of the quaternary aromatic nitrogen (Figure 3.4). Analog PL342 has a methylamine substituent instead of a primary amine at a position para-to-the-cation. The methylamine has a greater electron-donating ability than the amine substituent, indicated by the larger negative sigma values (Table 3.1). A slight increase in antimalarial activity is seen for PL342 in comparison to PL74, indicated by the $\mathrm{IC}_{50}$ that is lower than the $\mathrm{IC}_{50}$ of PL74. The small increase is insignificant by the evaluation standard set forth in this dissertation. However, the increase is still enough to prompt the design of analogs that include stronger electron-donating substituents at this location for future SAR studies. 


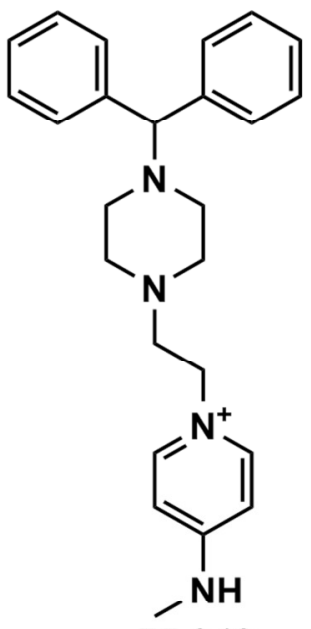

PL342

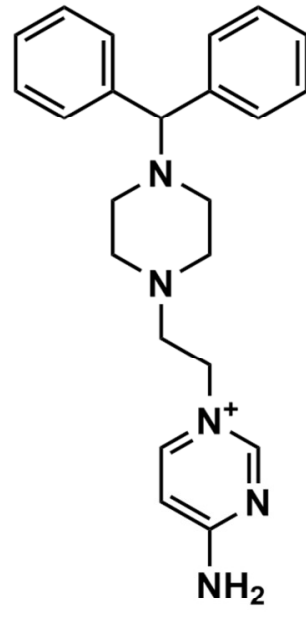

PL330

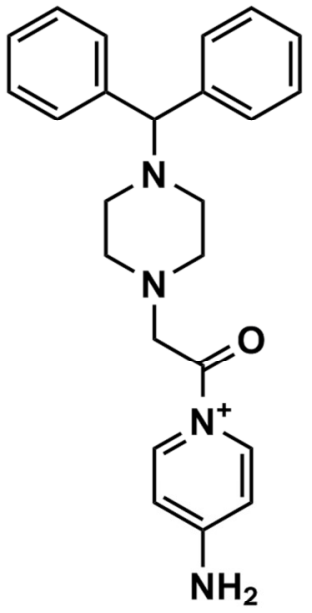

PL165<smiles>Nc1cc[n+](CC(=O)N2CCN(C(c3ccccc3)c3ccccc3)CC2)cc1</smiles>

PL240

Figure 3.4: PL74 Analogs

The second aromatic nitrogen in

PL330 serves as an electron sink by

Table 3.3: IC $_{50}$ Values for PL330, PL342, PL240, and PL165 (PL74 IC 50 included for comparison)

inductive effects, strongly drawing electron

density away from the quaternary nitrogen.

The carbonyl group of PL165 also serves as

an even stronger electron-withdrawing

$\mathrm{IC}_{50}(\mathrm{nM}) \mathrm{D} 6 \quad \mathrm{IC}_{50}(\mathrm{nM}) \mathrm{Dd} 2$ (CQ-sensitive) (CQ-resistant)

\begin{tabular}{lrr}
\hline PL74 & 385 & 245 \\
\hline PL342 & 266 & 206 \\
\hline PL330 & 1880 & 1385 \\
\hline PL165 & $>2500$ & $>2500$ \\
\hline PL240 & 647 & 984 \\
\hline
\end{tabular}

influence on the quaternary ammonium. The more distant carbonyl in PL240 has only a minor inductive effect on the quaternary ammonium. PL240, PL330 and PL165 all show a drop in antimalarial activity; the magnitudes of the loss of activity increases with the strength of electron-withdrawing modification (Table 3.3). Strong electron-withdrawing effects reduce the antimalarial activity. The increase of the cationic charge seems to be disfavored. 
In the analogs PL238, PL236, PL232 (Figure 3.5), the functionality of the RA-like moiety is incrementally subtracted. This series was planned to help determine which parts of the RA-like moiety are essential for antimalarial activity and/or reversal activity for CQ-resistant strains. It was envisioned that a loss of antimalarial activity against the resistant strain might be seen earlier in the series than the loss of activity against sensitive strain. Instead, a most surprising result was seen: there is total loss of antimalarial activity with the removal of even one phenyl ring (Table 3.4).

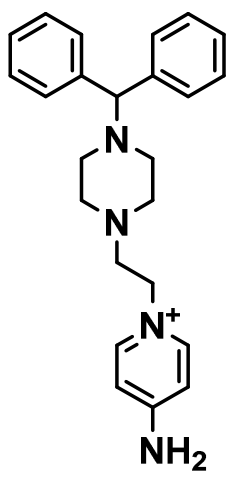

PL74

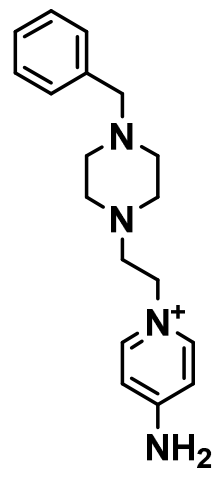

PL238<smiles>CN1CCN(CC[n+]2ccc(N)cc2)CC1</smiles>

PL236

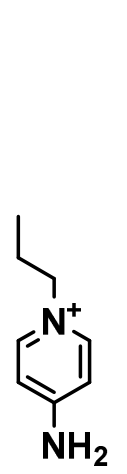

PL232<smiles>Nc1cc[n+](CN2CCC(Cc3ccccc3)CC2)cc1</smiles>

PL297

Figure 3.5: Analogs with RA Modifications

However, with the removal of a nitrogen from the piperazine ring, the loss of a phenyl ring is tolerated as shown by the activity of PL297, possibly indicating that it is the exposure of the nitrogen that is the underlying cause for activity loss.
Table 3.4: IC $_{50}$ Values for PL238, PL236, and PL232 ( $\mathrm{IC}_{50}$ of PL74 included for comparison)

\begin{tabular}{lcc}
\hline & $\begin{array}{c}\mathrm{IC}_{50}(\mathrm{nM}) \mathrm{D6} \\
(\mathrm{CQ}-\text { sensitive })\end{array}$ & $\begin{array}{c}\mathrm{IC}_{50}(\mathrm{nM}) 7 \mathrm{G} 8 \\
(\mathrm{CQ}-\text { resistant })\end{array}$ \\
\hline PL74 & 385 & $345(\mathrm{Dd} 2)$ \\
\hline PL238 & $>2500$ & $>2500$ \\
\hline PL236 & $>2500$ & $>2500$ \\
\hline PL232 & $>2500$ & $>2500$ \\
\hline PL297 & 654 & $371(7 \mathrm{G} 8) / 684(\mathrm{Dd} 2)$ \\
\hline
\end{tabular}


The sensitivity to RA modifications is a very different than what is seen for the Reversed-CQ SAR. For quinoline analogs, PL06 and DM1020, the change from two phenyl rings to one showed no loss of antimalarial activity. ${ }^{69}$ PL110, PL91 and PL228, reveals a series of further RA modifications that led to significant increases in antimalarial activity (see Figure 3.6). ${ }^{73}$ The intolerance for modification to the RA moiety implies that the entirety of PL74 is the antimalarial pharmacophore. In this, PL74 analogs demonstrate a drastic departure from Reversed-CQ-like behavior, possibly indicating a mode of action other than the inhibition of hemozoin.

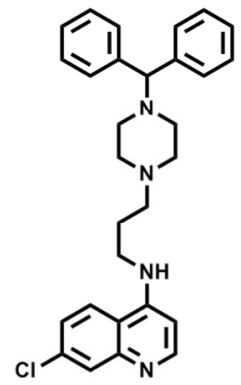

PL06

$\mathrm{IC}_{50}: 2.4 \mathrm{nM}$ D6 $\mathrm{IC}_{50}: 3.7 \mathrm{nM} \mathrm{Dd} 2$<smiles>CC(C)c1ccc(N2CCN(CCCNc3ccnc4cc(Cl)ccc34)CC2)cc1</smiles>

PL110

$\mathrm{IC}_{50}: 0.7 \mathrm{nM}$ D6 $\mathrm{IC}_{50}: 0.6 \mathrm{nM} \mathrm{Dd} 2$

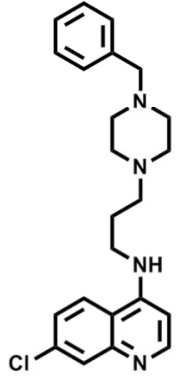

DM1020

$\mathrm{IC}_{50}: 2.4 \mathrm{nM}$ D6 $\mathrm{IC}_{50}: 7.0 \mathrm{nM} \mathrm{Dd} 2$

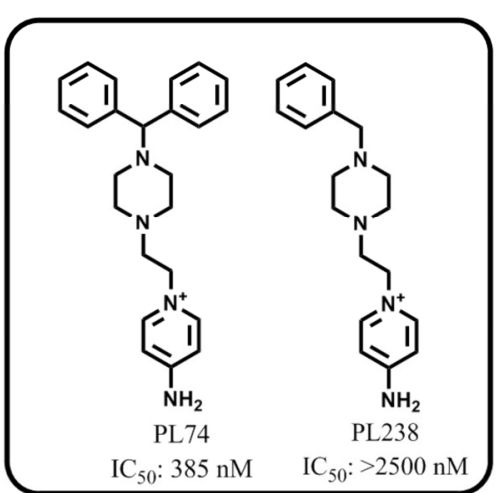<smiles>Clc1ccc2c(NCCCN3CCN(c4ccccc4)CC3)ccnc2c1</smiles><smiles>Clc1ccc2c(NCCCN3CCN(CC4CCCCC4)CC3)ccnc2c1</smiles>

PL228 $\mathrm{IC}_{50}: 0.2 \mathrm{nM}$ D6 $\mathrm{IC}_{50}: 2.4 \mathrm{nM} \mathrm{Dd} 2$

Figure 3.6: Reversed-CQ Compounds with RA Modifications

(Compounds synthesized by Steven Burgess and Bornface Gunsaru with PL74 and PL238 included for comparison) 
The inactivity of PL238, while differing from PL74 by the loss of a single phenyl, suggests the possibility of an antimalarial different from the Reversed-CQs, and so possibly an enzyme binding site. The regain of activity with the change to a piperidine ring in PL297 may be showing the lipophilicity of a binding site. These indications of a possible new mechanism of antimalarial activity warrants further investigation. 


\section{Chapter 4}

\section{Structure Activity Relationship: Part 2}

In the course of the SAR study, several analogs synthesized were made with the pyridine ring attached to the head group via an amine linkage. It was surprising to find that there is also antimalarial activity among these compounds. Eight compounds are presented. Although the eight compounds comprise a sparse and somewhat disjointed SAR study, they raise some interesting questions regarding the activity of the aminelinkage compounds.

The compounds were purified and the in vitro antimalarial activities were measured in triplicate through drug susceptibility assays against $P$. falciparum parasites

in red blood cell culture. ${ }^{63}$ As before, the results are interpreted as active or inactive; compounds with an $\mathrm{IC}_{50}>2500 \mathrm{nM}$ are considered inactive.

PL167 is the most active antimalarial compound among this group. PL167 is based on the 3-aminopyridine and was synthesized via the alternate synthetic route for the pyridinium salts; in this case the amine substituent acts as the nucleophile leading to the amine linkage, instead of the aromatic nitrogen acting as the nucleophile leading to the pyridinium salt as with 4-aminopyridine. The synthesis pathway is shown in Figure 4.1. PL169 was also made in this same reaction sequence but starting with the 2aminopyridine. The syntheses of the remaining analogs are quite varied and given in Chapter 7. 
<smiles>Nc1cccnc1</smiles><smiles>CCCCC(C)C(=O)CCl</smiles>

PL171

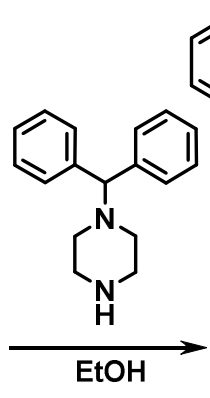

$\|_{N}$

PL166

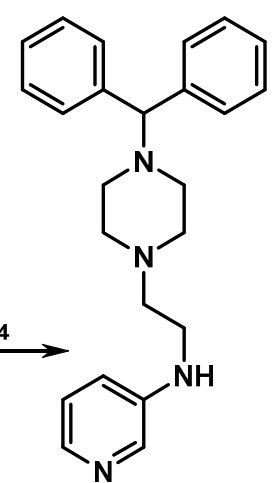

PL167

Figure 4.1: Synthesis Pathway for PL167

Upon in vitro testing, PL167 showed good antimalarial activity, with an $\mathrm{IC}_{50}$ of $450 \mathrm{nM}$ against D6 (a CQ-sensitive strain) and $173 \mathrm{nM}$ against Dd2 (a CQ-resistant strain). While PL167, based on 3-aminopyridine, is an active compound, PL169, based on the 2-aminopyridine, is inactive (Figure 4.2, Table 4.1). This is not the expected result based on the quinoline compounds. In an SAR study of aminoquinolines, Egan found that 2-aminoquinoline and 4-aminoquinoline derivatives which are conjugated had strong antimalarial activity while the 3 -aminoquinoline did not. ${ }^{54}$ Egan also found that the 4aminoquinoline derivatives had better antimalarial activity than the 2-aminoquinoline derivatives. $^{54}$ The strong antimalarial activity of PL169, the 3-aminopyridine derivative, is uncharacteristic of the aminoquinoline antimalarial activity suggested by Egan.

PL360 is an analog of particular interest in that it was designed as a pyridine mimic of CQ to address the question of whether or not these pyridine-based compounds are recognized by the CQ resistance mechanism (Figure 4.2). It was hypothesized that if 
<smiles>c1ccc(NCCN2CCN(C(c3ccccc3)c3ccccc3)CC2)cc1</smiles>

PL76<smiles>c1ccc(C(c2ccccc2)N2CCN(CCNc3ccccn3)CC2)cc1</smiles>

PL169<smiles>c1ccc(C(c2ccccc2)N2CCN(CCNc3cccnc3)CC2)cc1</smiles>

PL167<smiles>CCN(CC)CCCC(C)Nc1ccncc1</smiles>

PL360<smiles>CCN(CC)CCCC(C)Nc1ccnc2cc(Cl)ccc12</smiles>

CQ<smiles>c1ccc(C(c2ccccc2)N2CCN(CCNCc3ccncc3)CC2)cc1</smiles>

PL215<smiles>O=C(NCCN1CCN(C(c2ccccc2)c2ccccc2)CC1)c1ccncc1</smiles>

PL329<smiles>O=[N+]([O-])c1cnccc1NCCN1CCN(C(c2ccccc2)c2ccccc2)CC1</smiles>

PL343<smiles>Oc1cnccc1NCCN1CCN(C(c2ccccc2)c2ccccc2)CC1</smiles>

PL350

Figure 4.2: Amine-Linkage Analogs

Table 4.1: $\mathrm{IC}_{50}$ Values of Analogs of Analogs with Amine Linkage ( $\mathrm{IC}_{50}$ of PL74 included for comparison)

\begin{tabular}{lcc} 
& $\begin{array}{c}\mathrm{IC}_{50}(\mathrm{nM}) \mathrm{D6} \\
(\mathrm{CQ}-\text { Sensitive })\end{array}$ & $\begin{array}{c}\mathrm{IC}_{50}(\mathrm{nM}) \mathrm{Dd} 2 \\
(\mathrm{CQ}-\text { Resistant })\end{array}$ \\
\hline PL74 & 385 & 245 \\
\hline PL76 & $>2500$ & $>2500$ \\
\hline PL167 & 450 & 173 \\
\hline PL169 & $>2500$ & $>2500$ \\
\hline PL215 & $>2500$ & 1267 \\
\hline PL329 & $>2500$ & $>2500$ \\
\hline PL343 & $>2500$ & 1957 \\
\hline PL350 & 851 & 2030 \\
\hline PL360 & $>2500$ & $>2500(7 \mathrm{G} 8)$ \\
\hline
\end{tabular}


this CQ mimic is active against the CQ-sensitive strain and not against the CQ-resistant strain, then it may be concluded that the activity of the pyridine moiety is similar to the quinoline moiety. Antimalarial testing resulted in an $\mathrm{IC}_{50}>2500 \mathrm{nM}$ for both $\mathrm{D} 6$ (a CQsensitive strain) and 7G8 (a CQ-resistant strain). If there is CQ-like antimalarial activity that arises from the 4-aminopyridine, it should be seen in this analog. The inactivity of PL360 suggests that the aminopyridine moiety does not completely encompass the antimalarial activity of the amine-linkage molecules; more than the aminopyridine seems necessary for activity.

PL350, a 4-aminopyridine-based compound, is the closest analog to the aminelinkage structure first proposed for PL74 (and now referred to as PL388); PL350 differs by the addition of a 3-hydroxy substituent (Figure 4.2). Upon in vitro testing PL350 showed antimalarial activity against the sensitive strain, with an $\mathrm{IC}_{50}$ of $851 \mathrm{nM}$ against D6 (a CQ-sensitive strain) and $2030 \mathrm{nM}$ against Dd2 (a CQ-resistant strain), making PL350 the only molecule in this study to show the significant reduction of reversal agent activity with retention of antimalarial activity. A general trend that is seen among the pyridine and quinoline compounds is that for a given compound the $\mathrm{IC}_{50}$ value is lower against the CQ-resistant strain than against the CQ-sensitive strain. The trend can be seen in the compounds in this study (Table 4.1). The trend may be a reflection of the fitness level of the strains. The adaptations that endow a strain with drug resistance seem to be costly in terms of overall fitness as shown by competitive growth measurements. ${ }^{66}$ With strain fitness in mind, the $\mathrm{IC}_{50}$ results for PL350 being 2.5 times higher against the resistant strain than against the sensitive strain is a significant result. It is interesting that 
in this molecule the reversal agent activity seems to be uncoupled from the antimalarial activity and yet no modifications have been made to what is perceived as the reversal agent portion of the molecule. This may be an important design lead for investigation of the essential moiety for the reversal of CQ resistance in further SAR studies of the aminelinkage compounds.

PL343 is arranged like PL350 but has a 3-nitro group instead of a 3-hydroxy group; PL343 has an $\mathrm{IC}_{50}$ of >2500 nM for D6 (a CQ-sensitive strain) and $1957 \mathrm{nM}$ for Dd2 (a CQ-resistant strain). It is interesting that the change from the 3-hydroxy to the 3nitro substituent changes the CQ-sensitive antimalarial activity from $851 \mathrm{nM}$ to inactive, while the CQ-resistant antimalarial activity is the same for both (Table 4.2).

PL215 and PL329 have a carbon moiety inserted between the secondary amine and the pyridine ring (Figure 4.2). For PL329, the carbon moiety is a carbonyl and the compound is inactive against both strains. For PL215, the carbon moiety is a methyl group and the compound is inactive against D6 (a CQ-sensitive strain) but retains slight activity against Dd2 (a CQ-resistant strain). In addition, PL76 is based on a phenyl moiety instead of a pyridine moiety and is found to be inactive for both the CQ-sensitive and CQ-resistant strains, suggesting that the aromatic nitrogen is an essential moiety for in vitro antimalarial activity. Certainly, a more thorough SAR study is needed to elucidate the pattern of antimalarial activity among the amine-linkage molecules. 


\section{Chapter 5}

\section{Quaternary Ammonium Compounds}

Because the range among antimalarial drugs is limited in terms of number of unique targets, and because cross-resistance to all deployed drugs continues to emerge, it is urgent that new antimalarials continue to be developed with some priority given to molecules that have modes of action different from those currently in use. If PL74 has a unique mode of antimalarial action, as suggested in the SAR study, then it is important that we explore this compound further to gain understanding of its antimalarial mode of action and its suitability as a lead compound for drug development.

A survey of literature reveals rich veins of research into applications for quaternary ammonium compounds. The work of Dr. Henri Vial and associates at University of Montpellier II shows a relentless pursuit of understanding of the biogenesis of phospholipids in P. falciparum and the rational design of novel choline inhibitors as antimalarials (References included in discussion). A careful look at the work to elucidate the mode of action of their lead compound gives insight into a possible mechanism of activity and a possible direction for future work to optimize PL74 into a drug.

\section{The Antimalarial Action of Albitiazolium}

The P. falciparum blood stage proliferation process demands the biosynthesis of large amounts of phospholipids for the construction of membranes. From the time of the 
parasite's invasion of the red blood cell (RBC) until the rupture of the cell 48 hours later, the phospholipid content of the cell increases 500-600 fold. ${ }^{74-76}$ Because the increased amount of phospholipids is essential for the maturation and replication of the parasite, the phospholipid synthesis process is an attractive target to consider for drug development. ${ }^{77}$

The biosynthesis of phospholipids in P. falciparum is well known. ${ }^{78-81}$ The majority of the phospholipids are phosphatidylcholine (40-50\%) and phosphatidylethanolamine $(35-45 \%) .{ }^{82}$ An overview of these synthetic pathways is shown in Figure 5.1. The production of phosphatidylcholine begins with the uptake of host choline into the infected RBC. The uptake occurs mainly via a saturatable process, and occurs through the erythrocyte choline transporter. One quarter of the choline enters via the New Permeation Pathway (NPP) which is a parasite-induced channel in the membrane of the erythrocyte. ${ }^{83-87}$ The choline is further transported through the parasite membranes through a dedicated choline transporter. ${ }^{88}$ The capacity of the transporters of choline through the erythrocyte membrane is much lower than the capacity of the transporters through the parasite membranes, making the trans-erythrocyte membrane transport the probable rate-limiting step. ${ }^{88}$ Choline is transformed to phosphocholine in the cytosol of the parasite, then to cytidine diphosphate choline, and finally to phosphatidylcholine via choline kinase, CTP-phosphocholine cytidylyltransferase, and choline/ethanolamine phosphotransferase.

Phosphatidylethanolamine is made from ethanolamine. Ethanolamine diffuses from the plasma through both the erythrocyte and parasite membranes into the cytosol, or is made by decarboxylation of serine. ${ }^{78-81}$ The serine is either imported or captured from 
hemoglobin degradation products. In the same manner as choline, ethanolamine is transformed to phosphoethanolamine, then to cytidine diphosphate ethanolamine, and finally to phosphatidylethanolamine via ethanolamine kinase, CTP-phosphoethanolamine cytidylytransferanse, and choline/ethanolamine phosphotransferase. In addition, phosphoethanolamine can be converted to phosphocholine by methylation via the phosphoethanolamine methyltransferase. In the same way, phosphatidylethanolamine can be converted to phosphotidylcholine (Figure 5.1).

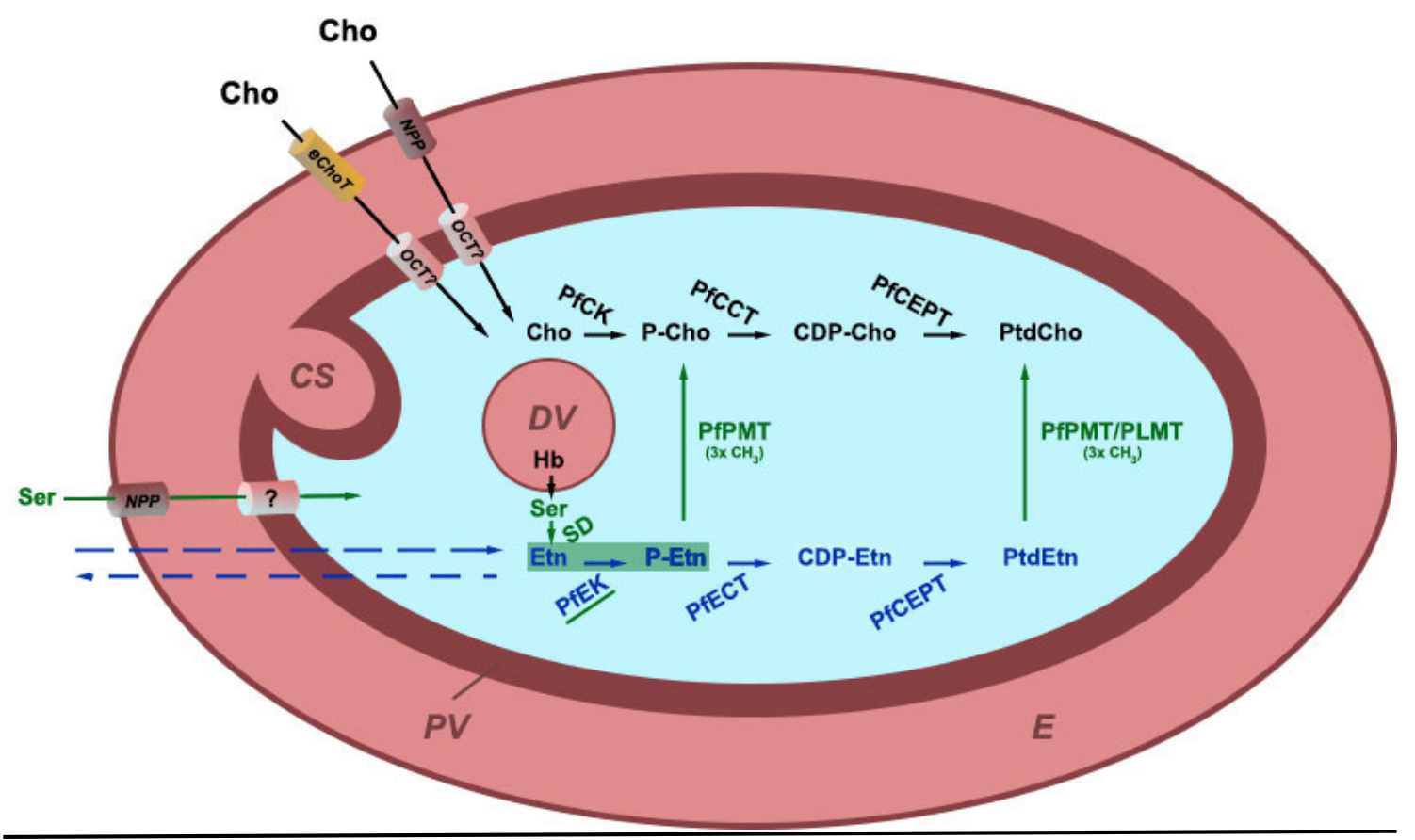

Figure 5.1: Biosynthetic Pathways of Phospholipids

Remake of graphic from ChemMedChem 2012, 7, 22-31

Compartments: E: erythrocyte, CS: cytosome, PV: parasitophorous vacuole, DV: digestive vacuole Transporters : NPP: new permeation pathway; OCT: organic-cation transporter; eChoT:erythtocyte choline transporter

Enzymes: PfCK: choline kinase; PfCCT: CTP-phosphocholine cytidylyltransferase; PfCEPT: choline/ethanolamine cytidylyltransferase; PfPMT: phosphoethanolamine methyltransferase; PLMT: phospholipid methyltransferace; SD: serine decarboxylase

Substrates: Cho: choline; P-Cho: phosphocholine; CDP-Cho: cytidine diphosphate choline; PtdCho: phosphatidylcholine; P-Etn: phosphoethanolamine; CDP-Etn: cytidine diphosphate ethanolamine; PtdF.tn: nhosnhatidvlethanolamine: Hh: heme: Ser: serine: Ftn: ethanolamine 
The pathways from choline to phosphatidylcholine (Figure 5.1: shown in black) and from ethanolamine to phosphatidylethanolamine (Figure 5.1: shown in blue) are known as the Kennedy pathways, and are highly conserved in eukaryotes. The pathway from serine to phosphoethanolamine via decarboxylation and then to phosphocholamine via methyltransferase has been identified in P. falciparum but is more plant-like in nature; this pathway is named the serine decarboxylation-phosphoethanolamine methylation (SDPM) pathway (Figure 5.1: shown in green). ${ }^{78-81}$

The Vial group set out to identify choline analogs with antimalarial activity. By the screening of ammonium salts for antimalarial activity, several such analogs were discovered. ${ }^{89-91}$ By comparing and contrasting the active and inactive molecules, it was seen that the antimalarial activity was increased by the addition of a 10-to-12 carbon chain and by adding lipophilic bulk around the nitrogen, creating a head group between 200 and $400 \AA^{3} .^{91}$ A selection of a few of the more active compounds found from their SAR studies are shown in Figure 5.2.

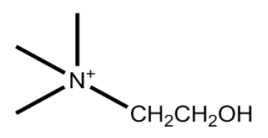

Choline
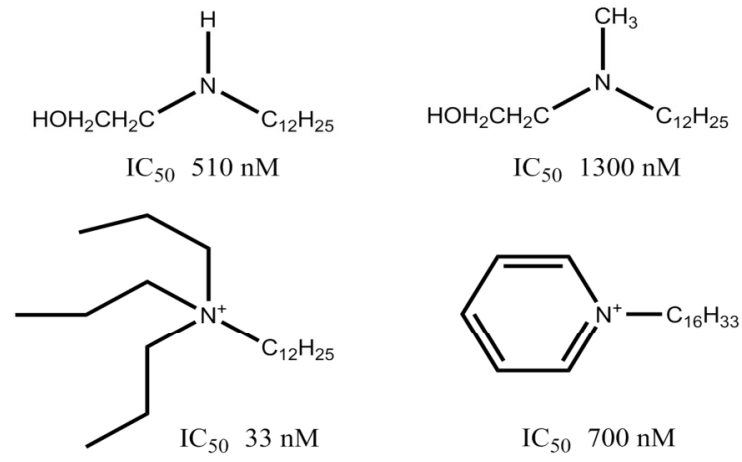

Figure 5.2: Choline Analogs 
The potential potencies of these compounds were revealed when bis-ammonium salts were formed by tethering a set of duplicate ammonium compounds together with a long carbon chain. From compounds shown in Figure 5.3, it can be seen that changing the original mono-structure to a bis-structure can lead to a large improvement in antimalarial activity, shown by the decrease in $\mathrm{IC}_{50}$ values. $^{90}$

G25 and MS1 both showed good antimalarial activity in vitro as indicated by the $\mathrm{IC}_{50}$ values shown. ${ }^{90,91}$ In addition, both G25 and MS1 showed potent activity in vivo when administered intraperitoneally to $P$. vinckei-infected mice; their $\mathrm{ED}_{50}$ values were $0.22 \mathrm{mg} / \mathrm{kg}$ and $1.6 \mathrm{mg} / \mathrm{kg}$, respectively. Further testing for compound G25 revealed its potency against $P$. falciparum in Aotus monkeys; a complete cure was achieved at a dose of $0.30 \mathrm{mg} / \mathrm{kg}$. In spite of the good results seen for both of these bis-quaternary compounds, they were found to have bioavailability problems on oral administration that was attributed to the low permeability of the gastero-intestinal barrier to the permanent cationic charges. $^{90,91}$

T3 was chosen as the Vial group's lead molecule because it was envisioned that a neutral pro-drug could be designed that would improve the oral availability of the drug. ${ }^{90,91}$ The neutral pro-drug (Pro-T3) is transformed to the drug by the enzymatic action of an esterase. ${ }^{91} \mathrm{~T} 3$ and Pro-T3 have very good antimalarial activity in vitro against $P$. falciparum; the $\mathrm{IC}_{50}$ of $\mathrm{T} 3$ is $2.25 \mathrm{nM}$ and the $\mathrm{IC}_{50}$ of Pro-T3 is $3.0 \mathrm{nM}^{91}$ In addition T3 showed good activity in vivo when administered intraperitoneally to $P$. vinckei-infected mice with an $\mathrm{EC}_{50}$ of $0.2 \mathrm{mg} / \mathrm{kg}$, however it was shown to be ineffective when administered orally with an $\mathrm{ED}_{50}$ of $13 \mathrm{mg} / \mathrm{kg} .{ }^{91}$ The in vivo activity of Pro-T3 


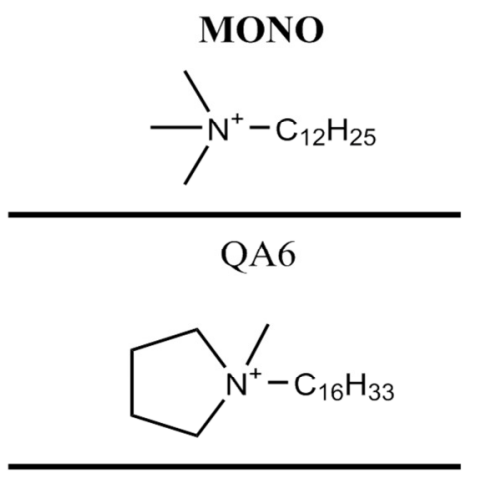

E26

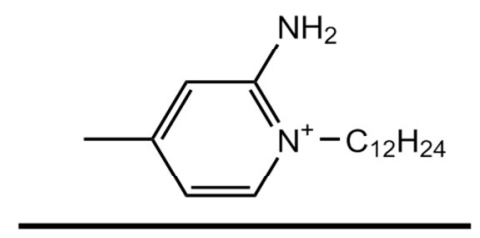

MS23

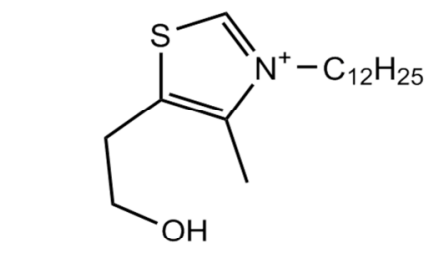

BIS

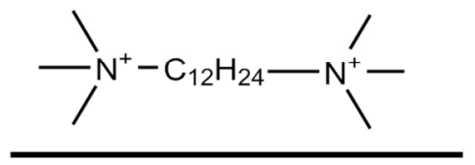

$\mathrm{T} 4$

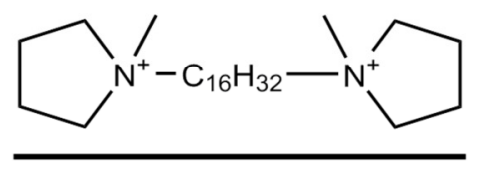

G25

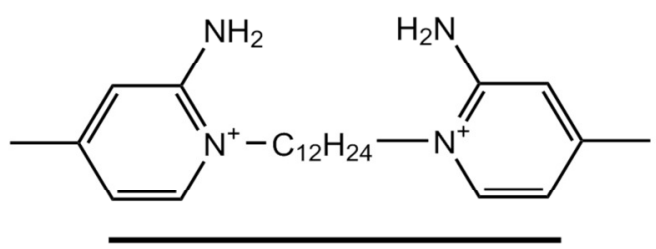

MS1

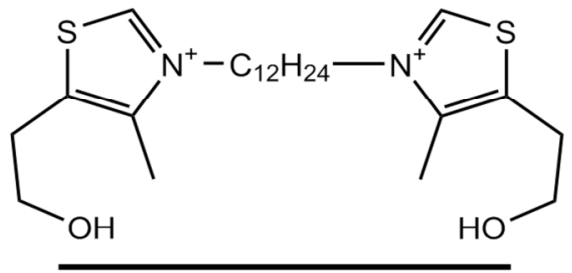

T3

PRO-DRUG

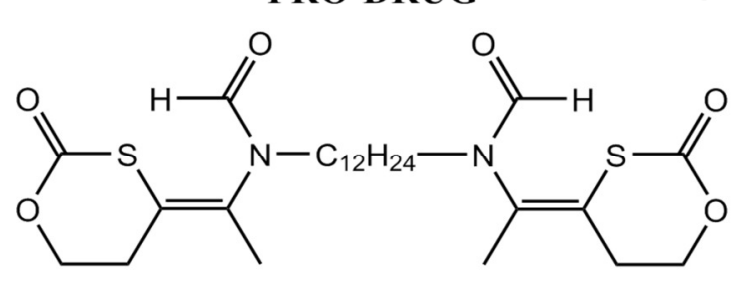

Pro-T3

Figure 5.3: Mono- and Bis-Quaternary Ammonium Compounds

\begin{tabular}{cccc}
\hline \multicolumn{4}{c}{ Table 5.1: The Antimalarial Activity of Mono- and Bis-Quaternary Ammonium Compounds } \\
\hline Mono-Compound & in vitro $\mathrm{IC}_{50}(\mathrm{nM})$ & Bis-Compound & in vitro $\mathrm{IC}_{50}(\mathrm{nM})$ \\
\hline QA6 & 500 & T4 & 90 \\
\hline E26 & 420 & G25 & 0.64 \\
\hline MS23 & 1550 & MS1 & 0.5 \\
\hline T1 & 70 & T3 & 2.25 \\
\hline & & Pro-T3 & 3.0 \\
\hline
\end{tabular}


when administered intraperitoneally to $P$. vinckei-infected mice was nearly the same T3 with an $\mathrm{IC}_{50}$ of $0.25 \mathrm{mg} / \mathrm{kg}$; Pro-T3 was found to be more effective than $\mathrm{T} 3$ when administered orally with an $\mathrm{EC}_{50}$ of $5 \mathrm{mg} / \mathrm{kg} .{ }^{91}$ The neutral pro-drug approach has been successful as shown by activity upon oral administration. A Pro-T3 analog that could not be transformed to the thiazolium showed an in vitro $\mathrm{IC}_{50}<10 \mu \mathrm{M}$, suggesting the transformation of Pro-T3 to the active form does occur in vivo. ${ }^{90}$

Based on the dramatic increase in the antimalarial activity seen in the bisammonium compounds, it was hypothesized based on the structures of the active analogs that there are two active anionic binding sites on the target protein. The optimized chain length suggests the distant between the active sites. ${ }^{91}$ The SAR included alterations to the chain, and all alterations tried diminished the antimalarial activity. The negative impact of polar functional groups added to the carbon chain suggested that the region between the active sites is hydrophobic. The negative impact of aromatic rings that add rigidity to the chain suggests that the pathway between the binding regions is narrow or convoluted. ${ }^{91}$

In the paper, "Transport and Pharmacodynamics of Albitiazolium, an Antimalarial Drug Candidate", the Vial group reports the results of their exploration of the mode of action of albitiazolium (T3). A detailed analysis of the inhibitory effect of albitiazolium on phosphocholine and phosphoethanolamine biosynthesis was performed for three distinct parasite development stages in the erythrocyte. The measurements were made at the ring stage, which is the immature parasite stage from invasion to the formation of the parasitophorous vacuole; the trophozoite stage, which is a maturation 
phase that includes heightened metabolism; and finally the schizont stage, in which the DNA replicates and is followed by rapid cell division. ${ }^{92}$ Because the need for phospholipids differs throughout the stages, it was expected that the potency of the drug would show a stage-specific pattern. The drug concentration that inhibited $50 \%$ of the phosphocholine synthesis $\left(\mathrm{PC}_{50}\right)$ was determined to be $2.8 \mu \mathrm{M}$ for the ring stage, $26 \mu \mathrm{M}$ for the trophozoite stage and $9.3 \mu \mathrm{M}$ for the schizont stage. ${ }^{88}$ The drug concentration that inhibited $50 \%$ of the phosphoethanolamine synthesis $\left(\mathrm{PE}_{50}\right)$ was greater than $1000 \mu \mathrm{M}$ for all three developmental stages. ${ }^{88}$ Albitiazolium thus specifically inhibited phosphocholine synthesis, and had its most potent immediate effect against the immature parasite. In addition, increased choline concentrations in the cell media showed an antagonistic effect on the antimalarial potency albitiazolium, indicating that not only does albitiazolium inhibit phosphocholine synthesis, but it is that inhibition that leads to its overall antimalarial affect. On further in vitro testing, it was shown that even with short drug exposure times of 1 to 2 hours at any parasitic stage of development, the drug accumulated within the intracellular parasite and led to its collapse at the onset of the schizont stage. ${ }^{77,93}$

Albitiazolium was shown to accumulate selectively in the infected RBCs. ${ }^{93}$ When erythrocytes were incubated at $37^{\circ} \mathrm{C}$ in $30 \mu \mathrm{M}$ albitiazolium media less than 0.01 $\mathrm{pmol} / 10^{7} \mathrm{RBC} \cdot \mathrm{min}^{-1}$ entered the uninfected RBC. A 400-fold accumulation of drug inside the infected RBC was measured when the cell media concentration was at 100 nM. ${ }^{88}$ The uptake of albitiazolium into the infected RBC proceeded linearly until saturation at $5 \mu \mathrm{M} .^{88}$ The selective uptake into the infected RBC implicates the parasite- 
induced NPP. Furosemide is a known NPP inhibitor, ${ }^{84,94,95}$ and was shown to inhibit albitiazolium uptake. ${ }^{88}$ However, even at very high concentrations furosemide was only able to reduce the uptake by $85 \% .^{88}$ It appears that the majority of the albitiazolium enters the RBC via the NPP, but some uptake is via an unknown route that is not inhibited by furosemide.

Albitiazolium is then transported from the $\mathrm{RBC}$ into the parasite, most likely via an organic cation transporter. ${ }^{89}$ The cross inhibition of choline on albitiazolium transport and of albitiazolium on choline transport was taken as evidence that they leave the RBC cytosol and enter the parasite by way of the same transporter. ${ }^{88}$ The capacity of NPPmediated transport of the albitiazolium from the plasma into the cytosol of the RBC is much smaller than the capacity of its transport from the cytosol of the RBC into the parasite. ${ }^{88}$ Because the second transporter in the series is larger, it seems reasonable to conclude that the majority of the drug accumulation is inside the parasite, not in the cytosol of the RBC. Accumulation measurements on a choline analog that is closely related to albitiazolium was found to reside $77 \%$ inside the parasite and $23 \%$ in the cytosol of the RBC. ${ }^{88}$

Albitiazolium interferes with choline phospholipid production in two ways, inhibiting both the transport of choline from host plasma to parasite cytosol, and inhibiting enzymatic transformations of choline to phosphatidylcholine. Albitiazolium has been shown to inhibit the transport of choline with an $\mathrm{IC}_{50}$ of $19 \mu \mathrm{M}$ in infected RBCs incubated in the presence of $15 \mu \mathrm{M}$ choline. ${ }^{88}$ When this was repeated in the presence of furosemide, the NPP inhibitor, the $\mathrm{IC}_{50}$ for choline transport was $1.9 \mu \mathrm{M} .^{88}$ 
This suggests that the drug is inhibiting the transport of choline through the erythrocytic choline transporter. The parasitic biosynthesis pathway from choline to phosphatidylcholine involves three enzymes: choline kinase, CTP-phosphocholine cytidylyltransferase, and choline/ethanolamine cytidylyltransferase. Albitiazolium inhibited each of these enzymes with $\mathrm{IC}_{50} \mathrm{~s}$ of $1.5 \mathrm{nM}, 2.5 \mathrm{nM}$, and $4.2 \mathrm{nM}$, respectively, when assessed on parasite extracts at optimal conditions for enzymatic catalysis.

In addition, it may also be that a portion of this drug accumulates in the digestive vacuole of the parasite and inhibits the biocrystallization of hemozoin as has been

determined for other bis-thiazolium compounds. ${ }^{96}$ The affinity for the binding with heme has been shown to both enhance the level of accumulation in the infected RBC and the antimalarial activity of the bis-thiazolium compounds, although this has not been thought to be the primary mode of action for this class of antimalarials. ${ }^{96}$

\section{The Anticancer Activity of bis-Quaternary Ammonium Compounds}

Neoplastic cancer is an area where bis-quaternary ammonium compounds are found to be useful. ${ }^{97}$ Cancer is often viewed as simply wild proliferation of a cell but a deeper look shows the basis of cancer is damage to genes that encode proteins used to send signals to the nucleus to initiate cell growth, mitosis, differentiation, and/or apoptosis. $^{98}$ As a result of accentuated or diminished messages, cells begin to behave in abnormal ways, often resulting in malignant tumors. 
The ras gene family encodes proteins that are involved in the signaling of cellular functions. Oncogenic ras genes are found in $25 \%$ of human cancer and their mutations have been found to have impaired ability to terminate signaling, resulting in the upregulation of cell proliferation. ${ }^{99,100}$ Choline kinase (ChoK) is thought to be a part of this signaling pathway that controls the regulation of cell growth. ${ }^{97}$ ChoK catalyzes the transformation of choline phosphocholine (PCho) and elevated concentrations of PCho are found in cancer cells that have ras mutations. Also, inhibition of ChoK with bisquaternary ammonium compounds has been shown to correlate with the inhibition of tumor cell proliferation. ${ }^{97}$

Joaquin Campos, Antonio Espinosa, and coworkers have performed a QSAR study based on the lead bis-quaternary ammonium compound of Hemicholinium-3 (Figure 4) in hope of developing an effective antiproliferant drug. Hemicholinium-3 is a known, potent ChoK inhibitor in vitro, but it is unsuitable for use as a drug because it causes respiratory paralysis. ${ }^{101}$ The SAR studies have led them to bis-aminopyridinium compounds with improved activity without the respiratory paralysis side-effect.

Examples of their active compounds are shown in Figure 4.

Campos and Espinosa have found that the quaternary nitrogen is essential to inhibitory activity and that an electron donating group at the position para-to-thequaternary-nitrogen on the pyridine ring enhances activity. They have also found that the number and distribution of the cationic charges greatly influence their activity and toxicity. 
Molecular orbital calculations were used in an attempt to find trends that explained the changes in potency seen through the series. ${ }^{102}$ It was found that the ChoK inhibition tightly correlated with the energies of the HOMOs and LUMOs of the compounds; increases in the energy level of the frontier orbitals led to increased activity. The HOMO and LUMO energies levels increased as the electron-donating ability of the para substituent increased. The authors stressed the need for a quantitative approach to
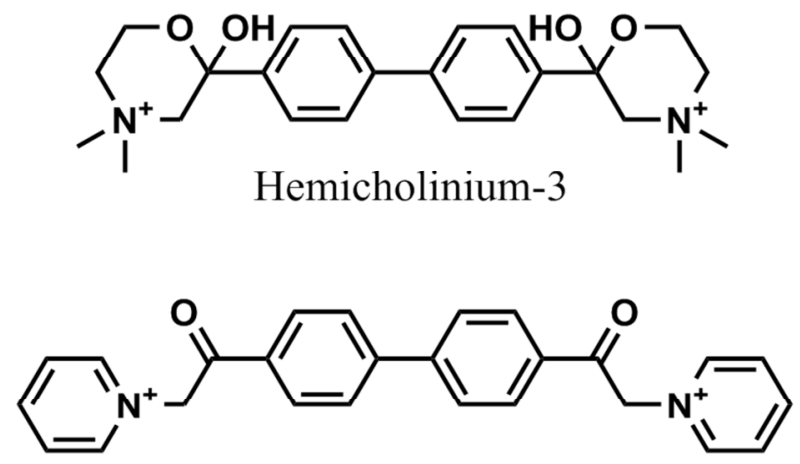

\begin{tabular}{|c|c|}
\hline $\begin{array}{c}\mathrm{IC}_{50} \\
\text { ex-vivo } \\
\text { ChoK } \\
\text { inhibition }\end{array}$ & $\begin{array}{c}\mathrm{IC}_{50} \\
\text { in vivo } \\
\text { antiproliferative } \\
\text { activity }\end{array}$ \\
\hline $500 \mathrm{nM}$ & $500,000 \mathrm{nM}$ \\
\hline $1300 \mathrm{nM}$ & $1000 \mathrm{nM}$ \\
& \\
\hline $9600 \mathrm{nM}$ & \\
& \\
& \\
\hline
\end{tabular}

Figure 5.4: Structure and Activity of Bis-Quaternary Compounds 
the SAR because analogs that appeared to be very different may in fact be electronically similar, while those that appear similar may be very different. Also, it was pointed out that a deeper understanding of the electronic nature of the inhibitor would lead to a better understanding of the possible interaction between the enzyme and the inhibitor. In the case of ChoK and the 4-aminopyridinium compounds it was rationalized that the high energy level of the LUMO was probably more significant than the high energy level of the HOMO. The high HOMO orbital is a trait that would be seen if the enzyme was acting as a base, but it does not seem to apply to these compounds with an electrondeficient nitrogen as its active center. However, the higher energy of the LUMO may suggest that the inhibitor is accepting electrons from the enzyme. Another possible explanation is that the higher the energy of the LUMO results in a weaker solvent shell around the molecule, easing the way to exclude water for a stronger interaction with the enzyme.

\section{Considerations for Future PL74 SAR}

This author believes that it is quite possible that PL74 is acting as a choline analog, thereby possibly inhibiting phospholipid synthesis in the $P$. falciparum parasite. Dr. Vial's research suggests that the mono-quaternary compounds inhibit the choline transport from the plasma into the erythrocyte, so this would be the first possible site of action to investigate for PL74. The diphenylmethylpiperazine headgroup on PL74 was in fact added to the molecule for the purpose of inhibiting PfCRT (which is a transporter) so 
it may be that this moiety is also effective in the inhibition of the erythrocytic choline transporter. From the results of the SAR presented in this dissertation, it can be seen that the activity is dependent on the whole headgroup; the removal of a single phenyl ring was not tolerated.

If PL74 is a choline synthesis inhibitor, it is a unique one. It is interesting that in Dr. Vial's study that they found that a 10-to-12 carbon chain was essential for strong activity. PL74 does not have the "essential" long chain. Also, Dr. Vial suggests that the optimum volume for the head group was about 200-400 $\AA^{3}$; If PL74 is considered a chain-less headgroup, where the whole molecule is considered headgroup, then it is much larger than the suggested dimensions. Also, there are some pyridinium compounds among Dr. Vial's analogs but no 4-aminopyridine compounds. In fact, in a search conducted for analogous compounds in the literature, this author did not find any antimalarial choline analogs that were 4-aminopyridiniums. If PL74 is acting as a choline analog inhibiting phospholipid synthesis, then it would be novel in structure, and this might indicate a new mode of action. The shape of the molecule, and the clues from the SAR as an inverse map of an unknown active site, seem to indicate that it would bind to an active site shaped differently than the site hypothesized by the Vial group based on the shape of their active analogs.

Nevertheless, the large increase in activity for the bis-quaternary compounds compared to the mono-compounds, makes this researcher wonder if PL74 is half of a great antimalarial drug. Bis-PL74 analogs might lead to a fruitful class of molecules for SAR exploration. 
The work of Campos and Espinosa is of interest because their analogs are 4aminopyridiniums applied to the inhibition of human phospholipid synthesis. The use of molecular orbital modeling to look deeper into the trends seen, as the SAR of PL74 is expanded, could be a beneficial addition. Also, the work they have done in finding substituents that increase the electron donation of the amine would also be useful to consider using in designing future PL74 analogs. 


\section{Chapter 6}

\section{Summary and Conclusion}

Malaria is an on-going tragedy, taking too many lives and locking people, communities, and even nations into poverty and hopelessness. The goal to eradicate malaria is certainly an honorable goal and hopefully achievable. To intervene and change this situation, it will take everyone working together: Charitable people donating ITNs for those who need them but cannot afford to buy them; scientists doing ingenious science in pursuit of vaccines, producing the best vaccines possible; organizations tracking resistance, making deployment policies, and evaluating the actions that are being taken. But at the center of this campaign there has to be a continuous stream of safe, affordable, curative drugs to save lives and decrease the opportunity for transmission of the malaria parasites, staying at least one drug ahead of resistant strains.

The Peyton Lab Reversed-CQ project shows promise of being able to produce a safe, inexpensive, effective antimalarial drug that can be of use in the effort to eradicate malaria. By functionalizing CQ with an RA moiety the resistance mechanism can be overcome, as demonstrated by the in vitro and in vivo activity of the prototype molecule, PL01.

PL74 was first thought to be a minimal version of a Reversed-CQ compound and an SAR study was pursued in hope that the activity could be optimized. During this 
work, it was discovered that the structure originally assumed for PL74 was incorrect and that PL74 is a pyridinium salt.

In the SAR study there are two findings that indicate a different mode of action for PL74. The intolerance of the removal of a phenyl group from the RA portion of the molecule, revealed by the inactivity of analog PL238 in contrast with compounds made by Steve Burgess and Bornface Gunsaru, showed a drastic departure from Reversed-CQ behavior. The antimalarial activity of PL167, with 3-aminopyridine attached to the RA group via an amine linkage, was unexpected; in addition, the inactivity of PL360, the CQ-mimic, and PL169, with 2-aminopyridine attached to the RA group via an amine linkage, was unexpected. These results are opposite the behavior predicted by earlier aminoquinoline work reported by Egan. The overall message from this SAR is that PL74 is not like the Reversed-CQ compounds and the hope is that these indications are pointing to not only a different, but a useful, antimalarial mechanism.

A review of the literature found that quaternary ammonium salts, including pyridinium salts, are often biologically active molecules and often operate as choline analogs. Two case studies were reviewed, one looking at Dr. Henri Vial's work with antimalarial choline analogs and the second looking at Campos/Espinosa's work on anticancer choline analogs. In both lines of research it was found that the bis-quaternary drugs were significantly more active than the mono-compounds, and, in both cases, these compounds exerted their cytotoxic action by inhibition in the phosphatidylcholine biosynthesis pathway. The literature study uncovered a wealth of ideas and methods for future investigations into the antimalarial action of PL74. 
Additional SAR study for PL74 is needed in two directions. The optimization of the antimalarial activity of PL74 may be possible through the addition of electrondonating substituents both on the amine substituent and on the ring. Also, the design and synthesis of bis-PL74 compounds seems to be an important next step for this research. Using molecular orbital calculations in the design of analogs may bring more clarity to the process. The exploration of the mode of action of PL74 should be continued because of the great need for more antimalarial drugs and because there is a possibility that this research could lead to an effective antimalarial drug. 


\section{Chapter 7}

\section{Experimental Methods}

All names were generated using ChemBioDraw Ultra 13.0. Purities were analyzed using a Varian Prostar Binary HPLC system, measuring by UV detection at 254 and $325 \mathrm{~nm}$, using a Varian ProStar 325 UV/Vis dual wavelength detector using Method 2. Method 2 was done with Supelco Ascentis C18 column (15 cm x $4.6 \mathrm{~cm}, 5 \mu \mathrm{m}$ pore size), from 99:5 water/acetonitrile with $0.1 \%$ formic acid in both to $30: 70$, at $1 \mathrm{~mL} / \mathrm{min}$, over 10 minutes. High resolution accurate mass data was generated by injecting samples into methanol:water at a flow rate of $0.2 \mathrm{ml} / \mathrm{min}$ directed to a Thermo LTQOrbitrap XL Discovery max spectrometer (San Jose, CA, USA) equipped with an ESI ion max source. The ionization interface was operated in the positive mode using the following settings: source voltage, $4 \mathrm{kV}$; sheath and aux gas flow rates, 20 and 5 units respectively; tube lens voltage, $90 \mathrm{~V}$; capillary voltage, $50 \mathrm{~V}$; and capillary temperature, $300^{\circ} \mathrm{C}$. The Orbitrap mass analyzer was externally calibrated prior to analysis to obtain mass accuracy within $\pm 2-3 \mathrm{ppm} .1 \mathrm{H}, 13 \mathrm{C}$ and $2 \mathrm{D}$ NMR experiments were run on a Bruker 600MHz AVANCE-III instrument, using the standard pulse sequences provided, including zg30, zgpg30, cosygpqf, hsqcetgpsi2, hmbcgplpndqf, and noesyph, at $25^{\circ} \mathrm{C}$.

\section{PL72: 2-(4-Benzhydrylpiperazin-1-yl)ethan-1-ol}

1-(2-Hydroxyethyl)piperazine (2.0 g, $15.4 \mathrm{mmol})$ was dissolved in DMF (20 mL). $\mathrm{K}_{2} \mathrm{CO}_{3}(4.27 \mathrm{~g}, 3.1 \mathrm{mmol})$ and $\mathrm{KI}$ (catalytic amount) were added. The mixture was 
stirred at room temperature while chlorodiphenylmethane $(2.74 \mathrm{~mL}, 3.12 \mathrm{~g}, 15.4 \mathrm{mmol})$ was added dropwise. The solution was stirred at room temperature for two hours and then heated to $76{ }^{\circ} \mathrm{C}$ for 22 hours. The reaction solution was cooled to room temperature, diluted with distilled water $(100 \mathrm{~mL})$ and extracted with diethyl ether $(3 \times 20 \mathrm{~mL})$. The combined diethyl ether was washed with brine $(30 \mathrm{~mL})$, dried over $\mathrm{MgSO}_{4}$, and evaporated to give PL72 (3.39 g, $11.4 \mathrm{mmol}, 74 \%)$.

\section{PL73: 1-Benyzhydryl-4-(2-chloroethyl)piperazine}

PL72 (1.13 g, $3.8 \mathrm{mmol}$ ) was dissolved in chloroform (10 mL). DMF (2 drops) and thionyl chloride $(200 \mu \mathrm{L})$ was added and solution was refluxed with stirring for 1.5 hours. Additional thionyl chloride $(400 \mu \mathrm{L})$ was added and the solution was refluxed for 40 more minutes, during which a white precipitate formed. The solid was collected by filtration, washed with diethyl ether and air dried to give PL73 $(\sim 1.34 \mathrm{~g}, 3.8 \mathrm{mmol}$, $100 \%$ ) and used without further purification.

Alternate Synthesis of PL73: Diphenylmethylpiperazine $(25.21 \mathrm{~g}, 100 \mathrm{mmol})$ and $\mathrm{K}_{2} \mathrm{CO}_{3}$ (27.98 g, $202 \mathrm{mmol}$ ) was stirred in 1,2-dichloroethane (85.0 mL, $106 \mathrm{~g}, 1.1 \mathrm{~mol}$ ) and heated to $80^{\circ} \mathrm{C}$ for 48 hours. The reaction mixture was cooled to room temperature and partitioned between water and $\mathrm{CHCl}_{3}$. The $\mathrm{CHCl}_{3}$ solution was evaporated down to brown clay. The brown clay was separated on a silica column (40 g) with ethyl acetate eluent to give PL73 (4.63g, $13.2 \mathrm{mmol}, 13 \%)$. 


\section{PL74: 4-Amino-1-[2-(4-benzhydrylpiperazin-1-yl)ethyl]pyridinium chloride}

PL73 (1.34 g, $3.8 \mathrm{mmol})$ and 4-aminopyridine $(0.53 \mathrm{~g}, 5.6 \mathrm{mmol})$ were stirred into EtOH $(15 \mathrm{~mL})$ and refluxed for 21 hours. The reaction solution was condensed to half volume by evaporation and the resulting white precipitate was collected by filtration, washed with chilled EtOH and then with diethyl ether, and air dried to yield PL74 (0.49 g, 1.2 $\mathrm{mmol}, 32 \%$ ) as a white solid. HPLC (Method 2) $\mathrm{t}_{\mathrm{R}}=5.72 \mathrm{~min}$ (99\% pure). MS(ESI): $m / z=373.2385(\mathrm{M}+) .{ }^{1} \mathrm{H} \mathrm{NMR} \delta(\mathrm{ppm})\left(600 \mathrm{MHz}, \mathrm{CH}_{3} \mathrm{OH}-\mathrm{d}_{4}\right): 8.03(2 \mathrm{H}, \mathrm{d}, \mathrm{J}=7.22 \mathrm{~Hz})$, 7.41-7.41 (4 H, m), $7.25(4 \mathrm{H}, \mathrm{t}, \mathrm{J}=7.61 \mathrm{~Hz}), 7.16(2 \mathrm{H}, \mathrm{t}, \mathrm{J}=7.36 \mathrm{~Hz}), 6.79(2 \mathrm{H}, \mathrm{d}, \mathrm{J}=$ 7.23 Hz), 4.15-4.20 (3 H, m), $2.74(2 \mathrm{H}, \mathrm{t}, \mathrm{J}=5.79 \mathrm{~Hz}), 2.53(4 \mathrm{H}, \mathrm{s}), 2.38(3 \mathrm{H}, \mathrm{br} \mathrm{s})$.

${ }^{13} \mathrm{C}$ NMR $\delta(\mathrm{ppm})\left(600 \mathrm{MHz}, \mathrm{CH}_{3} \mathrm{OH}-\mathrm{d}_{4}\right): 160.8,144.5,144.1,129.5,129.0,128.1$, $110.3,77.8,58.8,56.0,54.3,53.2$.

\section{PL76: [2-(4-Benzhydryl-piperazin-1-yl)-ethyl]-phenylamine}

PL73 (1.00 g, $3.4 \mathrm{mmol})$ and aniline $(0.05 \mathrm{~mL}, 0.05 \mathrm{~g}, 0.54 \mathrm{mmol})$ was stirred together in EtOH $(3 \mathrm{ml})$ and microwave heated to $130{ }^{\circ} \mathrm{C}$ for 15 minutes. Two more additions of aniline (each $0.1 \mathrm{~mL}, 0.1 \mathrm{~g}, 1.1 \mathrm{mmol}$ ) were added and the reaction was microwave heated to $130{ }^{\circ} \mathrm{C}$ for 15 minutes after each addition. The solvent was evaporated and the solid was purified on alumina with hexane/EtOAc gradient to 100\% EtOAc, yielding PL76 (0.03 g, $0.08 \mathrm{mmol}, 3 \%)$. HPLC (Method 2) $\mathrm{t}_{\mathrm{R}}=9.41 \mathrm{~min}(85 \%$ pure). MS(ESI): $m / z=372.4342(\mathrm{M}+) .{ }^{13} \mathrm{C} \mathrm{NMR} \delta(\mathrm{ppm})\left(\mathrm{CHCl}_{3}-\mathrm{d}\right): 148.6,142.8,129.2,128.5,128.4$, $127.9,126.9,126.9,117.2,112.9,77.5,76.3,57.9,56.7,54.0,53.2,51.9,51.8,40.3,1.0$ 


\section{PL165: 4-Amino-1-[2-(4-benzhydryl-piperazin-1-yl)-acetyl]-pyridinium chloride}

PL170 (0.66 g, $3.2 \mathrm{mmol})$ and diphenylmethylpiperazine (1.20 g, $4.8 \mathrm{mmol})$ were stirred together in $\mathrm{EtOH}(3 \mathrm{~mL})$ and microwave heated to $103{ }^{\circ} \mathrm{C}$ for 15 minutes. The solvent was evaporated and the solid product was purified on a basic alumina column with a EtOAc/MeOH gradient to 30\% MeOH, yielding PL165 (0.51 g, $1.2 \mathrm{mmol}, 38 \%$ ). HPLC (Method 2) $\mathrm{t}_{\mathrm{R}}=7.31 \mathrm{~min}\left(92 \%\right.$ pure). $\mathrm{MS}(\mathrm{ESI}): \mathrm{m} / z=387.2179(\mathrm{M}+) .{ }^{1} \mathrm{H}$ NMR $\delta$ $(\mathrm{ppm})\left(600 \mathrm{MHz}, \mathrm{CH}_{3} \mathrm{OH}-\mathrm{d}_{4}\right): 8.41(2 \mathrm{H}, \mathrm{dd}, \mathrm{J}=4.99,1.63 \mathrm{~Hz}), 7.70(2 \mathrm{H}, \mathrm{dd}, \mathrm{J}=5.01$, 1.65 Hz), 7.47 (4 H, d, J = 7.73 Hz), $7.29(4 \mathrm{H}, \mathrm{t}, \mathrm{J}=7.60 \mathrm{~Hz}), 7.19(2 \mathrm{H}, \mathrm{t}, \mathrm{J}=7.37 \mathrm{~Hz})$, $4.30(1 \mathrm{H}, \mathrm{s}), 3.25(2 \mathrm{H}, \mathrm{s}), 2.67(4 \mathrm{H}, \mathrm{s}), 2.53(4 \mathrm{H}, \mathrm{br} \mathrm{s}) .{ }^{13} \mathrm{C} \mathrm{NMR} \delta(\mathrm{ppm})\left(\mathrm{CH}_{3} \mathrm{OH}-\mathrm{d}_{4}\right)$ :

${ }^{13} \mathrm{C} \mathrm{NMR} \delta(\mathrm{ppm})\left(\mathrm{CH}_{3} \mathrm{OH}-\mathrm{d}_{4}\right): 171.8,150.9,147.5,144.1,129.6,129.0,128.1,115.2$, 77.7, 62.9, 54.6, 52.9.

\section{PL166: 2-(4-Benzhydrylpiperazin-1-yl)-N-pyridin-3-yl-acetamide}

PL171 (1.71 g, 10.0 mmol), Diphenylmethylpiperazine (2.88 g, 11.4 mmol), $\mathrm{K}_{2} \mathrm{CO}_{3}(2.11$ $\mathrm{g}, 15.2 \mathrm{mmol})$, and $\mathrm{KI}(1.80 \mathrm{~g}, 10.8 \mathrm{mmol})$ were stirred in DMF (60 mL) and refluxed for 24 hours at $60{ }^{\circ} \mathrm{C}$. The reaction mixture was cooled, diluted with water and extracted with DCM. The DCM was evaporated and the resulting dark oil was purified on an alumina column with EtOAc eluent, yielding PL166 (2.33 g, 6.0 mmol, 60\%).

\section{PL167: [2-(4-Benzhydryl-piperazin-1-yl)-ethyl]-pyridin-3-yl-amine}

PL166 (2.5 g, $6.5 \mathrm{mmol})$ was dissolved in DCM (30 mL) and chilled to $0{ }^{\circ} \mathrm{C}$. Then $1 \mathrm{M}$ LiAlH in THF( $3 \mathrm{~mL})$ was added dropwise. The solution was stirred at $0{ }^{\circ} \mathrm{C}$ for one hour 
and then at room temperature for 18 hours. The reaction was followed by TLC. The solution was again chilled to $0{ }^{\circ} \mathrm{C}$, then $1 \mathrm{M} \mathrm{LiAlH}_{4}$ in THF $(2 \mathrm{~mL}) 2$ was added and the mixture was stirred for 1 hour at $0{ }^{\circ} \mathrm{C}$ and then at room temperature for 48 hours. The reaction was diluted with water and extracted with EtOAc, yielding PL167, (trace amount). HPLC (Method 2) $t_{R}=6.24 \min \left(96 \%\right.$ pure). $M S(E S I): m / z=373.2385(\mathrm{M}+) .{ }^{1} \mathrm{H}$ $\operatorname{NMR} \delta(\mathrm{ppm})\left(600 \mathrm{MHz}, \mathrm{CH}_{3} \mathrm{OH}-\mathrm{d}_{4}\right): 7.81(1 \mathrm{H}, \mathrm{d}, \mathrm{J}=2.86 \mathrm{~Hz}), 7.64(1 \mathrm{H}, \mathrm{dd}, \mathrm{J}=4.71$, $1.33 \mathrm{~Hz}), 7.31-7.35$ (4 H, m), $7.16(4 \mathrm{H}, \mathrm{t}, \mathrm{J}=7.61 \mathrm{~Hz}), 7.03-7.09$ (3 H, m), $6.92(1 \mathrm{H}$, ddd, J = 8.38, 2.88, 1.34 Hz), $4.14(1 \mathrm{H}, \mathrm{s}), 3.14(2 \mathrm{H}, \mathrm{s}), 2.52(2 \mathrm{H}, \mathrm{t}, \mathrm{J}=6.77 \mathrm{~Hz}), 2.47$ (4 H, br s), 2.36 (4 H, br s). ${ }^{13} \mathrm{C}$ NMR $\delta(\mathrm{ppm})\left(600 \mathrm{MHz}, \mathrm{CH}_{3} \mathrm{OH}-\mathrm{d}_{4}\right): 146.9,144.1$, $137.7,135.7,129.6,129.0,128.1,125.5,120.1,77.8,58.0,54.5,52.8,41.0$.

\section{PL168: 2-(4-Benzhydrylpiperazin-1-yl)-N-pyridin-2-yl-acetamide}

PL172 (1.72 g, $6.5 \mathrm{mmol})$, diphenylmethylpiperazine (2.87 g, $11.4 \mathrm{mmol}), \mathrm{K}_{2} \mathrm{CO}_{3}(2.12$ $\mathrm{g}, 15.4 \mathrm{mmol})$, and $\mathrm{KI}(1.75 \mathrm{~g}, 12 \mathrm{mmol})$ were stirred in DMF (50 mL) and refluxed for 24 hours at $60{ }^{\circ} \mathrm{C}$. The reaction mixture was cooled, diluted with water and extracted with DCM. The DCM was evaporated and the resulting thick oil was purified on an alumina column with 50\%EtOAc/50\% hexane eluent, yielding PL168 (1.73 g, 4.48 mmol, 69\%).

\section{PL169: [2-(4-Benzhydryl-piperazin-1-yl)-ethyl]-pyridin-2-yl-amine}

PL 168 (0.67 g, $1.7 \mathrm{mmol})$ was dissolved in THF (12 mL) and added dropwise into a $1 \mathrm{M}$ $\mathrm{LiAlH}_{4}$ in THF solution $(3.6 \mathrm{~mL})$ which was chilled to $0{ }^{\circ} \mathrm{C}$. The reaction was stirred on 
ice for 15 minutes, then stirred at room temperature for 18 hours. The reaction was quenched with the addition of EtOAc $(5 \mathrm{~mL})$, then water $(10 \mathrm{~mL})$, then $2 \mathrm{M} \mathrm{NaOH}(1$ $\mathrm{mL})$. The reaction solution was diluted with water $(30 \mathrm{~mL})$ and extracted with EtOAc and purified on Alumina with EtOAc, yielding PL169 (0.60 g, 1.6 mmol, 95\%). HPLC (Method 2) $\mathrm{t}_{\mathrm{R}}=6.68 \mathrm{~min}\left(76 \%\right.$ pure). $\mathrm{MS}(\mathrm{ESI}): \mathrm{m} / z=373.2386(\mathrm{M}+) .{ }^{1} \mathrm{H}$ NMR $\delta$ $(\mathrm{ppm})\left(600 \mathrm{MHz}, \mathrm{CH}_{3} \mathrm{OH}-\mathrm{d}_{4}\right): 7.92-7.93(1 \mathrm{H}, \mathrm{m}), 7.46(5 \mathrm{H}, \mathrm{d}, \mathrm{J}=7.75 \mathrm{~Hz}), 7.29(4 \mathrm{H}, \mathrm{t}$, $\mathrm{J}=7.62 \mathrm{~Hz}), 7.19(2 \mathrm{H}, \mathrm{t}, \mathrm{J}=7.37 \mathrm{~Hz}), 6.54-6.55(2 \mathrm{H}, \mathrm{m}), 4.27(1 \mathrm{H}, \mathrm{s}), 3.42(2 \mathrm{H}, \mathrm{t}, \mathrm{J}=$

$6.62 \mathrm{~Hz}), 2.65(3 \mathrm{H}, \mathrm{s}), 2.54-2.54(8 \mathrm{H}, \mathrm{br} \mathrm{m}) .{ }^{13} \mathrm{C} \mathrm{NMR} \delta(\mathrm{ppm})\left(600 \mathrm{MHz}, \mathrm{CH}_{3} \mathrm{OH}-\mathrm{d}_{4}\right)$ : ${ }^{13} \mathrm{C} \mathrm{NMR} \delta(\mathrm{ppm})\left(\mathrm{CH}_{3} \mathrm{OH}-\mathrm{d}_{4}\right): 148.0,144.1,138.9,129.6,129.5,129.0,128.1,113.4$, $78.1,77.8,58.3,54.4,52.8,39.5$.

\section{PL170: 4-Amino-1-(2-chloroacetyl)pyridinium chloride}

4-Aminopyridine (2.65 g, $28.0 \mathrm{mmol})$ and $\mathrm{K}_{2} \mathrm{CO}_{3}(5.80 \mathrm{~g}, 41.7 \mathrm{mmol})$ was dissolved in DCM $(75 \mathrm{~mL})$. Chloroacetylchloride $(3.5 \mathrm{ml})$ was added dropwise and the solution was stirred and refluxed for 4 hours. The reaction solution was diluted with $200 \mathrm{~mL}$ of ice water and the resulting precipitate was filtered and air dried, yielding PL170 (1.00 g, 4.8 mmol, 17\%). PL170 was used without further purification.

\section{PL171: 2-Chloro-N-pyridin-3-ylacetamide}

3-Aminopyridine (2.83 g, $30.1 \mathrm{mmol})$ was dissolved in DCM (100 mL).

Chloroacetylchloride $(3.5 \mathrm{ml})$ was added dropwise and the solution was stirred at room 
temperature for three days. The solid was filtered, washed with DCM and air dried, yielding PL 171 (5.98 g, $34.8 \mathrm{mmol}, 86 \%$ ), which was used without further purification.

\section{PL172: 2-Chloro-N-pyridin-2-ylacetamide}

2-Aminopyridine (2.84 g, $30.2 \mathrm{mmol})$ was dissolved in DCM (100 mL).

Chloroacetylchloride $(3.5 \mathrm{ml})$ was added dropwise and the solution was stirred at room temperature for three days. The solid was filtered, washed with DCM and air dried, yielding PL 172 (4.41 g, $25.7 \mathrm{mmol}, 85 \%)$, which was used without further purification.

\section{PL215: [2-(4-Benzhydryl-piperazin-1-yl)-ethyl]-pyridin-4-ylmethylamine}

PL373 (3.37 g, $11.4 \mathrm{mmol}$ ) and 4-pyridine carboxaldehyde (2.5 mL, $2.2 \mathrm{~g}, 14.7 \mathrm{mmol})$ were stirred together with $\mathrm{MgSO}_{4}$ in toluene at room temperature for 48 hours. The solution was filtered and then the solvent evaporated. The solid was taken up in $\mathrm{MeOH}$. $\mathrm{NaBH}_{4}(0.88 \mathrm{~g})$ was added and the solution was stirred for 4 days. The reaction was quenched with water, the product was extracted $\mathrm{CHCl}_{3}$ and then the solvent was evaporated. The solid was purified on a basic alumina column with a $20 \% \mathrm{MeOH} / 80 \%$ EtOAc eluent, yielding PL215 (1.14 g, 2.95 mmol, $26 \%)$. HPLC (Method 2) $t_{R}=4.67$ $\min \left(87 \%\right.$ pure). MS(ESI): $m / z=387.2544(\mathrm{M}+) .{ }^{1} \mathrm{H}$ NMR $\delta(\mathrm{ppm})\left(600 \mathrm{MHz}, \mathrm{CH}_{3} \mathrm{OH}-\right.$ $\left.\mathrm{d}_{4}\right):{ }^{1} \mathrm{H} \mathrm{NMR} \delta(\mathrm{ppm})\left(\mathrm{CH}_{3} \mathrm{OH}-\mathrm{d}_{4}\right): 8.46(2 \mathrm{H}, \mathrm{d}, \mathrm{J}=5.29 \mathrm{~Hz}), 7.41(6 \mathrm{H}, \mathrm{t}, \mathrm{J}=7.56 \mathrm{~Hz})$, $7.26(4 \mathrm{H}, \mathrm{t}, \mathrm{J}=7.55 \mathrm{~Hz}), 7.17(2 \mathrm{H}, \mathrm{d}, \mathrm{J}=7.42 \mathrm{~Hz}), 4.22(1 \mathrm{H}, \mathrm{s}), 3.82(2 \mathrm{H}, \mathrm{s}), 2.70(2$ $\mathrm{H}, \mathrm{t}, \mathrm{J}=6.72 \mathrm{~Hz}), 2.53(3 \mathrm{H}, \mathrm{t}, \mathrm{J}=6.94 \mathrm{~Hz}) .{ }^{13} \mathrm{C} \mathrm{NMR} \delta(\mathrm{ppm})\left(\mathrm{CH}_{3} \mathrm{OH}-\mathrm{d}_{4}\right): 150.2$, $144.0,129.6,129.0,128.1,125.0,125.0,77.7,58.2,54.5,53.0,52.7,46.2$. 


\section{PL232: 4-Amino-1-ethyl-pyridinium chloride}

4-Aminopyridine $(1.0 \mathrm{~g}, 10.6 \mathrm{mmol})$ and acetylchloride $(7.6 \mathrm{~mL}, 6.9 \mathrm{~g}, 88 \mathrm{mmol})$ were dissolved into DCM and stirred at room temperature for 12 hours. The reaction mixture was filtered and the solids were washed with DCM and then purified on a silica column with an eluent mix of $90 \% \mathrm{CHCl}_{3} / 10 \% \mathrm{MeOH}$. The resulting solid was dissolved in THF

(8 $\mathrm{mL}$ ) and added dropwise to a chilled solution of $1 \mathrm{M} \mathrm{LiAlH}_{4}$ in THF (3 mL) which had been chilled to $0{ }^{\circ} \mathrm{C}$. The reaction was stirred for 1 hour at $0{ }^{\circ} \mathrm{C}$ and then for 24 hours at room temperature. The reaction was quenched with water, the solvent was evaporated, and the residue was purified on silica column with an eluent mix of $90 \% \mathrm{CHCl}_{3} / 10 \%$ $\mathrm{MeOH}$, yielding PL232 (0.06 g, $0.38 \mathrm{mmol}, 3.6 \%)$. HPLC $($ Method 2$) \mathrm{t}_{\mathrm{R}}=1.49 \mathrm{~min}(85 \%$ pure). $\mathrm{MS}(\mathrm{ESI}): m / z=123.09128(\mathrm{M}+) .{ }^{1} \mathrm{H} \mathrm{NMR} \delta(\mathrm{ppm})\left(600 \mathrm{MHz}, \mathrm{CH}_{3} \mathrm{OH}-\mathrm{d}_{4}\right): 7.98(2$ $\mathrm{H}, \mathrm{d}, \mathrm{J}=5.77 \mathrm{~Hz}), 6.54(2 \mathrm{H}, \mathrm{dd}, \mathrm{J}=5.32,1.61 \mathrm{~Hz}), 3.20(2 \mathrm{H}, \mathrm{q}, \mathrm{J}=7.22 \mathrm{~Hz}), 1.26(3 \mathrm{H}$, $\mathrm{t}, \mathrm{J}=7.22 \mathrm{~Hz})$.

\section{PL236: 4-Amino-1-[2-(4-methyl-piperazin-1-yl)-ethyl]-pyridinium chloride} 4-Aminopyridine (1.05 g, $11.2 \mathrm{mmol})$, 1,2-dichloroethane $(8.0 \mathrm{~mL}, 6.4 \mathrm{~g}, 64 \mathrm{mmol})$ and $\mathrm{Et}_{3} \mathrm{~N}(0.5 \mathrm{~mL}, 0.7 \mathrm{~g}, 6.8 \mathrm{mmol})$ were stirred together and microwave heated to $120{ }^{\circ} \mathrm{C}$ for 15 minutes. The reaction was cooled to $0{ }^{\circ} \mathrm{C}$ and filtered. The filtrate was evaporated, and the residue was stirred in to 1-methylpiperazine $(6.0 \mathrm{ml}, 6.6 \mathrm{~g}, 67 \mathrm{mmol})$ and heated to 95 ${ }^{\circ} \mathrm{C}$ for 26 hours. The reaction mixture was cooled, diluted with $\mathrm{MeOH}$ and filtered. The filtrate was evaporated and the residue was purified on a basic alumina column with a EtOAc/MeOH gradient to 20\% MeOH, yielding PL236 (0.13g, $0.51 \mathrm{mmol}, 4.5 \%$ ). 
HPLC $($ Method 2$) t_{\mathrm{R}}=1.19 \min (100 \%$ pure $) . \operatorname{MS}(\mathrm{ESI}): \mathrm{m} / z=221.17657(\mathrm{M}+) .{ }^{1} \mathrm{H}$ NMR $\delta$ $(\mathrm{ppm})\left(600 \mathrm{MHz}, \mathrm{CH}_{3} \mathrm{OH}-\mathrm{d}_{4}\right): 8.08(2 \mathrm{H}, \mathrm{m}), 6.84(2 \mathrm{H}, \mathrm{m}), 4.23(2 \mathrm{H}, \mathrm{t}, \mathrm{J}=5.74 \mathrm{~Hz})$, $2.78(2 \mathrm{H}, \mathrm{t}, \mathrm{J}=5.75 \mathrm{~Hz}), 2.51-2.54(8 \mathrm{H}, \mathrm{br} \mathrm{m}), 2.29(3 \mathrm{H}, \mathrm{s}) .{ }^{13} \mathrm{C} \mathrm{NMR} \delta(\mathrm{ppm})(600$ $\left.\mathrm{MHz}, \mathrm{CH}_{3} \mathrm{OH}-\mathrm{d}_{4}\right):{ }^{13} \mathrm{C} \mathrm{NMR} \delta(\mathrm{ppm})\left(\mathrm{CH}_{3} \mathrm{OH}-\mathrm{d}_{4}\right): 161.6,145.3,111.2,59.5,56.8,54.3$, 46.8 .

\section{PL238: 4-Amino-1-[2-(4-benzyl-piperazin-1-yl)-ethyl]-pyridinium chloride}

PL364 (0.58 g, $1.7 \mathrm{mmol})$ was dissolved in anhydrous THF $(30 \mathrm{~mL})$ and chilled to $0{ }^{\circ} \mathrm{C}$. $1 \mathrm{M} \mathrm{LiAlH} 4$ in THF $\left(2.8 \mathrm{ml}, 2.8 \mathrm{mmol} \mathrm{LiAlH}_{4}\right)$ was added dropwise with stirring for 1 hour and then at room temperature for 12 hours. More $1 \mathrm{M} \mathrm{LiAlH}_{4}$ in THF (4.0 ml, 4.0 mmol $\mathrm{LiAlH}_{4}$ ) was added and the reaction was stirred at $60{ }^{\circ} \mathrm{C}$ for 12 hours. The reaction was quenched with EtOAc $(10 \mathrm{~mL})$, and then water $(30 \mathrm{~mL})$. The product was extracted from the quenched reaction with EtOAc $(6 x, 300 \mathrm{~mL}$ total). The EtOAc was evaporated and the resulting residue was purified on a basic alumina column with EtOAc/MeOH gradient to 40\% MeOH, yielding PL238, (0.29 g, $0.87 \mathrm{mmol}, 51 \%)$. HPLC (Method 2) $\mathrm{t}_{\mathrm{R}}=1.50 \mathrm{~min}(89 \%$ pure $) . \mathrm{MS}(\mathrm{ESI}): \mathrm{m} / \mathrm{z}=297.20771(\mathrm{M}+) .{ }^{1} \mathrm{H} \mathrm{NMR} \delta(\mathrm{ppm})(600 \mathrm{MHz}$, $\left.\mathrm{CH}_{3} \mathrm{OH}-\mathrm{d}_{4}\right):{ }^{1} \mathrm{H}$ NMR $\delta(\mathrm{ppm})\left(\mathrm{CH}_{3} \mathrm{OH}-\mathrm{d}_{4}\right): 8.00(2 \mathrm{H}, \mathrm{d}, \mathrm{J}=5.83 \mathrm{~Hz}), 7.34-7.36(4 \mathrm{H}$, m), 7.27-7.31 (1 H, m), $6.58(2 \mathrm{H}, \mathrm{dd}, \mathrm{J}=5.35,1.64 \mathrm{~Hz}), 3.57(2 \mathrm{H}, \mathrm{s}), 3.31(2 \mathrm{H}, \mathrm{t}, \mathrm{J}=$ $6.75 \mathrm{~Hz}), 2.63(2 \mathrm{H}, \mathrm{t}, \mathrm{J}=6.76 \mathrm{~Hz}), 2.56-2.58(8 \mathrm{H}, \mathrm{br} \mathrm{m}) .{ }^{13} \mathrm{C} \mathrm{NMR} \delta(\mathrm{ppm})(600 \mathrm{MHz}$, $\left.\mathrm{CH}_{3} \mathrm{OH}-\mathrm{d}_{4}\right):{ }^{13} \mathrm{C} \mathrm{NMR} \delta(\mathrm{ppm})\left(\mathrm{CH}_{3} \mathrm{OH}-\mathrm{d}_{4}\right): 158.3,146.3,144.1,143.3,129.6,129.0$, 128.1, 110.0, 104.8, 77.8, 58.6, 56.3, 54.2, 53.3. 


\section{PL240: 4-amino-1-[2-(4-benzhydryl-piperazin-1-yl)-2-oxo-ethyl]-pyridinium}

\section{chloride}

Diphenylmethylpiperazine $(2.52 \mathrm{~g}, 10.0 \mathrm{mmol})$ and $\mathrm{K}_{2} \mathrm{CO}_{3}(2.83 \mathrm{~g}, 20.0 \mathrm{mmol})$ were slurried in DCM (50 mL). Chloroacetyl chloride $(2.4 \mathrm{~mL}, 3.4 \mathrm{~g}, 30 \mathrm{mmol})$ was added slowly and stirred at room temp for 12 hours. The reaction mixture was partitioned between DCM and water. The DCM solution was dried over $\mathrm{MgSO}_{4}$ and then the solvent was evaporated to yield a thick oil. The oil and 4-aminopyridine (0.94 g, $10 \mathrm{mmol})$ were stirred in EtOH (100 mL) and heated to $90{ }^{\circ} \mathrm{C}$ for 12 hours. The solvent was evaporated and the resulting oil was purified on basic alumina with an ethylactetate/methanol gradient to 40\% methanol to yield PL240 (3.04 g, $7.2 \mathrm{mmol}, 72 \%$ ). HPLC (Method 2) $\mathrm{t}_{\mathrm{R}}=7.74 \mathrm{~min}\left(97 \%\right.$ pure). $\mathrm{MS}(\mathrm{ESI}): m / z=387.21776(\mathrm{M}+) .{ }^{1} \mathrm{H} \mathrm{NMR} \delta(\mathrm{ppm})(600 \mathrm{MHz}$, $\left.\mathrm{CH}_{3} \mathrm{OH}-\mathrm{d}_{4}\right):$ 7.92-7.94 $(2 \mathrm{H}, \mathrm{m}), 7.49-7.49(5 \mathrm{H}, \mathrm{m}), 7.32(5 \mathrm{H}, \mathrm{t}, \mathrm{J}=7.62 \mathrm{~Hz}), 7.23(2 \mathrm{H}$, $\mathrm{t}, \mathrm{J}=7.38 \mathrm{~Hz}), 6.82-6.87(2 \mathrm{H}, \mathrm{m}), 5.19(2 \mathrm{H}, \mathrm{s}), 4.36(1 \mathrm{H}, \mathrm{s}), 3.64(2 \mathrm{H}, \mathrm{t}, \mathrm{J}=4.94 \mathrm{~Hz})$, $3.57(2 \mathrm{H}, \mathrm{t}, \mathrm{J}=4.91 \mathrm{~Hz}), 2.54(2 \mathrm{H}, \mathrm{t}, \mathrm{J}=4.85 \mathrm{~Hz}), 2.45(2 \mathrm{H}, \mathrm{t}, \mathrm{J}=5.00 \mathrm{~Hz}) .{ }^{13} \mathrm{C} \mathrm{NMR}$ $\delta(\mathrm{ppm})\left(\mathrm{CH}_{3} \mathrm{OH}-\mathrm{d}_{4}\right):{ }^{13} \mathrm{C}$ NMR $\delta(\mathrm{ppm})\left(\mathrm{CH}_{3} \mathrm{OH}-\mathrm{d}_{4}\right): 166.0,161.1,145.4,143.6,129.7$, $129.0,128.3,110.3,77.2,52.8,52.5,49.6,46.0,43.7$.

\section{PL297: 4-Amino-1-[2-(4-benzyl-piperidin-1-yl)-ethyl]-pyridinium}

PL170 (0.65 g, $3.1 \mathrm{mmol})$ and 4-benzylpiperidine $(0.58 \mathrm{~mL}, 0.58 \mathrm{~g}, 5.7 \mathrm{mmol})$ and $\mathrm{K}_{2} \mathrm{CO}_{3}(1.14 \mathrm{~g}, 8.2 \mathrm{mmol})$ were stirred together in DMF and room temperature for 2 weeks. The solution was filtered and evaporated, resulting in an oily residue. The residue was dissolved in THF $(25 \mathrm{~mL})$ and $1 \mathrm{M} \mathrm{LiAlH}_{4}$ in THF $(0.6 \mathrm{~mL}$ was added; the 
solution was stirred at room temperature for 12 hours. The reaction was quenched with EtOAc, then with water, and then cooled to room temperature. The product was extracted with EtOAc $(4 x, 300 \mathrm{~mL}$ total). The solvent was evaporated and the resulting oil was purified on a silica column with 30\% MeOH/70\% EtOAc, yielding PL297 (0.13 g, $0.39 \mathrm{mmol}, 13 \%)$. HPLC (Method 2) $\mathrm{t}_{\mathrm{R}}=1.5 \mathrm{~min}(55 \%$ pure $) . \operatorname{MS}(\mathrm{ESI}): \mathrm{m} / \mathrm{z}=\mathrm{xxx}$ (M+).

\section{PL324: 4-Amino-1-[2-(4-benzhydrylpiperazin-1-yl)-ethyl]-2-methylpyridinium chloride}

PL73 (1.57 g, $5.0 \mathrm{mmol})$ and 4-amino-2-methylpyridine (0.54 g, $5.0 \mathrm{mmol})$ were stirred into $\mathrm{EtOH}(10 \mathrm{~mL})$ and microwave heated to $100{ }^{\circ} \mathrm{C}$ for 15 minutes. The solvent was evaporated and the residue was columned on a basic alumina column with an ethylacetate/methanol gradient to $20 \%$ methanol, to yield PL324 (0.83 g, $2.0 \mathrm{mmol}, 40 \%$ yield). $\operatorname{HPLC}($ Method 2$) \mathrm{t}_{\mathrm{R}}=5.65 \mathrm{~min}(98 \%$ pure $) . \mathrm{MS}(\mathrm{ESI}): \mathrm{m} / z=387.2544(\mathrm{M}+) .{ }^{1} \mathrm{H}$ NMR (ppm)(600 MHz, $\left.\mathrm{CH}_{3} \mathrm{OH}-\mathrm{d}_{4}\right): 7.96(1 \mathrm{H}, \mathrm{d}, \mathrm{J}=6.93 \mathrm{~Hz}), 7.41(4 \mathrm{H}, \mathrm{d}, \mathrm{J}=7.68$ Hz), 7.25 (4 H, t, J = 7.61 Hz), $7.17(2 \mathrm{H}, \mathrm{d}, \mathrm{J}=7.39 \mathrm{~Hz}), 6.67-6.71(2 \mathrm{H}, \mathrm{m}), 4.18-4.20$ $(3 \mathrm{H}, \mathrm{m}), 2.72(2 \mathrm{H}, \mathrm{t}, \mathrm{J}=5.95 \mathrm{~Hz}), 2.30-2.61(11 \mathrm{H}, \mathrm{m}) .{ }^{13} \mathrm{C} \mathrm{NMR} \delta(\mathrm{ppm})\left(\mathrm{CH}_{3} \mathrm{OH}-\mathrm{d}_{4}\right)$ :

${ }^{13} \mathrm{C}$ NMR $\delta(\mathrm{ppm})\left(\mathrm{CH}_{3} \mathrm{OH}-\mathrm{d}_{4}\right): 160.8,153.7,145.8,144.1,129.6,129.0,128.1,111.3$, $109.2,77.8,58.4,54.6,53.2,52.5,19.9$. 


\section{PL325: 4-Amino-1-[2-(4-benzhydrylpiperazin-1-yl)-ethyl]-3-methylpyridinium chloride}

PL73 (1.56 g, $5.0 \mathrm{mmol})$ and 4-amino-3-methylpyridine $(0.54 \mathrm{~g}, 5.0 \mathrm{mmol})$ were stirred together in $\mathrm{EtOH}(10 \mathrm{ml})$ and microwave heated to $100{ }^{\circ} \mathrm{C}$ for 15 minutes. The solvent was evaporated and the residue was columned on a basic alumina column with an ethylacetate/methanol gradient to $30 \%$ methanol, to yield PL325 (1.48 g, 3.5 mmol, $70 \%$ yield). HPLC (Method 2) $t_{R}=5.86 \min \left(99 \%\right.$ pure). $M S(E S I): m / z=287.2543(\mathrm{M}+) .{ }^{1} \mathrm{H}$ NMR (ppm)(600 MHz, $\left.\mathrm{CH}_{3} \mathrm{OH}-\mathrm{d}_{4}\right): 7.97-7.98(2 \mathrm{H}, \mathrm{m}), 7.41(4 \mathrm{H}, \mathrm{d}, \mathrm{J}=7.69 \mathrm{~Hz}), 7.25$ $(4 \mathrm{H}, \mathrm{t}, \mathrm{J}=7.55 \mathrm{~Hz}), 7.17(2 \mathrm{H}, \mathrm{d}, \mathrm{J}=7.40 \mathrm{~Hz}), 6.80(1 \mathrm{H}, \mathrm{d}, \mathrm{J}=7.03 \mathrm{~Hz}), 4.17-4.18(3$ $\mathrm{H}, \mathrm{m}), 2.74(2 \mathrm{H}, \mathrm{t}, \mathrm{J}=5.85 \mathrm{~Hz}), 2.53(4 \mathrm{H}, \mathrm{s}), 2.38(3 \mathrm{H}, \mathrm{br} \mathrm{s}), 2.16(3 \mathrm{H}, \mathrm{s}) .{ }^{13} \mathrm{C}$ NMR $\delta$ $(\mathrm{ppm})\left(\mathrm{CH}_{3} \mathrm{OH}-\mathrm{d}_{4}\right): 144.1,143.0,142.7,129.6,129.0,128.1,109.5,77.7,58.8,56.0,54.3$, $53.2,14.4$

\section{PL327: 4-Amino-1-[2-(4-benzhydrylpiperazin-1-yl)-ethyl]-2-methoxypyridinium chloride}

PL73 (0.96 g, $3.1 \mathrm{mmol})$ and 4-amino-2-bromopyridine (0.52 g, $3.0 \mathrm{mmol})$ were stirred together in $\mathrm{EtOH}(3 \mathrm{~mL})$ and microwave heated to $100{ }^{\circ} \mathrm{C}$ for 10 minutes. The solvent was evaporated and the residue was columned on a basic alumina column with an ethylactate/methanol gradient to 30\% ethanol to yield PL327 (mass not recorded). HPLC (Method 2) $\mathrm{t}_{\mathrm{R}}=5.85 \min (96 \%$ pure $) . \mathrm{MS}(\mathrm{ESI}): \mathrm{m} / \mathrm{z}=403.2492(\mathrm{M}+) .{ }^{1} \mathrm{H} \mathrm{NMR}(\mathrm{ppm})(600$ $\left.\mathrm{MHz}, \mathrm{CH}_{3} \mathrm{OH}-\mathrm{d}_{4}\right):{ }^{1} \mathrm{H} \mathrm{NMR} \delta(\mathrm{ppm})\left(\mathrm{CH}_{3} \mathrm{OH}-\mathrm{d}_{4}\right): 7.75(1 \mathrm{H}, \mathrm{d}, \mathrm{J}=7.34 \mathrm{~Hz}), 7.41-7.41(4$ $\mathrm{H}, \mathrm{m}), 7.25(4 \mathrm{H}, \mathrm{t}, \mathrm{J}=7.61 \mathrm{~Hz}), 7.17(2 \mathrm{H}, \mathrm{d}, \mathrm{J}=7.37 \mathrm{~Hz}), 6.49(1 \mathrm{H}, \mathrm{dd}, \mathrm{J}=7.33,2.34$ 
Hz), $6.28(1 \mathrm{H}, \mathrm{d}, \mathrm{J}=2.34 \mathrm{~Hz}), 4.20(1 \mathrm{H}, \mathrm{s}), 4.15(2 \mathrm{H}, \mathrm{t}, \mathrm{J}=6.13 \mathrm{~Hz}), 4.05(3 \mathrm{H}, \mathrm{s})$, $2.67(2 \mathrm{H}, \mathrm{t}, \mathrm{J}=6.14 \mathrm{~Hz}), 2.54(5 \mathrm{H}, \mathrm{s}), 2.38(3 \mathrm{H}, \mathrm{br} \mathrm{s}) .{ }^{13} \mathrm{C} \mathrm{NMR} \delta(\mathrm{ppm})(600 \mathrm{MHz}$, $\left.\mathrm{CH}_{3} \mathrm{OH}-\mathrm{d}_{4}\right):{ }^{13} \mathrm{C}$ NMR $\delta(\mathrm{ppm})\left(\mathrm{CH}_{3} \mathrm{OH}-\mathrm{d}_{4}\right): 201.5,163.3,161.3,144.1,143.4,129.6$, $129.0,128.1,105.7,89.7,77.8,58.5,57.7,54.4,53.1$.

\section{PL328: 4-Amino-1-[2-(4-benzhydryl-piperazin-1-yl)-ethyl]-3-bromo-pyridinium chloride}

PL73 (1.05 g, $3.3 \mathrm{mmol})$ and 4-amino-3-bromopyridine $(0.51 \mathrm{~g}, 3.0 \mathrm{mmol})$ were stirred together in $\mathrm{EtOH}(3 \mathrm{~mL})$ and microwave heated to $100{ }^{\circ} \mathrm{C}$ for 10 minutes. The solvent was evaporated and the residue was columned on a basic alumina column with an ethylactate/methanol gradient to 30\% ethanol to yield PL328 (0.85g, $1.7 \mathrm{mmol}, 52 \%)$. HPLC (Method 2) $t_{\mathrm{R}}=5.82 \mathrm{~min}$ (97\% pure). MS(ESI): $\mathrm{m} / z=451.1497(\mathrm{M}+) .{ }^{1} \mathrm{H}$ NMR (ppm) $\left(600 \mathrm{MHz}, \mathrm{CH}_{3} \mathrm{OH}-\mathrm{d}_{4}\right):{ }^{1} \mathrm{H} \mathrm{NMR} \delta(\mathrm{ppm})\left(\mathrm{CH}_{3} \mathrm{OH}-\mathrm{d}_{4}\right): 8.57(1 \mathrm{H}, \mathrm{d}, \mathrm{J}=1.70 \mathrm{~Hz})$, 8.09 (1 H, dd, J = 7.16, 1.73 Hz), 7.39-7.43 (4 H, m), $7.26(4 \mathrm{H}, \mathrm{t}, \mathrm{J}=7.61 \mathrm{~Hz}), 7.16(2$ $\mathrm{H}, \mathrm{t}, \mathrm{J}=7.36 \mathrm{~Hz}), 6.94(1 \mathrm{H}, \mathrm{d}, \mathrm{J}=7.14 \mathrm{~Hz}), 4.21-4.22(3 \mathrm{H}, \mathrm{m}), 2.75(2 \mathrm{H}, \mathrm{t}, \mathrm{J}=5.67$ $\mathrm{Hz}), 2.54(5 \mathrm{H}, \mathrm{s}), 2.38(3 \mathrm{H}, \mathrm{br} \mathrm{s}) .{ }^{13} \mathrm{C}$ NMR $\delta(\mathrm{ppm})\left(600 \mathrm{MHz}, \mathrm{CH}_{3} \mathrm{OH}-\mathrm{d}_{4}\right):{ }^{13} \mathrm{C} \mathrm{NMR}$ $\delta(\mathrm{ppm})\left(\mathrm{CH}_{3} \mathrm{OH}-\mathrm{d}_{4}\right): 158.3,146.3,144.1,143.3,129.6,129.0,128.1,110.0,104.8,77.8$, $58.6,56.3,54.2,53.3$.

\section{PL 329: N-[2-(4-Benzhydryl-piperazin-1-yl)-ethyl]-isonicotinamide}

PL73 (4.17 g, $13.2 \mathrm{mmol})$ and Huing's base (5 mL) were dissolved in $\mathrm{CHCl}_{3}(150 \mathrm{~mL})$. Nicotinoyl chloride (3.0 g, $17 \mathrm{mmol})$ was added in small portions and the reaction was 
stirred for five days. The solution was filtered, washed with saturated $\mathrm{NaHCO}_{3}$ solution $(1 \mathrm{x})$, washed with water $(4 \mathrm{x})$, and then the solvent was evaporated. The solid was purified on Alumina column with EtOAC/MeOH gradient to $30 \% \mathrm{MeOH}$, yielding PL329 (0.67 g, 1.7 mmol, $13 \%)$. HPLC (Method 2) $t_{R}=7.73$ min (92\% pure). MS(ESI): $m / z=401.2338(\mathrm{M}+) .{ }^{1} \mathrm{H} \mathrm{NMR} \delta(\mathrm{ppm})\left(600 \mathrm{MHz}, \mathrm{CH}_{3} \mathrm{OH}-\mathrm{d}_{4}\right): 8.68(2 \mathrm{H}, \mathrm{dd}, \mathrm{J}=4.68$, $1.61 \mathrm{~Hz}), 7.76(2 \mathrm{H}, \mathrm{dd}, \mathrm{J}=4.60,1.65 \mathrm{~Hz}), 7.42(4 \mathrm{H}, \mathrm{d}, \mathrm{J}=7.68 \mathrm{~Hz}), 7.26(4 \mathrm{H}, \mathrm{t}, \mathrm{J}=$ $7.61 \mathrm{~Hz}), 7.16(2 \mathrm{H}, \mathrm{t}, \mathrm{J}=7.37 \mathrm{~Hz}), 4.24(1 \mathrm{H}, \mathrm{s}), 3.54(2 \mathrm{H}, \mathrm{t}, \mathrm{J}=6.76 \mathrm{~Hz}), 2.42-2.75$ (10 H, br m).

\section{PL330: 1-[2-(4-Benzhydrylpiperazin-1-yl)-ethyl]pyrimidin-4-ylamine}

PL73 (1.05 g, $3.3 \mathrm{mmol})$ and 3-aminopyrimidine were stirred together in ethanol (5 mL) and microwave heated at $100{ }^{\circ} \mathrm{C}$ for 15 minutes. The solid was filtered, then air dried, then columned on a basic alumina column with EtOAc/MeOH gradient up to $40 \%$ $\mathrm{MeOH}$, and followed by recrystallization in $\mathrm{MeOH}$, yielding PL330 (.69 g, $1.6 \mathrm{mmol}$, $51 \%)$. HPLC (Method 2) $t_{R}=5.32 \min \left(99 \%\right.$ pure). $\operatorname{MS}(\mathrm{ESI}): \mathrm{m} / z=374.2339(\mathrm{M}+) .{ }^{1} \mathrm{H}$ NMR $\delta(p p m)\left(\mathrm{CH}_{3} \mathrm{OH}-\mathrm{d}_{4}\right): 8.57(1 \mathrm{H}, \mathrm{d}, \mathrm{J}=1.88 \mathrm{~Hz}), 8.14(1 \mathrm{H}, \mathrm{dd}, \mathrm{J}=7.45,2.02 \mathrm{~Hz})$, $7.41(4 \mathrm{H}, \mathrm{d}, \mathrm{J}=7.63 \mathrm{~Hz}), 7.26(4 \mathrm{H}, \mathrm{t}, \mathrm{J}=7.56 \mathrm{~Hz}), 7.17(2 \mathrm{H}, \mathrm{d}, \mathrm{J}=7.32 \mathrm{~Hz}), 6.74(1$ $\mathrm{H}, \mathrm{d}, \mathrm{J}=7.45 \mathrm{~Hz}), 4.20(1 \mathrm{H}, \mathrm{s}), 4.17(2 \mathrm{H}, \mathrm{t}, \mathrm{J}=5.55 \mathrm{~Hz}), 2.74(2 \mathrm{H}, \mathrm{t}, \mathrm{J}=5.56 \mathrm{~Hz})$, $2.55(4 \mathrm{H}, \mathrm{s}), 2.38(2 \mathrm{H}, \mathrm{s}) .{ }^{13} \mathrm{C} \mathrm{NMR} \delta(\mathrm{ppm})\left(600 \mathrm{MHz}, \mathrm{CH}_{3} \mathrm{OH}-\mathrm{d}_{4}\right):{ }^{13} \mathrm{C} \mathrm{NMR} \delta$ $(\mathrm{ppm})\left(\mathrm{CH}_{3} \mathrm{OH}-\mathrm{d}_{4}\right):{ }^{13} \mathrm{C}$ NMR $\delta(\mathrm{ppm})\left(\mathrm{CH}_{3} \mathrm{OH}-\mathrm{d}_{4}\right): 165.9,155.2,147.2,144.1,129.6$, $129.0,128.1,106.0,77.8,58.2,54.2,53.2,53.1$. 


\section{PL342: 1-[2-(4-Benzhydryl-piperazin-1-yl)-ethyl]-4-methylamino-pyridinium chloride}

PL73 (0.89 g, $2.8 \mathrm{mmol})$ and 4-(methylamino)pyridine (0.30 g, $2.8 \mathrm{mmol})$ were stirred in EtOH ( $3 \mathrm{~mL}$ ), then microwave heated to $130{ }^{\circ} \mathrm{C}$ for 15 minutes. The solvent was evaporated and the residue was purified on a basic alumina column with EtOAc/MeOH gradient to 40\% MeOH, yielding PL 342 (0.1 g, 0.24 mmol, 8.8\%). HPLC (Method 2) $\mathrm{t}_{\mathrm{R}}=5.80 \min (99 \%$ pure $) . \mathrm{MS}(\mathrm{ESI}): \mathrm{m} / z=387.2543(\mathrm{M}+) .{ }^{1} \mathrm{H} \mathrm{NMR} \delta(\mathrm{ppm})(600 \mathrm{MHz}$, $\left.\mathrm{CH}_{3} \mathrm{OH}-\mathrm{d}_{4}\right):{ }^{1} \mathrm{H}$ NMR $\delta(\mathrm{ppm})\left(\mathrm{CH}_{3} \mathrm{OH}-\mathrm{d}_{4}\right): 8.13-8.14(1 \mathrm{H}, \mathrm{m}), 7.97(1 \mathrm{H}, \mathrm{dd}, \mathrm{J}=7.16$, $1.86 \mathrm{~Hz}), 7.41-7.41(4 \mathrm{H}, \mathrm{m}), 7.25(4 \mathrm{H}, \mathrm{t}, \mathrm{J}=7.61 \mathrm{~Hz}), 7.16(2 \mathrm{H}, \mathrm{t}, \mathrm{J}=7.36 \mathrm{~Hz}), 6.80-$ $6.81(2 \mathrm{H}, \mathrm{m}), 4.19(3 \mathrm{H}, \mathrm{t}, \mathrm{J}=5.82 \mathrm{~Hz}), 2.97(3 \mathrm{H}, \mathrm{s}), 2.74(2 \mathrm{H}, \mathrm{t}, \mathrm{J}=5.79 \mathrm{~Hz}), 2.53(4$ $\mathrm{H}, \mathrm{s}), 2.38(4 \mathrm{H}, \mathrm{br} \mathrm{s}) .{ }^{13 \mathrm{C}} \mathrm{NMR} \delta(\mathrm{ppm})\left(600 \mathrm{MHz}, \mathrm{CH}_{3} \mathrm{OH}-\mathrm{d}_{4}\right): 159.5,145.3,144.1$, $142.8,129.6,129.0,128.1,111.4,105.8,77.8,58.8,55.9,54.3,53.2$.

\section{PL343: [2-(4-Benzhydryl-piperazin-1-yl)-ethyl]-(3-nitro-pyridin-4-yl)-amine}

PL373 (1.05 g, $3.6 \mathrm{mmol}$ ) and 4-chloro-3-nitropyridine were slurried in water (4 mL) and microwave heated to $130{ }^{\circ} \mathrm{C}$ for 30 minutes. The reaction mixture was diluted with additional water $(100 \mathrm{~mL})$ and extracted with EtOAc $(3 \mathrm{x} ; 300 \mathrm{~mL}$ total). The EtOAc was evaporated and the residue was columned on basic alumina with EtOAc/MeOH gradient to $30 \% \mathrm{MeOH}$, yielding PL343 (0.69g, $1.7 \mathrm{mmol}, 46 \%)$. HPLC (Method 2) $\mathrm{t}_{\mathrm{R}}=6.87 \mathrm{~min}$ (98\% pure). MS(ESI): $m / z=418.2241(\mathrm{M}+) .{ }^{1} \mathrm{H}$ NMR $\delta(\mathrm{ppm})\left(600 \mathrm{MHz}, \mathrm{CH}_{3} \mathrm{OH}-\mathrm{d}_{4}\right)$ :

$9.08(1 \mathrm{H}, \mathrm{s}), 8.22(1 \mathrm{H}, \mathrm{d}, \mathrm{J}=6.31 \mathrm{~Hz}), 7.46-7.48(5 \mathrm{H}, \mathrm{m}), 7.29(5 \mathrm{H}, \mathrm{t}, \mathrm{J}=7.62 \mathrm{~Hz})$, $7.19(2 \mathrm{H}, \mathrm{t}, \mathrm{J}=7.36 \mathrm{~Hz}), 6.98(1 \mathrm{H}, \mathrm{d}, \mathrm{J}=6.33 \mathrm{~Hz}), 4.27(1 \mathrm{H}, \mathrm{s}), 3.51(2 \mathrm{H}, \mathrm{t}, \mathrm{J}=6.34$ 
$\mathrm{Hz}), 2.74(2 \mathrm{H}, \mathrm{t}, \mathrm{J}=6.33 \mathrm{~Hz}), 2.62(4 \mathrm{H}, \mathrm{br} \mathrm{s}), 2.50(4 \mathrm{H}, \mathrm{br} \mathrm{s}) .{ }^{13} \mathrm{C} \mathrm{NMR} \delta$ $(\mathrm{ppm})\left(\mathrm{CH}_{3} \mathrm{OH}-\mathrm{d}_{4}\right):{ }^{13} \mathrm{C} \mathrm{NMR} \delta(\mathrm{ppm})\left(\mathrm{CH}_{3} \mathrm{OH}-\mathrm{d}_{4}\right): 152.9,150.1,149.1,144.2,131.2$, 129.6, 129.0, 128.1, 110.1, 77.9, 56.4, 54.1, 53.2, 40.2.

\section{PL350: 4-[2-(4-Benzhydryl-piperazin-1-yl)-ethylamino]-pyridin-3-ol}

PL343 (0.22 g, $0.53 \mathrm{mmol})$ was dissolved in $\mathrm{MeOH}$ and evaporated onto neutral Alumina. $\mathrm{FeCl}_{3}(0.23 \mathrm{~g}, 1.4 \mathrm{mmol})$ and hydrazine monohydrate $(2.5 \mathrm{~mL}, 2.4 \mathrm{~g}, 48.5$ mmol ) was ground into the alumina. The alumina was loaded into a microwave vial and heated at $130 \%$ for 10 minutes. The mixture was cooled, slurried in EtOAc and filtered through Celite. The EtOAc was evaporated down to a thick oil. The oil was brought up in dry THF and added dropwise into a boiling solution of dry THF $(10 \mathrm{~mL})$ with isoamyl nitrite $(0.1 \mathrm{~mL})$. The solution was stirred and refluxed for 4 hours, then evaporated down to oil and purified on an alumina column with $\mathrm{EtOAc} / \mathrm{MeOH}$ gradient, yielding the hydroxide side product (mass not recorded ). HPLC (Method 2) $t_{R}=7.59 \min (92 \%$ pure). MS(ESI): $m / z=388.29800(\mathrm{M}+)$.

\section{PL360: 1N,1N-Diethyl-4N-pyridin-4-ylpentane-1,4-diamine}

4-Chloropyridine (2.05 g, $21 \mathrm{mmol})$ was stirred into 2-amino-5-diethylaminopentane (20 $\mathrm{ml}, 25 \mathrm{~g}, 155 \mathrm{mmol}$ ) and heated to $135{ }^{\circ} \mathrm{C}$ for 16 hours. The excess solvent was distilled off using a short-path distillation apparatus and distilling up to $120{ }^{\circ} \mathrm{C}$ at $0.05 \mathrm{~atm}$, leaving a brown residue. The residue was separated on silica preparative TLC plates with an eluent mix of $\mathrm{CHCl}_{3}: \mathrm{MeOH}: \mathrm{NH}_{4} \mathrm{OH}$ in 5:1:0.2 ratio, respectively. The product was 
found in a clear band at $R_{f}=0.6$. The bands were collected, extracted off the silica with the eluent solvent mix, and the solvent was evaporated, yielding a dark oil. The oil was further purified on a silica column using a $\mathrm{CHCl}_{3}$ (with $2 \% \mathrm{Et}_{3} \mathrm{~N}$ )/MeOH (with $2 \% \mathrm{Et}_{3} \mathrm{~N}$ ) gradient to $30 \% \mathrm{MeOH}$ (with $2 \% \mathrm{Et}_{3} \mathrm{~N}$ ), yielding PL360 (0.01 g, $0.4 \mathrm{mmol}, 0.2 \%$ ).

HPLC (Method 2) $t_{R}=1.45 \min \left(99 \%\right.$ pure). MS(ESI): $m / z=236.21203(\mathrm{M}+) .{ }^{1} \mathrm{H}$ NMR $\delta$ $(\mathrm{ppm})\left(600 \mathrm{MHz}, \mathrm{CH}_{3} \mathrm{OH}-\mathrm{d}_{4}\right):{ }^{1} \mathrm{H} \mathrm{NMR} \delta(\mathrm{ppm})\left(\mathrm{CH}_{3} \mathrm{OH}-\mathrm{d}_{4}\right): 7.84(2 \mathrm{H}, \mathrm{d}, \mathrm{J}=5.80 \mathrm{~Hz})$, $6.42(2 \mathrm{H}, \mathrm{dd}, \mathrm{J}=5.55,1.55 \mathrm{~Hz}), 3.45-3.51(1 \mathrm{H}, \mathrm{m}), 2.46(4 \mathrm{H}, \mathrm{q}, \mathrm{J}=7.22 \mathrm{~Hz}), 2.37$ (2 $\mathrm{H}, \mathrm{d}, \mathrm{J}=7.84 \mathrm{~Hz}), 1.40-1.50(5 \mathrm{H}, \mathrm{m}), 1.09(3 \mathrm{H}, \mathrm{d}, \mathrm{J}=6.40 \mathrm{~Hz}), 0.93(6 \mathrm{H}, \mathrm{t}, \mathrm{J}=7.20$ $\mathrm{Hz}) .{ }^{13} \mathrm{C} \mathrm{NMR} \delta(\mathrm{ppm})\left(\mathrm{CH}_{3} \mathrm{OH}-\mathrm{d}_{4}\right): 155.9,149.2,108.6,53.6,49.6,49.6,48.4,47.8$, $47.8,35.5,23.7,20.7,20.7,11.1$.

\section{PL350: 4-[2-(4-Benzhydryl-piperazin-1-yl)-ethylamino]-pyridin-3-ol}

PL343 (0.22 g, $0.53 \mathrm{mmol})$ was dissolved in $\mathrm{MeOH}$ and evaporated onto neutral Alumina. $\mathrm{FeCl}_{3}(0.23 \mathrm{~g}, 1.4 \mathrm{mmol})$ and hydrazine monohydrate $(2.5 \mathrm{~mL}, 2.4 \mathrm{~g}, 48.5$ mmol ) was ground into the alumina. The alumina was loaded into a microwave vial and heated at $130 \%$ for 10 minutes. The mixture was cooled, slurried in EtOAc and filtered through Celite. The EtOAc was evaporated down to a thick oil. The oil was brought up in dry THF and added dropwise into a boiling solution of dry THF (10 mL) with isoamyl nitrite $(0.1 \mathrm{~mL})$. The solution was stirred and refluxed for 4 hours, then evaporated down to oil and purified on an alumina column with EtOAc/MeOH gradient, yielding the hydroxide side product (mass not recorded ). HPLC (Method 2) $t_{R}=7.59 \min (92 \%$ pure). $\operatorname{MS}(\mathrm{ESI}): m / z=388.29800(\mathrm{M}+)$. 


\section{PL364: 4-Amino-1-[2-(4-benzyl-piperazin-1-yl)-acetyl]-pyridinium chloride}

Piperazine (13.07 g, $152 \mathrm{mmol})$ was dissolved in DCM (50 mL) and benzylbromide (6 $\mathrm{ml}, 8.7 \mathrm{~g}, 50 \mathrm{mmol}$ ) was added in dropwise; the solution was stirred at room temperature for several days. The reaction mixture was washed with water $(6 \mathrm{x}, 300 \mathrm{~mL}$ total $)$ and then the solvent was evaporated, yielding a white solid. The entire amount of solid and $\mathrm{K}_{2} \mathrm{CO}_{3}(7.63 \mathrm{~g}, 55.2 \mathrm{mmol})$ were stirred together in DMF (50 mL), then PL170 (5.93 $\mathrm{g}$, $28.6 \mathrm{mmol}$ ) was added and the mixture was stirred at $40{ }^{\circ} \mathrm{C}$ for 16 hours. The reaction was cooled and filtered. The solvent was evaporated and the residue was purified on a basic alumina column with $\mathrm{CHCl}_{3}$ eluent, yielding PL364 (0.58 g, 1.7 mmol, 5.9\%). MS(ESI): $m / z=311.18743(\mathrm{M}+) .{ }^{1} \mathrm{H}$ NMR $\delta(\mathrm{ppm})\left(600 \mathrm{MHz}, \mathrm{CH}_{3} \mathrm{OH}-\mathrm{d}_{4}\right):{ }^{1} \mathrm{H}$ NMR $\delta$ $(\mathrm{ppm})\left(\mathrm{CH}_{3} \mathrm{OH}-\mathrm{d}_{4}\right): 8.42(2 \mathrm{H}, \mathrm{dd}, \mathrm{J}=5.11,1.62 \mathrm{~Hz}), 7.71(2 \mathrm{H}, \mathrm{dd}, \mathrm{J}=5.05,1.62 \mathrm{~Hz})$, 7.33-7.36 (4 H, m), 7.29-7.29 (1 H, m), $3.59(2 \mathrm{H}, \mathrm{s}), 3.25(2 \mathrm{H}, \mathrm{s}), 2.63(8 \mathrm{H}, \mathrm{br} \mathrm{d}, \mathrm{J}=$

$35.18 \mathrm{~Hz}) .{ }^{13} \mathrm{C}$ NMR $\delta(\mathrm{ppm})\left(600 \mathrm{MHz}, \mathrm{CH}_{3} \mathrm{OH}-\mathrm{d}_{4}\right):{ }^{13} \mathrm{C} \mathrm{NMR} \delta(\mathrm{ppm})\left(\mathrm{CH}_{3} \mathrm{OH}-\mathrm{d}_{4}\right)$ : $171.8,150.9,147.5,138.4,130.8,129.4,128.5,115.2,63.9,62.9,54.1,53.8$.

\section{PL373: 2-(4-Benzhydryl-piperazin-1-yl)-ethylamine}

Diphenylmethylpiperazine (1.31 g, $5.2 \mathrm{mmol})$, bromoethylphthalamide (1.29 g, 5.1 $\mathrm{mmol}), \mathrm{K}_{2} \mathrm{CO}_{3}(1.21 \mathrm{~g}, 8.8 \mathrm{mmol})$, and $\mathrm{KI}(.95 \mathrm{~g}, 5.8 \mathrm{mmol})$ were slurried in acetonitrile and microwave heated to $100{ }^{\circ} \mathrm{C}$ for 30 minutes. The reaction mixture was cooled, diluted with $\mathrm{CHCl}_{3}$ and filtered. The $\mathrm{CHCl}_{3}$ was evaporated leaving a thick oil. The oil was stirred in $\mathrm{MeOH}$ and a white solid precipitated, which was filtered and air dried. The white solid was slurried in EtOH. Hydrazine monohydrate $(27 \mathrm{~mL})$ was added and the 
mixture was refluxed for 8 hours, then cooled to room temperature and filtered. The EtOH was evaporated yielding PL373, which was used without further purification.

\section{In vitro drug susceptibility assays ${ }^{63}$}

Both CQS (D6) and CQR (Dd2) P. falciparum maintained continuously in culture were used. ${ }^{103}$ Asynchronous cultures were diluted with uninfected RBCs and complete medium (RPMI-1640 with $0.5 \%$ Albumax II) to achieve $0.2 \%$ parasitemia and $2 \%$ hematocrit. In 96-well microplates, CQ (positive control) or RCQ diluted in complete medium from $10 \mathrm{mM}$ stock in DMSO were added to the cell mixture to yield triplicate wells with drug concentrations ranging from 0 to $10^{-4} \mathrm{M}$ in a final well volume of 100 $\mu \mathrm{L}$. After $72 \mathrm{~h}$ of incubation under standard culture conditions, plates were harvested and read by the SYBR Green I fluorescence-based method ${ }^{103}$ using a 96-well fluorescence plate reader (Gemini-EM, Molecular Devices), with excitation and emission wavelengths at 497 and $520 \mathrm{~nm}$, respectively. The fluorescence readings were plotted against $\log [\mathrm{drug}]$, and the $\mathrm{IC}_{50}$ values were obtained from curve fitting performed by nonlinear regression using either Prism (GraphPad) or Excel (Microsoft) software. 


\section{References}

(1) WHO World Malaria Report, World Health Organization: 2013.

(2) Murray, C. J. L.; Rosenfeld, L. C.; Lim, S. S.; Andrews, K. G.; Foreman, K. J.; Haring, D.; Fullman, N.; Naghavi, M.; Lozano, R.; Lopex, A. D. Global Malaria Mortality Between 1980 and 2010: A Systematic Analysis. The Lancet 2012, 379, 413431.

(3) Gallup, J.; Sachs, J. The Economic Burden of Malaria. The American Journal of Tropical Medicine and Hygiene 2001, 64, 85-96.

(4) Greenwood, B. M.; Bojang, K.; Whitty, C. J.; Targett, G. A. T. Malaria. The Lancet 2006, 365, 1487-1498.

(5) Cox-Singh, J.; Davis, T. M.; Lee, K. S.; Shamsul, S. S.; Matusop, A.; Ratnam, S.; Rahman, H. A.; Conway, D. J.; Singh, B. Plamodium knowlesi Malaria in Humans is Widely Distributed and Potentially Life Threatening. Clinical Infectious Diseases 2008, 46, 165-171.

(6) Yazdani, S. S.; Mukherjee, P.; Chauhan, V. S.; Chitnes, C. E. Immune Responses to Asexual Blood-Stages of Malaria Parasites. Current Molecular Medicine 2006, 6, 187-203.

(7) White, N. J.; Pukrittayakamee, S.; Hien, T. T.; Faiz, M. A.; Mokuolu, L. A.; Dondorp, A. M.: Malaria. In The Lancet; August 15, 2013 ed.: http://dx.doi.org/10.1016/S0140-6736(13)60024-0, 2013.

(8) Tuteja, R. Malaria - An Overview. FEBS Journal 2007, 274, 4670.

(9) Anopheles Mosquitoes. http://www.cdc.gov/malaria/about/biology/ mosquitoes/ (accessed March 8, 2014).

(10) Service, M. W.; Townson, H.: The Anopheles Vector. In Essential Malariology; 4th ed.; Warrell, D. A., Gilles, H. M., Eds.; Arnold: New York, 2002; pp 59-84.

(11) Warrell, D. A.: Clinical Features of Malaria. In Essential Malariology; 4th ed.; Warrell, D. A., Gilles, H. M., Eds.; Arnold: New York, 2002; pp 191-218.

(12) Ramirez, J. L.; Garver, L. S.; Dimopoulos, G. Challenges and Approaches for Mosquito Targeted Malaria Control. Current Molecular Medicine 2009, 9, 116-130. 
(13) Phillips-Howard, P. A., et al. Efficacy of Permethrin-Treated Bed Nets in teh Prevention of Mortality in Young Children in an Area of High Perennial Malaria Transmission in Western Kenya. American Journal of Tropical Medicine and Hygiene 2003, 68, 23-39.

(14) Richie, T. L.; Saul, A. Progress and Challenges for Malaria Vaccines. Nature 2002, 415, 694-701.

(15) Seder, R. A., et al. Protection Against Malaria by INtravenous Immunization with a Nonreplicating Sporozoite Vaccine. Science 2013, 341, 1359-1365.

(16) Thera, M. A.; Plowe, C. V. Vaccines for Malaria: How Close Are We? Annual Review of Medicine 2012, 63, 345-357.

(17) Vaughan, A. M.; Kappe, S. H. I. Marlaria Vaccine Development: Persistent Challenges. Current Opinion in Immunology 2012, 24, 324-331.

(18) Saxena, A. K.; Wu, Y.; Garboczi, D. N. Plasmodium P25 and P28 Surface Proteins: Potential Transmission-Blocking Vaccines. Eukaryotic Cell 2007, 6, 12601265.

(19) Shimp, J., Richard L. ; Rowe, C.; Reiter, K.; Chen, B.; Nguyen, V.; Aebig, J.; Rausch, K. M.; Kumar, K.; Wu, Y.; Jin, A. J.; Jones, D. S.; Narum, D. L. Development of a Pfs25-EPA Malaria Transmission Blocking Vaccine as a Chemically Conjugated Nanparticle. Vaccine 2013, 31, 2954-2962.

(20) Greenwood, D. The Quinine Connection. Journal of Antimicrobial Chemotherapy 1992, 30, 417-427.

(21) Woodward, R. B.; Doering, W. E. The Total Synthesis of Quinine. The Journal of the American Chemical Society 1944, 66, 849.

(22) Smith, A. C.; Williams, R. M. Rabe Rest in Peace: Confirmation of the Rabe-Kindler Conversion of d-Quinotoxine into Quinine: Experimental Affirmation of the Woodward-Doering Formal Total Synthesis of Quinine. Angewandte Chemie, International Edition 2008, 47, 1736-1740.

(23) Coatney, G. Pitfalls in a Discovery: The Chronicle of Chloroquine. American Journal of Tropical Medicine and Hygiene 1963, 12, 121-128.

(24) Malaria: Parasite Biology, Pathogenesis, and Protection; Sherman, I. W., Ed.; ASM Press: Washington, D. C., 1998. 
(25) Bray, P. G.; Ward, S. A.; O'Neill, P. M. Quinolines and Artemisinin: Chemistry, Biology and History. Current Topics in Microbiology 2005, 295, 3-38.

(26) Antimalarials, C.-O. R. G. o. Q. a. I. D. a. Chemical Studies on Quighaosu (Artemisinin). Journal of Traditional Chinese Medicine 1982, 2, 3-4.

(27) Krungkrai, S. R.; Yuthanvong, Y. The Antimalarial Action of Qinghaosu and Artensunate in Combination with Agents that Moderate Oxidative Stress. Transactions of the Royal Society of Tropical Medicine and Hygiene 1987, 81, 710-714.

(28) Levander, O. A.; Ager, A. L.; Morris, V. C.; May, R. G. Qinghaosu, Dietary Vitamine E, Selenium, and Cod-liver oil: Effect on the Susceptibility of Mice to the Malarial Parasite, Plasmodium Yoelii. American Journal of Clinical Nutrition 1989, 50, 346-352.

(29) Posner, G. P.; Oh, C. H. Regiospecifically Oxygen-18 Labeled 1,2,4trioxane: A Simple Chemical Model Systems to Probe the Mechanism(s) for the Antimalarial Activity of Artemisinin (Qinghaosu). Journal of the American Chemical Society 1992, 114, 8328-8329.

(30) Meunier, B.; Robert, A. Heme as Trigger and Target for TrioxaneContaining Antimalarial Drugs. Accounts of Chemical Research 2010, 43, 1444-1451.

(31) WHO World Malaria Report, World Health Organization. 2005.

(32) Martinelli, A.; Moreira, R.; Ravo, P. V. Malaria Combination Therapies: Advantage and Shortcomings. Mini-Reviews in Medicinal Chemistry 2008, 8, 201-212.

(33) Na-Bangchang, K.; Karbwang, J. Current Status of Malaria Chemotherapy and the Role of Pharmacology in Antimalarial Drug Research and Development. Fundamental and Clinical Pharmacology 2009, 23, 387.

(34) Nzila, A. Inhibitors of De Novo Folate Enzymes in Plasmodium falciparum. Drug Discovery Today 2006, 11, 939-944.

(35) Phyo, A. P., et al. Emergence of Artemisinin-Resistant Malaria on the Western Border of Thailand: A Longitudinal Study. The Lancet 2012.

(36) Desai, M.; ter Kuile, F. O.; Nosten, F.; McGready, R.; Asamoa, K.; Brabin, B.; Newman, R. D. Epidemiology and Burden of Malaria in Pregnancy. The Lancet Infectious Diseases 2007, 7, 93-104.

(37) Arinaitwe, E.; Ades, V.; Walakira, A.; Boaz, N.; Mugagga, O.; Patil, T. S.; Schwartz, A.; Kamya, M. R.; Nasr, S.; Change, M.; Filler, S.; Dorsey, G. Intermittent 
Preventive Therapy with Sufladoxine-Pyrimethamine for Malaria in Pregnancy: A Cross-Sectional Study from Tororo, Uganda. PLOS One 2013, 8, 1-6.

(38) Wilson, A. L. A Systematic Review and Meta-Analysis of the Efficacy and Safety of Intermittent Preventive Treamtent of Malaria in Children. PLOS One 2011, $6,1-12$.

(39) van Vagt, M.; van Beest, A.; Sicuri, E.; van Tulder, M.; Grobusch, M. P. Malaria Treatment and Prophylaxis in Endemic and Non-Endemic Countries: Evidence on Strategies and Their Cost-Effectiveness. Future Microbiology 2011, 6, 1485-1497.

(40) Cairns, M.; Ghani, A.; Okell, L.; Gosling, R.; Carneiro, I.; Anto, F.; Asoala, V.; Owusu-Agyei, S.; Greenwood, B.; Chandramohan, D.; Milligan, P. Modelling the Protective Efficacy for Alternative Delivery Schedules fo $\mathrm{r}$ Intermittent Preventive Treatment of Malaria in Infants and Children. PLOS One 2011, 6, 1-10.

(41) Dicko, A.; Amadou, B.; Dicko, M.; Diallo, A. I.; Tembine, I.; Dicko, Y.; Dara, N.; Sidibe, Y.; Santara, G.; Conare, T.; Chandramohan, D.; Cousens, S.; Milligan, P. J.; Diallo, D. A.; Doumbo, O. K.; Greenwood, B. Malaria Morbidity in Children in the Year after They Had Received Intermittent Preventive Treatment of Malaria in Mali: A RAndomized Control Trial. Plos One 2011, 6, 1-9.

(42) Tourism towards 2030: Global Overview. In UNWTO General Assembly 19th Session; United Nations World Tourism Organization: Gyeongju Republic of Korea, 2011.

(43) Kain, K. C.; Shanks, G. D.; Keystone, J. S. Malaria Chemoprophylaxis in the Age of Drug Resistance. Currently Recommended Drug Regimens. Clinical Infectious Diseases 2001, 33, 226-234.

(44) Chen, L. H.; Wilson, M. E.; Schlagenhauf, P. Prevention of Malaria in Long-term Travelers. The Journal of the American Medical Association 2006, 296, 2234 2241.

(45) Chulay, J. D. Challenges in the Development of Antimalarial Drugs with Causal Prophylactic Activity. Transactions of the Royal Society of Tropical Medicine and Hygiene 1998, 92, 577-579.

(46) Krugliak, M.; Zhang, F.; Ginsburg, H. Plasmodium falciparum Utilizes Only a Fraction of the Amino Acids Derived From the Diegestion of Host Cell Cytolsol for the Biosynthesis of its Proteins. Molecular and Biochemical Parasitology 2002, 119, 249-256. 
(47) Egan, T. J. Haemozoin Formation. Molecular and Biochemical Parasitology 2008, 157, 127-136.

(48) Pandey, A. V.; Babbarwal, V. K.; Okoyeh, J. N.; Joshi, R. N.; Puri, S. K.; Singh, R. L.; Chauhan, V. S. Formation in Malaria: A Two-step Process Involving Histidine-Rich Proteins and Lipids. Biochem and Biophysical Research Communications 2003, 208.

(49) Jackson, K. E.; Klonis, N.; Ferguson, D., et al. Food Vacuole-Associated Lipid Bodies and Heterogeneous Lipid Environments in the Malaria Parasite, Plasmodium falciparum. Molecular Microbiology 2004, 2004, 109-122.

(50) Coppens, I.; Vielemeyer, O. Insights into Unique Physiological Features of Neutral Lipids in Apicomplexa: From Storage to Potential Mediation in Parasite Metabolic Activities. International Journal for Parasitology 2005, 35, 597-615.

(51) Pisciotta, J. M.; Coppens, I.; Tripathi, A. K., et al. The Role of Neutral Lipid Nanospheres in Plasmodium falciparum Here Crystallization. Biochemistry Journal 2007, 402, 197-204.

(52) Foley, M.; Tilley, L. Quinoline Antimalarials: Mechanisms of Action and Resistance. International Journal for Parasitology 1997, 27, 231-240.

(53) Natarajan, J. K.; Alumasa, J.; Yearick, K.; Ekoue-Kovi, K. A.; Casabianca, L. B.; de Dios, A. C.; Wolf, C.; Roepe, P. D. 4-N,4-S \& 4-O Chloroquine Analogues: Influence of Side Chain Length and Quinolyl Nitrogen pKa on Actrivity vs. Chloroquine Resistant Malaria. Journal of Medicinal Chemistry 2008, 51, 3466-3479.

(54) Egan, T. J.; Hunter, R.; Kaschula, C. H.; Marques, H. M.; Misplon, A.; Walden, J. Structure-Function Relationships in Aminoquinolines: Effect of Amino and Chloro Groups on Quinoline-Hematin Complex Formation, Inhibition of Hematin Formation and Antiplasmodial Activity. Journal of Medicinal Chemistry 2000, 43, 283291.

(55) Kelly, J. X.; Winter, R. W.; Cornea, A.; Peyton, D. H.; Hinrichs, D. J.; Riscoe, M. The Kinetics of Uptake and Accumulation of 3,6-bis-[omega]diethylaminoamyloxyxanthone by the Human Malaria Parasite Plasmodium falciparum. Molecular and Biochemical Parasitology 2002, 123, 47-54.

(56) Gildenhuys, J.; le Roe, T.; Egan, T. J.; de Villiers, K. A. The Single Crystal X-Ray Structure of B-Hematin DMSO Solvate Grown in the Presence of Chloroquine, a B-Hematin Growth-Rate Inhibitor. Journal of the American Chemical Society 2013, 135, 1037-1047. 
(57) Krogstad, D. L.; Gluzman, I. Y.; Kyle, D. E.; Oduola, A. M.; Martin, S. K.; Milhous, W. K.; Schlesinger, P. H. Efflux of Chloroquine from Plasmodium falciparum: Mechanism of Chloroquine Resistance. Science 1987, 238, 1283-1285.

(58) Fidock, D. A.; Nomura, R.; Talley, A. K.; Copper, R. A.; Dzekunov, S. M.; Ferdig, M. T.; Ursos, L. M.; Sidhu, A. B.; Naude, B.; Deitsch, K. W.; Su, X. Z.; Wootton, J. C.; Roepe, P. D.; Wellems, T. E. Mutations in the P. falciparum Digestive Vacuole Transmembrane Protein PfCRT and Evidence for Their Role in Chloroquine Resistance. Molecular Cell 2000, 6, 861-871.

(59) Martin, S. K.; Oduola, A. M.; Milhous, W. K. Reversal of Chloroquine Resistance in Plasmodium falciparum by Verapamil. Science 1987, 235, 899-901.

(60) Bray, P. G.; Martin, R. E.; Tilley, L.; Ward, S. A.; Kirk, K.; Fidock, D. A. Defining the Role of PfCRT in Plasmodium falciparum Chloroquine Resistance. Molecular Microbiology 2005, 56, 323.

(61) Munagala, S.; Sirasani, G.; Kokkonda, P.; Phadke, M.; Krynetskaia, N.; Lu, P.; Sharom, F. J.; Chaudhury, S.; Abdulhameed, M. D. M.; Tawa, G.; Wallqvist, A.; Martinez, R.; Childres, W.; Abou-Gharbia, M.; Krynetskiy, E.; Andrade, R. B. Synthesis and Evaluation of Strychnos Alkaloids as MDR Reversal Agents for Cancer Cell Eradication. Bioorganic and Medicinal Chemistry 2014, 22, 1148-1155.

(62) Bhattacharjee, A. K.; Kyle, D. E.; Vennerstrom, J. L.; Milhous, W. K. A 3D QSAR Pharmacophore Model and Quantum Chemical Structure-Activity Analysis of Chloroquine(CQ)-Resistance Reveral. Journal of Chemical Information and Modeling 2002, 42, 1212-1220.

(63) Burgess, S. J.; Selzer, A.; Kelly, J. X.; Smilkstein, M. J.; Riscoe, M. K.; Peyton, D. H. A Chloroquine-like Molecule Designed to Reverse Resistance in Plamodium falciparum. Journal of Medical Chemistry 2006, 49, 5623-5625.

(64) Bhattacharjee, A. K.; Kyle, D. E.; Vennerstrom, J. L. Structural Analyi of Chloroquine Reistance Reversal by Imipramine Analogs. Antimicrobial Agents and Chemotherapy 2001, 45, 2655-2657.

(65) De, D.; Krogstad, F. M.; Byers, L. D.; Krogstad, D. L. Structure-Activity Relationships for Antiplasmodial Activity Among 7-substituted 4-aminoquinolines. Journal of Medicinal Chemistry 1998, 41, 4918-4926.

(66) Rosenthal, P. J. The Interplay Between Drug Resistance and Fitness in Malaria Parasites. Molecular Microbiology 2013, 89, 1025-1038. 
(67) Carlton, J. M.; Hayton, K.; Carvo, P. V.; Walliker, D. Of Mice and Malaria Mutants: Unravelling the Genetics of Drug Resistance Using Rodent Malaria Models. Trends In Parasitology 2001, 17, 236-242.

(68) Lipinski, C. A.; Lombardo, F.; Dominy, B. W.; Feeney, P. J. Experimental and Computational Approaches to Estimate Solubility and Permeability in Drug Discovery and Development Settings. Advanced Drug Delivery Reviews 2001, 46, 3-26.

(69) Burgess, S. J. Design and Synthesis of Antimalarial Drugs Based on a Quninoline Scaffold. Portland State University, 2008.

(70) Shamloo, S. A Spectroscopic Structure-Activitiy Study of Revered Chloroquines in Order to Screen Antimalarial Capacityi Through Heme Binding Affinity and Inhibition of B-Hematin in vitro. Portland State University, 2008.

(71) Kelly, J. X. Investigation of the 3,6-bis-[omega]diethylaminoalkoxyxanthone Series as Antimalarial and Antileishmanial Agents. Portland State University, 2003.

(72) Leffler, J. E.; Grunwald, G.: Rates and Equilibria of Organic Reactions: As Treated by Statisticla Thermodynamic and Extrathermodynamic Methods; Wiley: New York, 1963.

(73) Gunsaru, B. Simplified Reversed Chloroquines to Overcome Malaria Resistance To Quinoline-Based Drugs. Portland State University, 2010.

(74) Holz, J., G.G. Lipids and the Malarial Parasite. Bulletin of the World Health Organization 1977, 55, 237-248.

(75) Vial, H. J.; Ancelin, M. Malaria Lipids. An Overview. Subcell Biochemistry 1992, 18, 259-306.

(76) Calas, M.; Cordina, G.; Bompart, J.; Ben Bari, M.; Jei, T.; Ancelin, M.; Vial, H. J. Antimalarial Activity of Molecules Interfering with Plamodium falciparum Phospholipid Metabolism. Structure-Activity Relationship Analysis. Journal of Medicinal Chemistry 1997, 40, 3557-3566.

(77) Wengelnik, K.; Vidal, V.; Ancelin, M.; Cathiard, A.; Morgat, J. L.; Kocken, C.; Calas, M.; herrera, S.; Thomas, A. W.; Vial, H. J. A Class of Potent Antimalarials and Their Specific Accumulation in Infected Erythrocytes. Science 2002, 295, 1311-1314.

(78) Vial, H. J.; Mamoun, C. B.: Plamodium Lipids: Metabolism and Function. In Molecular Approach to Malaria; Sherman, I., Ed.; ASM Press: Washington, DC, 2005; pp 327-352. 
(79) Elabbadi, N.; Ancelin, M.; Vial, H. J. Phospholipid Metabolism of Serine in Plamodium-Infected Erythrocytes Involves Phosphatidylserine and Direct Serine Decarboxylation. Biochemical Journal 1997, 324, 435-445.

(80) Pessi, G.; Kociubinski, G.; Mamoun, C. B. A Pathway for Phosphotidylcholine Biosynthesis in Plamodium falciparum Involving Phosphoethanolamine Methylation. Proceedings of the National Academy of Sciences 2004, 101, 6206-6211.

(81) Pessi, G.; Choi, J. Y.; Reynolds, J. M.; Voelker, D. R.; Mamoun, C. B. In vivo Evidence for the Specificity of Plasmodium falciparum Phosphoethanolamine Methyltransferase and Its Coupling to the Kennedy Pathway. The Journal of Biological Chemistry 2005, 280, 12461-12466.

(82) Vial, H. J.; Eldin, P.; Tielens, A. G.; J., v. H. J. Phospholipids in Parasitic Protozoa. Molecular and Biochemistry in Parasitology 2003, 2003, 143-154.

(83) Ginsburg, H.; Stein, W. D. Biophysical Analysis of Normal Transport Pathways Induced in Red Blood Cell Memebranes. The Journal of Membrane Biology 1987, 96, 1-10.

(84) Staines, H. M.; Kirk, K. Increased Choline Transport in Erythrocytes from Mice Infected With the Malaria Parasite Plasmodium vinckei vinckei. Biochemical Journal 1998, 334, 525-530.

(85) Kirk, K. Membrane Transport in the Malaria-infectged Erythrocyte. Physiological Reviews 2001, 81, 495-537.

(86) Ginsburg, H.; Stein, W. D. The New Permeability Pathways Induced by the Malaria Parasite in the Membrane of the Infected Erythrocyte: Comparison of the Results Using Different Experimental Techniques. . The Journal of Membrane Biology 2004, 197, 113.

(87) Biangini, G. A.; Ward, S. A.; Bray, P. G. Malaria Parasite Transporters as a Drug-Delivery Strategy. Trends in Parasiology 2005, 21, 299-301.

(88) Wein, S.; Maynadier, M.; Bordat, Y.; Perez, J.; Maheshwari, P.; BetteBobillo, P.; Tran Van Ba, C.; Penarete-Vargas, D.; Fraisse, L.; Cerdan, R.; Vial, H. J. Transport and Pharmacodynamics of Albitiazolium, An Antimalarial Drug Candidate. British Journal of Pharmacology 2012, 166, 2263-2276.

(89) Tischer, M.; Pradel, G.; Ohlsen, K.; Holzgrabe, U. Quaternary Ammonium Salts and Their Antimicrobial Potential: Targets or Nonspecfic Interactions? ChemMedChem 2012, 7, 22-31. 
(90) Salom-Roig, X. J.; Hamze, A.; Calas, M.; Vial, H. J. Dual Molecules as New Antimalarials. Combinatorial Chemistry and High Throughput Screening 2005, 8, 49-62.

(91) Peyrottes, S.; Caldarelli, S.; Wein, S.; Perigaud, C.; Pellet, A.; Vial, H. J. Choline Analogues in Malaria Chemotherapy. Current Pharmaceutical Design 2012, 18, 3453-3466.

(92) Bozdech, Z.; Llinas, M.; Pulliam, B. L.; Wong, E. D.; Jingchun, Z.; DeRisi, J. The Transcriptome of the Intraerythrocytic Development Cycle of Plasmodium falciparum. PLOS Biology 2003, 1-21

(93) Vial, H. J.; Wein, S.; C., F.; Kocken, C.; Nicolas, O.; Ancelin, M. L.; Bressolle, F.; Thomas, A.; Calas, M. Prodrugs of Bisthiazolium Salts are Orally Potent Antimalarials. Proceedings of the National Academy of Sciences 2004, 101, 1545815463.

(94) Kirk, K.; Horner, H. A.; Elford, B. C.; Ellory, J. C.; Newbold, C. I. Transport of Diverse Substrates into Malaria-Infected Erythrocytes via a Pathway Showing Functional Charateristics of a Chloride Channel. The Journal of Biological Chemistry 1994, 269, 3339-3347.

(95) Staines, H. M.; Alkhalil, A.; Allen, R. J.; De Jonge, H. R.; Derbyshire; S., E. E.; Ginsburg, H.; Hill, D.; Huber, S. M.; Kirk, K.; Lang, F.; Lisk, G.; Oteng, E.; Pillai, A.; Rayavara, K.; Rouhani, S.; Saliba, K.; Shen, C.; Solomon, T.; Thomas, S.; Verloo, P.; Desai, S. Electrophysiological Studies of Malaria Parasite-Infected Erythrocytes: Current Status. International Journal for Parasitology 2007, 37, 475.

(96) Biagini, G. A.; Richier, E.; Bray, P. G.; Calas, M.; Vial, H. J.; Ward, S. A. Heme Binding Contributes to Antimalarial Activity of Bis-Quaternary Ammoniums. Antimicrobial Agents and Chemotherapy 2003, 47, 2584-2589.

(97) Hernandez-Alcoceba, R.; Saniger, L.; Campos, J.; Nunez, M. C.; Khaless, F.; Gallo, M. A.; Espinosa, A.; lalcal, J. C. Choline Kinase Inhibitors as a Novel Approach for Antiprolilferative Drug Design. Oncogene 1997, 15, 2289-2301.

(98) Levitzki, A. Signal Tranduction Therapy. A Novel Approach to Disease Management. European Journal of Biochemistry 1994, 226, 1-13.

(99) Barbacid, M. ras Genes. Annual Review of Biochemistry 1987, 56, 779827.

(100) Lowry, D. R.; Willumsen, B. M. Function and Regulation of RAS. Annual Review of Biochemistry 1993, 62, 851-891. 
(101) Cuadrado, A.; Bruder, J. T.; Heidaran, M. A.; H., A.; Rapp, U. R.; Aaronson, S. A. H-ras and raf-1 Cooperate in Transformation of NIH3T3 Fibroblasts. Oncogene 1993, 8, 2443-2448.

(102) Campos, J.; Nunez, C.; Conego-Garcia, A.; Sanchez-Martin, R. M.; Hernandez-Alcoceba, R.; Rodriguez-Bonzalez, A.; Lacal, J. C.; Gallo, M. A.; Espinosa, A. QSAR-Derived Choline Kinase Inhibitors: How Rational Can Antiproliferative Drug Design Be? Current Medicinal Chemistry 2005, 10, 1095-1112.

(103) Smilkstein, M.; Sriwilaijaroen, N.; Kelly, J. X.; Wilairat, P.; Riscoe, M. Simple and Inexpensive Fluorescence-Based Techniquie for High-Throughput Antimalarial Drug Screening. Antimicrobial Agents and Chemotherapy 2004, 48, 1803 1806. 